SERVIÇO DE PÓS-GRADUAÇÃO DO ICMC-USP

Data de Depósito:

Assinatura:

\title{
Adaptação Dinâmica de Vídeo
}

\section{Robson Eisinger}

\section{Orientador: Prof. Dr. Rudinei Goularte}

Dissertação apresentada ao Instituto de Ciências Matemáticas e de Computação - ICMC-USP, como parte dos requisitos para obtenção do título de Mestre em Ciências - Ciências de Computação e Matemática Computacional.

USP - São Carlos

Abril/2007 

Adaptação Dinâmica de Vídeo

Robson Eisinger 



\section{Dedicatória}

Esta dissertação é dedicada aos tolos.

Que sonham quando ninguém mais deseja sonhar.

Que amam quando o amor virou tabu.

Olham para o céu e vislumbram o infinito.

Não temem que seus pés fiquem longe do chão.

Qualquer um pode sonhar, mas apenas um tolo acredita em seu próprio sonho. 


\section{Sumário}

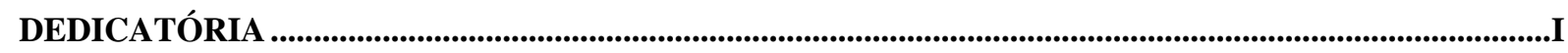

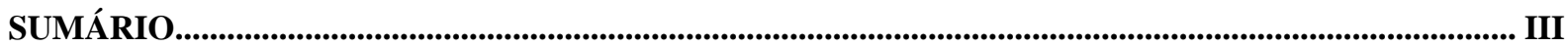

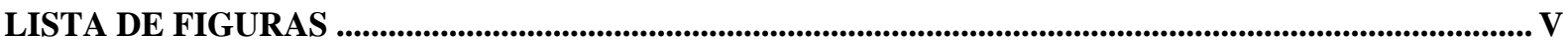

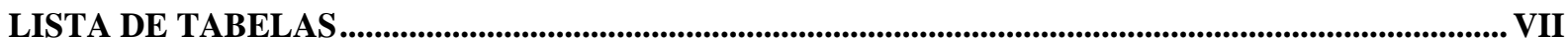

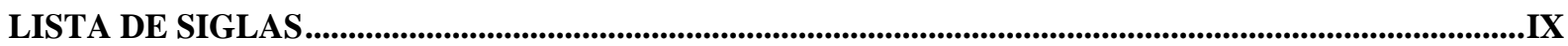

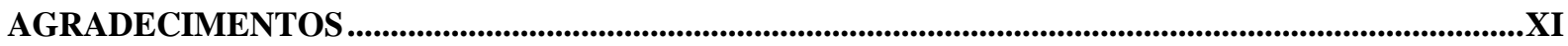

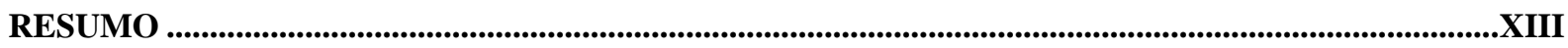

ABSTRACT ........................................................................................................................................................XIV

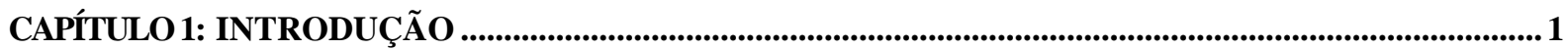

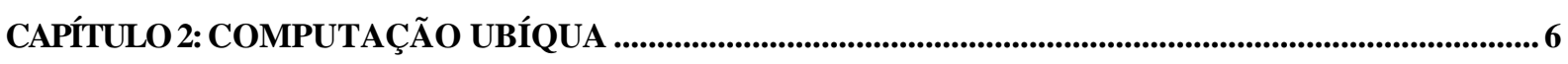

2.1 CONTEXTO

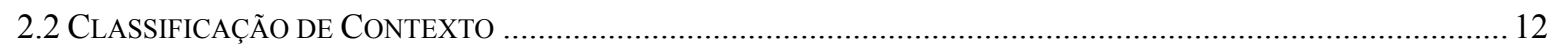

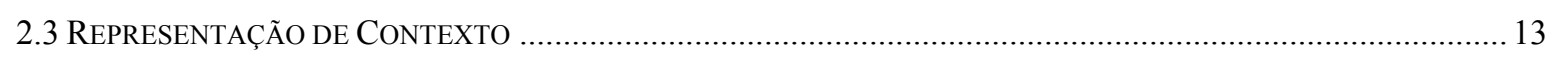

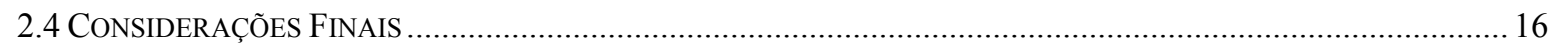

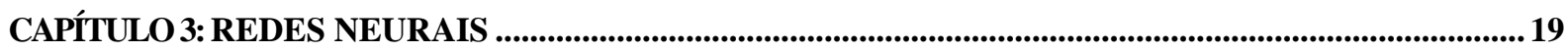

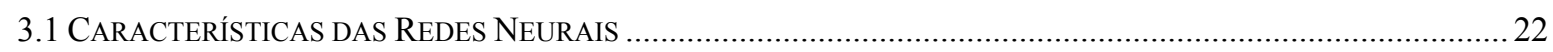

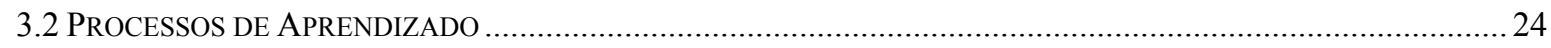

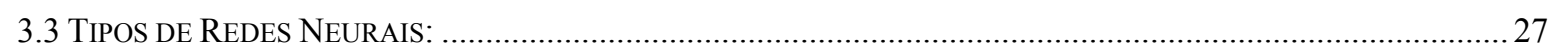

3.4 Perceptron de Múltiplas Camadas (Multi-Layer Perceptron) ………………............................. 29

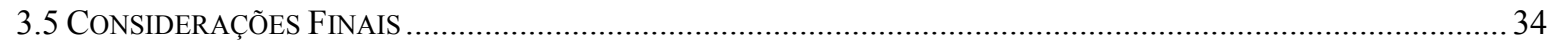

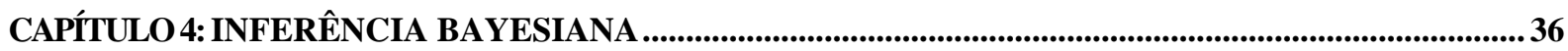

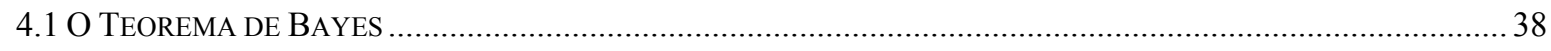

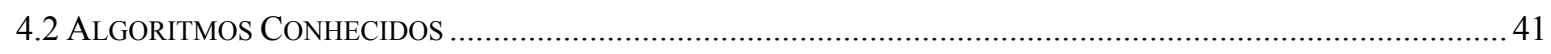

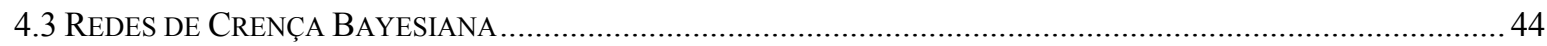

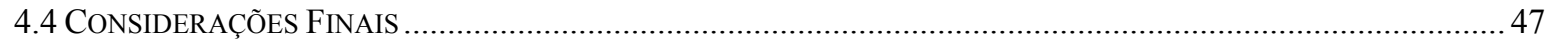

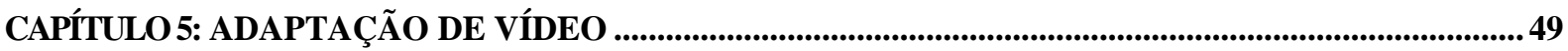

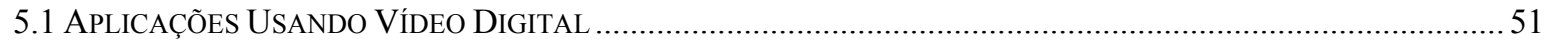

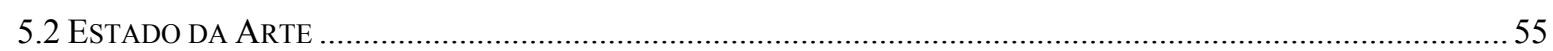

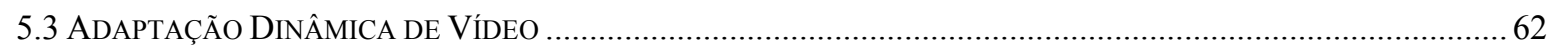

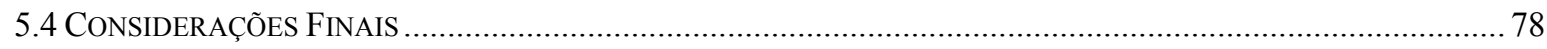


CAPÍTULO 6: RESULTADOS E DISCUSSÃO .82

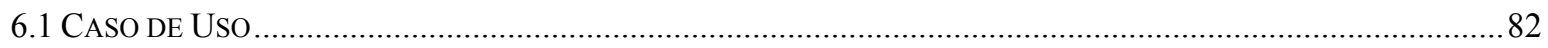

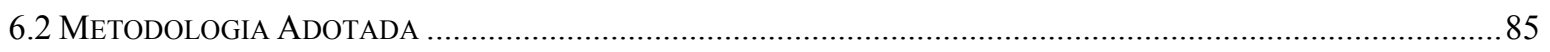

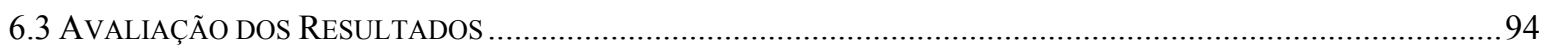

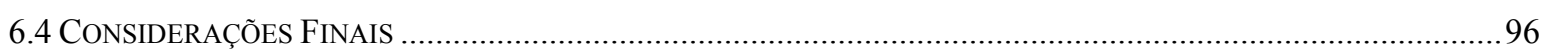

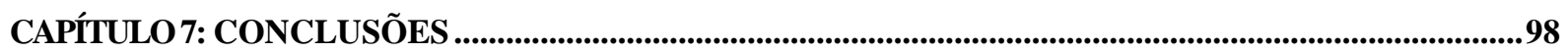

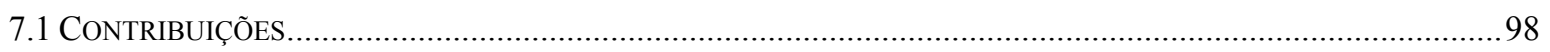

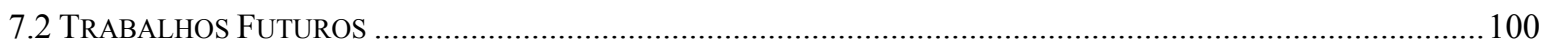

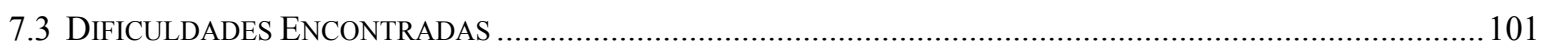

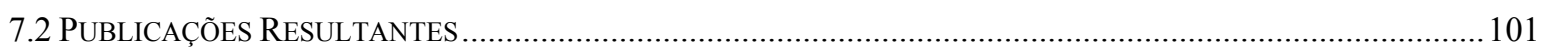

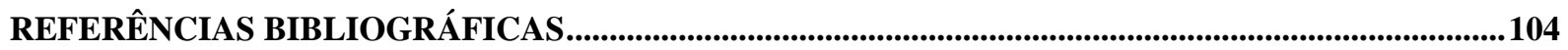




\section{Lista de Figuras}

Figura 1: Componentes do contexto do sistema (GOULARTE, 2003). 14

Figura 2 Definindo o tipo UserType como extensão do PrimaryContextType (GOULARTE, 2003)

Figura 3 - Exemplo de criação do Tipo NickName (GOULARTE, 2003)............................... 15

Figura 4: Estrutura Biológica de um Neurônio (KANDEL et al., 2000)..................................20

Figura 5: Modelo de Neurônio sugerido por McCulloch e Pitts (MCCULLOCH, 1943) .......21

Figura 6: Diagrama de Blocos do Aprendizado supervisionado (HAYKIN, 2001)................26

Figura 7: Aprendizado sem tutor ou não-supervisionado (HAYKIN, 2001).........................22

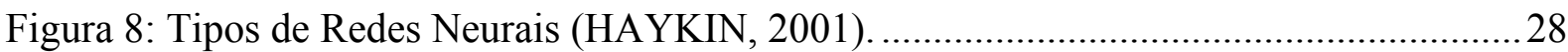

Figura 9 - Arquitetura Básica de um Perceptron (DRYFUS, 2005) ........................................ 30

Figura 10 - Dois exemplos de conjunto de amostras (DRYFUS, 2005)............................... 31

Figura 11 - Arquitetura Típica de uma MLP (DRYFUS, 2005)........................................... 34

Figura 12 - Exemplo de Rede Bayesiana (MITCHEL, 1997).............................................. 45

Figura 13: Infra-estrutura do protótipo de TV-I (Goularte, 2003) ........................................54

Figura 14 - Arquitetura do Sistema iClass (SANTE et al., 2004)..........................................55

Figura 15 - Tecnologia SureStream da Real Networks (Real, 2002) .....................................57

Figura 16 - Função de Utilidade (Wang et al., 2003) ...............................................................58

Figura 17 - Arquitetura do Sistema de Adaptação ................................................................... 64

Figura 18 - Captura da Informação de Contexto "resolução do dispositivo" (MANZATO,

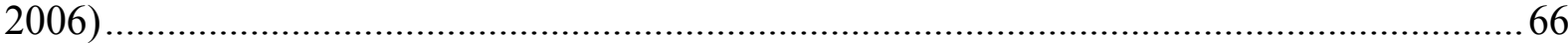

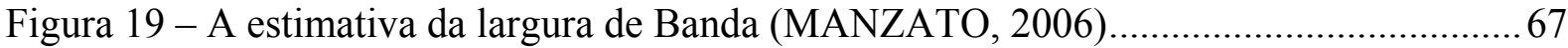

Figura 20 - Representação de Contexto: Dispositivos (EISINGER et al., 2005) ....................69

Figura 21 - Especificação de um Dispositivo ........................................................................... 70

Figura 22 - Definição de um novo dispositivo ……................................................................ 71

Figura 23 - Especificação de uma Memória usando a biblioteca contextual ........................... 71

Figura 24 - Especificação do Tipo Velocidade (SpeedType).................................................. 72

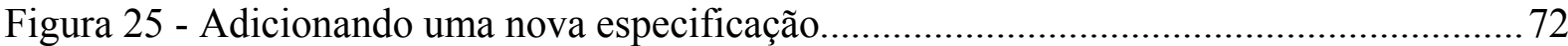

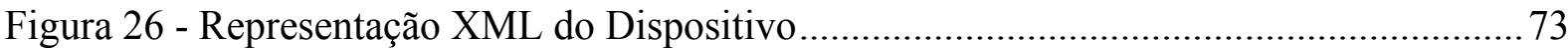

Figura 27 - Algoritmo para adaptação de vídeo definido por Manzato (MANZATO, 2006).. 74

Figura 28 - Arquitetura para o Mecanismo de Decisão.......................................................... 76 
Figura 29 - Algoritmo para o Mecanismo de Decisão .......................................................... 78

Figura 30 - Configuração da Aplicação de Treinamento de Borgelt (BORGELT, 2006) ....... 91

Figura 31 - Configuração da Aplicação para Executar uma Rede Neural (BORGELT, 2006) 92 Figura 32 - Configuração do Treinamento da Rede Bayesiana usando Yale 3.2 (MIERSWA et

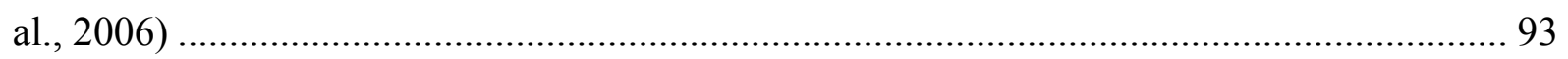

Figura 33 - Configuração da Execução de uma Rede Bayesiana usando Yale 3.2 (MIERSWA

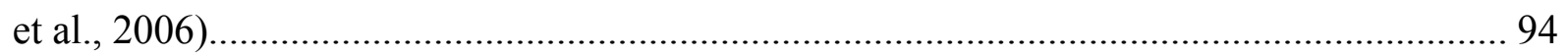

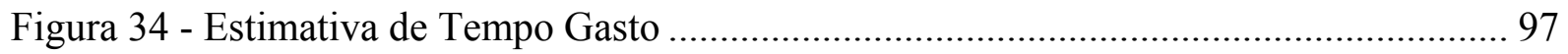




\section{Lista de Tabelas}

Tabela 1 - Alguns tipos presentes na Biblioteca Contextual (GOULARTE et al., 2006) ....... 16

Tabela 2 - Tabela de Probabilidades Condicionais (MITCHEL, 1997) ................................... 47

Tabela 3 - Regra de Decisão limitando a Resolução com base na Taxa de Bits (MANZATO,

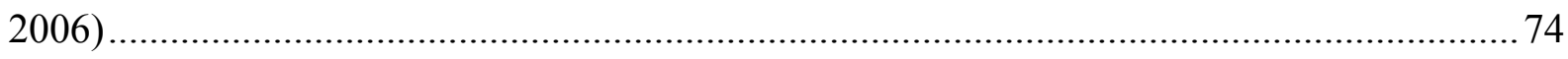

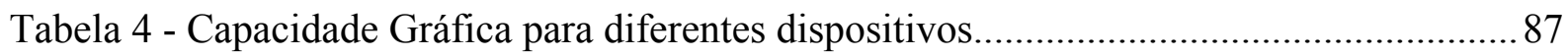

Tabela 5 - Tamanho do Quadro de um Fluxo de Vídeo .......................................................... 88

Tabela 6 - Capacidades Gráficas utilizadas no Primeiro Conjunto de Exemplos. ................... 88

Tabela 7 - Exemplos de Grau de Confidência ......................................................................... 92

Tabela 8 - Erros encontrados nas redes MLP e Bayesiana................................................... 95

Tabela 9 - Tempo estimado para execução da rede MLP (em milisegundos)......................... 96

Tabela 10 - Tempo estimado para execução da rede Bayesiana (em milisegundos) ...............96 


\section{Lista de Siglas}

\begin{tabular}{cl}
\hline \hline BP & Back-Propagation \\
CC/PP & Composite Capabilities/Preferences Profile \\
EP & Elementos de Processamento \\
ICMC & Instituto de Ciências Matemáticas e Computação \\
IP & Internet Protocol \\
IPTV & Internet Protocol Television \\
ITL & Information Technology Laboratory \\
JSP & Java Server Pages \\
LMS & Least Mean Squares \\
MAP & Maximum a Posteriori \\
MCE & Media Conversor Engine \\
MCM & Media Conversor Manager \\
MPEG & Moving Picture Experts Group \\
MLP & Multi-Layer Perceptron \\
QoS & Quality of Service \\
RNA & Rede Neural Artificial \\
RBF & Radial Basis Function \\
RTP & Real Time Protocol \\
SDP & Session Description Protocol \\
SNC & Sistema Nervoso Central \\
SNR & Signal-to-noise ratio \\
SVC & Scalable Vídeo Coding \\
TIC & Tecnologias de Informação e Comunicação \\
TV-I & Televisão Interativa \\
USP & Universidade de São Paulo \\
UMA & Universal Multimedia Access \\
XML & eXtensible Markup Language \\
\hline
\end{tabular}




\section{Agradecimentos}

Nossa vida é feita de momentos e quando vivenciamos algo importante, lembramos das pessoas que estavam lá, testemunhas silenciosas de nosso crescimento.

Primeiro nossa família, pessoas que o destino nos obriga a conviver desde o início de nossas vidas. Mas nas brigas, mesmo na distância, a família representa antes de tudo um porto seguro para voltarmos, reabastecer nosso animo e seguir mais uma vez pelo mar bravio. Lembro dos primeiros livros que ganhei de meu pai, o primeiro a me incentivar, a caminhar com meus próprios passos, um dos poucos que nunca teve vergonha de demonstrar abertamente seu orgulho, mesmo que meu orgulho me impedisse de aceitar tamanha “corujisse". Minha mãe, teimosa, não acredita em elogios, palavras de afeto, mas ainda assim me exibe como um troféu, sempre negando o orgulho enrustido. Meu irmão, que mesmo conhecendo o canalha bastardo que sou, mesmo com nossos pontos de vista divergentes, mesmo com nossa teimosia, eu sei que ele defenderia a mim com a mesma ferocidade que já o defendi. Minha irmã, que me presenteou com o sobrinho mais lindo do mundo, mesmo que o coitado seja um pouco parecido comigo. Meus avós paternos, que agüentaram a bronca de ser meus padrinhos, minha curiosidade e claro, meu amor por pastel de queijo. Meus avós maternos, pelos dias felizes, quando a família ainda se reunia.

Depois da família, que amamos por obrigação, conhecemos nossos amigos, pessoas que o destino nos ajuda a encontrar, mesmo que às vezes a gente ignore seu valor, seus conselhos. Mesmo o tempo passando, mesmo que os nomes de alguns acabem dando lugar ao anonimato, são tantos para agradecer e pouco espaço ou memória para isso. Muita coisa mudou em três anos, mesmo que no fim eu ainda insista que nada mudou. Então agradeço aqueles que participaram nessa mudança, seja com confidências, nas brigas ou simplesmente por serem parte do que sou hoje. Fernando Baiocco, Richard (Zoid), Mario (Yah), Danilo (Xarops), Adriana (Mina), Imyra (Mi-chan), Ottati, Brabuh, Vivi, Lara (Badmé), André (Ghaleon), Roberto (Shini), Julia e Renata (Mayu e Ayu), Tia Helga, Lauanda, Irys, Leo (Rakde), Taya, Pepe, Noscaj, Guiiiii, Leaf, Darkeye, Legos, Musa, Binha, Erick, Rogerinho, Sapo, Ivan (Presunto), Dema, Deminha, Glauco, Tatsuha e tantas outras pessoas que cruzaram minha vida e que em algum momento nestes três anos tiveram um papel especial e que, acredito, me consideraram um amigo.

Os colegas de faculdade, sejam professores ou alunos, que também considero como amigos, por vivenciarem meu amadurecimento. Agradeço aqui ao professor Edson, pelo apoio 
e fé que teve quando decidiu me orientar. Ao professor Rudinei, que deu continuidade a minha orientação, dando todo o suporte nos momentos que precisei, além da paciência que teve para entender os problemas que tive no decorrer do desenvolvimento deste trabalho. A professora Roseli, por emprestar seu conhecimento, sugerindo o estudo de Inferência Bayesiana e auxiliando na revisão dos resultados. Agradeço também ao apoio da CAPES, permitindo a realização do presente trabalho.

Encerrando os agradecimentos, falta apenas a base que sustenta toda nossa existência. Agradeço a Deus pelas pedras no caminho, que me mostraram que não existe um caminho fácil, que vencer cada desafio e seguir em frente é o maior dos prêmios. E sem dificuldades, o trabalho perderia todo seu mérito. 
O presente trabalho apresenta o resultado de um estudo comparando o uso de técnicas de aprendizado de máquina na adaptação dinâmica de vídeo. O sistema utiliza informações de contexto, como as características de um dispositivo, preferências do usuário e condições de rede, como entrada de um mecanismo de decisão responsável por encontrar parâmetros de codificação mais adequados ao contexto à geração de um novo fluxo de vídeo dinamicamente personalizado.

Palavras-chave: Computação Ubíqua, Adaptação de Conteúdo, Transmissão de Vídeo, Redes Neurais, Inferência Bayesiana; 


\section{Abstract}

This work presents the results of a comparative study about machine learning techniques used in dynamic video adaptation. The system uses contextual information, such as devices' characteristics, user's preferences and network condition as an input for a decision engine, responsible to find the best encoding parameters to be used during the generation of a new dynamically personalized video stream.

Keywords: Ubiquitous Computing, Content Adapting, Video Transmission, Neural Networks, Bayesian Inference. 
Capítulo 1

Introdução

"Desenvolvimento humano é o processo de alargamento das escolhas dos indivíduos proporcionando, a cada um, a oportunidade de tirar o melhor partido das suas capacidades: viver uma vida longa e saudável, adquirir conhecimentos e aceder aos recursos necessários para um nível de vida decente".

Sérgio Vieira de Mello

O homem, por sua natureza social, sempre sentiu a necessidade de se expressar. Não apenas comunicar-se com seus semelhantes, mas também deixar registros de sua existência. Na pré-história, nossos antepassados usavam pinturas, registrando assim seu cotidiano. Antes da invenção da escrita a transferência de conhecimento era limitada, restrita as pequenas comunidades e transmitida de modo oral. Com a escrita, detalhes que se perdiam com o passar das gerações e com a imprecisão do processo oral passaram a ser documentado, a história e o conhecimento começavam a ser repassados com uma maior precisão, não se limitando mais as pequenas comunidades. Mas o homem não descansa, avançando, transformando o presente e o futuro, num constante processo evolutivo, criando novos modos de comunicação e reinventando outros em um processo onde não existe uma simples substituição dos meios, mas, como diria Lévy, um deslocamento nos centros de gravidade (LÉVY, 1993). A história da comunicação é feita de movimentos crescentes e sucessivos, indo da oralidade à escrita, da escrita evoluiu para a imprensa, desta retornou à oralidade com o rádio e mais tarde com a televisão, até chegar recentemente a Internet. Assim, o constante aperfeiçoamento dos modos de veicular informação é uma conseqüência da necessidade do homem em comunicar, de sua expectativa de desvelar novos horizontes, explorar territórios alheios tendo como impulso o desejo de interação e descoberta.

Reduzir as distâncias, aproximar as pessoas. Em um mundo que muda a cada instante a Internet representa um papel importante, sendo uma das forças que impulsionaram o crescimento da globalização, com a popularização de seu acesso por conexões de banda larga e recente avanço da tecnologia de comunicação sem fio. Nesse cenário há uma clara tendência de convergência entre multimídia, Internet e meios de comunicação. Computadores portáteis e telefones celulares que antes se limitavam ao acesso de conteúdos escritos na Internet, 
ganham novas funcionalidades que passaram a permitir também o acesso de conteúdo multimídia, como é o caso de vídeo digital, derrubando assim o antigo paradigma de que a Internet seria restrita apenas aos computadores pessoais. E nessa eterna reinvenção de antigas tecnologias com a sobreposição de diferentes mídias explorando recursos da imprensa, rádio e televisão, cria-se espaço para o surgimento de novas tecnologias, impulsionadas pelo sucesso da Internet e explorando um novo paradigma onde o indivíduo deixa de desempenhar um papel de receptor passivo interagindo com o conteúdo multimídia. A expectativa dos usuários em acessar serviços em qualquer lugar e a qualquer momento, aliado ao interesse da indústria reforçam a tendência de convergência supracitada.

Prover um serviço ou conteúdo de modo transparente, isto é, independente do dispositivo ou meio usado no acesso, é interessante para o usuário considerando o cenário atual. Entretanto, não é simples obter essa transparência uma vez que o modo como determinado conteúdo ou serviço é acessado pode ser limitado, como é o caso de dispositivos com baixa resolução gráfica, dependerem do consumo de bateria ou mesmo terem baixa capacidade de memória ou processamento. Assim, um determinado conteúdo que seja adaptado para exibição em um laptop pode não ter a qualidade, tamanho ou formato apropriado para que possa ser exibido em outro dispositivo, como um celular. Nesse cenário o desafio é prover acesso a um rico conteúdo multimídia interativo para uma variedade de dispositivos, móveis ou não, atendendo suas restrições bem como os interesses dos usuários. E adaptar esse conteúdo antes de enviá-lo aos usuários é um modo de atender essas expectativas. Um exemplo de conteúdo que precisa ser adaptado para que possa ser visualizado em diferentes dispositivos é o vídeo digital, como conseqüência da necessidade de uma alta taxa de dados para sua transmissão. Em dispositivos com restrição na largura de banda disponível, como dispositivos sem fio, é interessante reduzir a taxa de dados transmitida e nem sempre isso pode ser resolvido a partir da compressão desses dados, pela limitação de processamento da maioria desses dispositivos.

Considerando apenas o caso de adaptação de vídeo, a maioria dos trabalhos encontrados na literatura preocupa-se com o ajuste na taxa de dados (bitrate ou taxa de bits) à largura de banda disponível para o dispositivo do usuário (MAGGIORINI; RIBONI, 2005) (LINCK et al., 2006) (CHEN; ZAKHOR, 2004). Entretanto, outros aspectos poderiam ser considerados ao adaptar um vídeo, procurando disponibilizá-lo em diferentes dispositivos. Mas os trabalhos que abordam esses outros aspectos apresentam apenas modelos para a adaptação de vídeo, sem definir o processo de decisão, isto é, como será aplicada a adaptação em cada caso (THANG et al., 2006) (HUIFENG et al., 2006). 
Lei sugere em seu trabalho duas classificações para o modo como uma mídia é gerada para sua distribuição: a partir de um processo de adaptação estático ou dinâmico (LEI; GEORGANAS, 2005). Na adaptação estática, versões em diferentes formatos e qualidades são previamente produzidas e armazenadas em um servidor. Essa abordagem não garante o melhor compromisso entre a qualidade da mídia e os requisitos/restrições do usuário/sistema além de não considerar as alterações no estado do sistema. Já na adaptação dinâmica, uma versão ótima, isto é, com os parâmetros adequados para determinada situação, é produzida sob demanda. Não apenas produzindo uma versão ótima sob demanda, mas também é possível com essa abordagem mudar os parâmetros da mídia conforme ela é transmitida, por exemplo, mudando sua taxa de bits de acordo com as variações do sistema. Considerando as vantagens e desvantagens de cada solução, a adaptação estática é simples de aplicar, exigindo pouco recurso e ajustes no servidor. Mas é restrita às versões já existentes da mídia, não atendendo da melhor maneira as necessidades de cada usuário. A adaptação dinâmica, por sua vez, consegue atender essas necessidades gerando sob demanda uma mídia adequada ao contexto atual do usuário. No entanto, isso só é possível com um consumo elevado de recursos do sistema.

Ainda considerando a adaptação dinâmica, conhecer as necessidades do usuário, bem como as características e restrições do sistema utilizado pelo mesmo (dispositivos usados, redes de comunicação e outros) é que permite gerar de modo eficiente uma versão personalizada do conteúdo original (LUM; LAU, 2005), (EISINGER et al., 2005). Obter, representar e processar essas informações dando subsídio à adaptação de conteúdo ainda é um problema em aberto. A Ciência de Contexto, uma subárea da Computação Ubíqua, estuda como obter e representar uma informação de modo a facilitar as alterações no comportamento do sistema, aproveitando as informações presentes nas interações entre usuários e aplicações, buscando adaptar os serviços para que atendam a necessidades específicas, no momento em que ocorrem e de modo transparente para o usuário (ABOWD et al., 2002). A Ciência de Contexto define meios para modelar e representar informações, entretanto, não considera o processamento, isto é, a análise e classificação das informações obtidas. Adaptar um fluxo de vídeo de modo automático e dinâmico pode ser tratado como um problema de classificação, utilizando as informações do contexto desse fluxo, isto é, as necessidades dos usuários e as características/restrições do sistema, para encontrar os parâmetros de configuração que melhor atendam esse contexto. Em problemas de classificação é notório o uso bem sucedido de técnicas de Aprendizado de Máquina em sua resolução, destacando-se as Redes Neurais 
Artificiais (HAYKIN, 2001) e a Inferência Bayesiana (MITCHEL, 1997). Contudo, poucos trabalhos utilizam essas técnicas na adaptação de vídeo.

Assim, o objetivo do presente trabalho é utilizar a Ciência de Contexto, como ferramenta para a obtenção e representação das informações, e o Aprendizado de Máquina, no processamento dessas informações, para definir um Mecanismo de Decisão capaz de adaptar um fluxo de vídeo dinamicamente. Para isso foi necessário definir como essas informações serão representadas e utilizadas pelo sistema (EISINGER et al., 2005) e realizar um estudo comparativo sobre qual técnica de Aprendizado de Máquina (Redes Neurais ou Inferência Bayesiana) é mais apropriada ao contexto do problema.

O modelo adotado no Mecanismo de Decisão considera as mudanças que ocorrem no sistema, como o estado da rede e/ou o tipo de dispositivo usado pelo usuário. Assim, essas informações são coletadas do ambiente e utilizadas como entrada desse Mecanismo, que para o modelo adotado foram limitadas à resolução gráfica do dispositivo e à largura de banda disponível. Essas informações fornecem subsídios para que o Mecanismo de Decisão encontre os parâmetros de configuração mais adequados para o fluxo de vídeo, no caso do presente trabalho, a taxa de quadros (framerate) e o tamanho de quadros (framesize). Dentre as contribuições do presente trabalho podem ser citadas a extensão do modelo para representação de contexto sugerido por Goularte (GOULARTE, 2003), com a adição da representação de dispositivos (EISINGER et al., 2005); o estudo comparativo das técnicas de Aprendizado de Máquina aplicadas à adaptação de um fluxo de vídeo, chegando à conclusão de que a rede Multi-layer Perceptron (MLP) é a técnica mais adequada na resolução do problema proposto (DRYFUS, 2005); e o próprio Mecanismo de Decisão, uma vez que não basta aplicar uma técnica de Aprendizado de Máquina, como a MLP, por exemplo, é preciso avaliar se já existe um fluxo de vídeo sendo fornecido pelo servidor que atenda as necessidades do usuário e considerar se a capacidade máxima de taxa de dados do servidor já foi atingida. Assim, o presente trabalho enriquece os atuais sistemas de adaptação dando um passo em direção a um sistema totalmente automático, usando as informações contextuais como subsídio na adaptação de um fluxo de vídeo, sempre que necessário. Para estabelecer as bases para a discussão do presente trabalho, esta dissertação foi organizada como segue.

$\mathrm{Na}$ visão de Mark Weiser, os serviços prestados com o auxilio de recursos computacionais devem se adaptar ao comportamento humano e não o contrário, sem ser intrusivo e se possível, imitando o modo natural de interação entre os seres humanos (WEISER, 1991). Assim é definida a Computação Ubíqua, tema do Capítulo 2. Abordando o 
significado de contexto, de um ponto de vista computacional, o propósito deste capítulo é definir subsídios para a representação das informações relevantes à adaptação de um fluxo de vídeo.

As técnicas de Aprendizado de Máquina estudadas neste trabalho foram divididas em dois capítulos. No Capítulo 3 os principais conceitos relacionados às Redes Neurais Artificiais são apresentados, concentrando a atenção nas redes de aprendizado supervisionado como a MLP (DRYFUS, 2005), pois como será explicado, considerando o problema proposto são as mais adequadas para sua resolução. O Capítulo 4, por sua vez, apresenta a Inferência Bayesiana (MITCHEL, 1997), uma técnica de Aprendizado de Máquina que utiliza uma abordagem estatística, dentre as diferentes variantes, as redes Bayesianas são as que mais se aproximam do problema aqui proposto.

O processo de adaptação de vídeo é abordado no Capítulo 5, apresentando um resumo das aplicações que poderiam se beneficiar com a adaptação dinâmica de vídeo, como é o caso da Telemedicina (JONES, 2006) e a Televisão Interativa (GOULARTE, 2003); também é apresentado o estado da arte na adaptação de conteúdo, com os principais trabalhos encontrados na literatura, encerrando o capítulo com uma arquitetura para um servidor de vídeo usando o Mecanismo de Decisão proposto, incluindo um modelo para representação do contexto de um dispositivo (EISINGER et al., 2005). O Capítulo 6 discute os resultados obtidos com as técnicas de Aprendizado de Máquina, apresentando inicialmente a metodologia de treinamento e teste adotada, descrevendo como o conjunto de exemplos foi elaborado, a preparação desses conjuntos para seu processamento por cada uma das técnicas e o treinamento e posterior teste/validação dos resultados. O capítulo encerra justificando a escolha da rede MLP, como a melhor solução, dentre as estudadas, para o problema da adaptação de fluxo de vídeo.

O Capítulo 7 apresenta as contribuições deste trabalho, as dificuldades encontradas e idéias para a continuidade do mesmo. 
Capítulo2

\section{Computação Ubíqua}

“Existe mais informação nas pontas de nossos dedos, durante uma caminhada por um bosque do que em qualquer sistema computacional, ainda assim, as pessoas consideram uma caminhada próximo de árvores relaxante e os computadores frustrantes. Máquinas que se adaptam ao ambiente humano ao invés de forçar as pessoas a compreenderem seu funcionamento farão o uso de um computador tão relaxante quanto caminhar em um bosque”.

Mark Weiser.

O termo Computação Ubíqua foi apresentado pela primeira vez por Mark Weiser em 1991 descrevendo um ambiente dotado de recursos computacionais que auxiliavam as atividades humanas (WEISER, 1991). Em sua visão, os serviços prestados por tais recursos devem se adaptar ao comportamento humano de modo não intrusivo, isto é, sem alterar o modo natural de interação entre seres humanos. Assim, a computação deve ser parte integrante do ambiente, transparente ao usuário, provendo serviços e informações quando e onde sejam desejados. Para que as idéias de Weiser se concretizem é preciso compreender o hábito das pessoas, ajudando-as em suas atividades cotidianas e estender o ambiente com dispositivos heterogêneos, oferecendo diferentes meios de interação, bem como gerenciando os dispositivos conectados a rede é um modo de fazê-lo (ABOWD; MYNATT, 2000). Em resumo, a Computação Ubíqua tem como principio o desenvolvimento de aplicações capazes de melhorar a interação usuário-computador, sendo dividida em três linhas de pesquisa:

- Interfaces Naturais.

- Captura e Acesso de Atividades Humanas.

- Computação Ciente de Contexto.

As pesquisas realizadas na área de Interfaces Naturais procuram meios para adaptar as interfaces computacionais à forma como as pessoas interagem com o ambiente. A comunicação entre seres humanos é realizada por meio da fala, gesticulação e escrita, e, explorando esses paradigmas, é possível desenvolver interfaces que facilitem a comunicação entre usuários e computadores, seja implícita ou explicitamente, tornando a interação usuáriocomputador não intrusiva e, portanto, ideal para a Computação Ubíqua (ABOWD; MYNATT, 
2000). Exemplos relevantes de projetos na área incluem uma tela interativa que utiliza um sensor de toque de múltiplos pontos ${ }^{1}$ (HAN, 2006), permitindo diversas aplicações, como por exemplo, o desenvolvimento de uma interface musical (DAVIDSON; HAN, 2006); outro trabalho interessante utiliza uma tela feita de uma fina neblina como alternativa aos monitores padrões, denominado FogScreen ${ }^{2}$ (RAKKOLAINEN; PALOVUORI, 2005), sendo aplicado em apresentações artísticas interativas (RAKKOLAINEN et al., 2006).

Uma preocupação comum entre as pessoas é registrar os momentos importantes da vida, seja fotografando as férias da família ou anotando em uma agenda o que foi discutido em uma reunião, preservando esses momentos para serem compartilhados ou relembrados posteriormente. Recursos computacionais podem ser usados no registro do cotidiano das pessoas, além de processar e disponibilizar esses registros para uso futuro. Liberar o usuário da tarefa de registrar suas experiências, deixando-o livre para se concentrar na síntese e compreensão da experiência em si é o objetivo das pesquisas realizadas na área de Captura e Acesso de Atividades Humanas. Dentre os trabalhos realizados nessa área podem ser citados o trabalho de Geyer, discutindo meios para indexar gravações multimídia de reuniões, categorizando em múltiplas dimensões (GEYER et al., 2005); um sistema desenvolvido para o reconhecimento de atividades de um usuário, dentro de uma casa, usando para isso sensores ubíquos (BEAUDIN et al., 2004); o ButterflyNet, um sistema móvel de captura e acesso que integra anotações com fotografias digitais capturadas durante pesquisa de campo no estudo de biologia (YEH et al., 2006); e o eClass, um sistema que captura uma aula tradicional, usando lousas eletrônicas, vídeo e áudio (BROTHERTON; ABOWD, 2004).

Por fim, a Computação Ciente de Contexto que explora a interação usuáriocomputador usando informações contextuais presentes na comunicação resultante dessa interação. Seu objetivo é prover serviços personalizados ou que se adaptem às necessidades do usuário, por exemplo, considerando as características dos dispositivos de interação. Um projeto precursor nessa área foi o Active Badge (WANT et al., 1992), desenvolvido no Olivetti Research Lab’s. Usando sensores espalhados em todo ambiente e o uso de crachás especialmente desenvolvidos, o Active Badge era usado na localização das pessoas dentro desse ambiente especial. Também pode ser citado o Context Kernel (NETO et al., 2005) desenvolvido no ICMC-USP, que armazenava e recuperava informações contextuais

\footnotetext{
${ }^{1}$ Vídeo de Demonstração Multi-Touch Screen: http://www.youtube.com/watch?v=NJKDBfdwabk Visitado em: $8 / 1 / 2007$.

${ }^{2}$ Vídeo de Demonstração FogScreen: http://www.youtube.com/watch?v=RfmSJQuhlk4 Visitado em: 8/1/2007.
} 
utilizando a infra-estrutura fornecida pela Internet, graças ao conceito de Web Services ${ }^{3}$. Como já explicado na Introdução, o presente trabalho encontra-se inserido nessa linha de pesquisa, usando informações contextuais coletadas do ambiente, como as características do dispositivo e rede, na adaptação dinâmica de conteúdo (EISINGER; GOULARTE, 2005).

A Computação Ubíqua propõe um futuro digital, onde a computação passa a ser parte da engrenagem que movimenta o mundo. Atualmente com a tendência de barateamento dos dispositivos computacionais, esse futuro não parece tão distante, com o surgimento de uma nova geração de dispositivos, melhorados computacionalmente, usando novas tecnologias, como o Bluetooth $^{4}$, uma tecnologia de comunicação sem fio de baixo custo que permite, por exemplo, controlar um microondas pela Internet. Assim, a Computação Ubíqua aproveita a familiaridade, experiência e habilidades em lidar com o dia a dia do mundo, em outras palavras, o mundo passa a ser uma interface para a computação e a computação, um complemento às interações do dia a dia (DOURISH, 2004).

O presente trabalho usa Computação Ubíqua, mais especificamente a Ciência de Contexto, na obtenção e representação das informações do sistema e usuário. Essas informações são peça-chave na construção do Mecanismo de Decisão, definindo como o fluxo de vídeo será adaptado. Entender como a Computação Ubíqua foi utilizada no presente trabalho é a proposta do presente capítulo, dividido como segue. A Seção 2.1 define contexto sob o ponto de vista computacional, considerando a definição dada por diversos autores, chegando à definição mais apropriada ao contexto do presente trabalho. Definido contexto, o próximo passo é identificar os diferentes tipos de contexto, classificando-os de modo a definir quais contextos são mais adequados ao problema de adaptação de vídeo. Assim, a classificação dos diferentes tipos contextuais é o tema da Seção 2.2. Com os tipos contextuais, é possível definir uma maneira de representar contexto, a Seção 2.3 mostra uma possível representação para contexto, proposta por Goularte (GOULARTE, 2003). O capítulo encerra com a Seção 2.4, resumindo tudo o que foi apresentado e comentando como a Computação Ubíqua encontra-se inserida neste trabalho.

\subsection{Contexto}

A cada instante os seres humanos trocam informações em seu cotidiano, seja de forma explícita, por exemplo, usando a linguagem oral, e/ou implícita, por meio de gesticulação ou

\footnotetext{
${ }^{3}$ http://www.w3.org/2002/ws/ Visitado pela última vez em: 8/1/2007.

${ }^{4}$ http://www.bluetooth.com/bluetooth/ Visitado pela última vez em: 26/2/2007
} 
expressões faciais. Para a linguagem oral, essas informações implícitas complementam a interação, tornando-a rica e facilitando seu entendimento, ou seja, contextualizando o que é falado. No entanto, em uma interação usuário-computador, não existe um aproveitamento dessas informações implícitas, como acontece na interação entre pessoas, em outras palavras, perde-se toda informação contextual relacionada.

O uso do termo contexto na literatura não é recente, sendo usado em áreas como Lingüística, Inteligência Artificial e Visão Computacional. Na Computação Ubíqua, o termo contexto representa um papel importante, considerando o modo como o sistema operacional reage e/ou é sensível ao ambiente. Em outras palavras, mesmo quando mudamos o ambiente, como sistemas computacionais harmonizam com essas variações? (DOURISH, 2004)

Ao incorporar noções de contexto em tecnologias interativas, os pesquisadores acreditavam que essas tecnologias poderiam se tornar mais sensíveis aos detalhes de uso em ambientes específicos seja pela adição de sensores, o gerenciamento de informação ou mesmo a parametrização do sistema. Não existe um uso especifico para contexto, variando conforme a situação e entender a relação em potencial entre computação e contexto, para a Computação Ubíqua, é uma das principais preocupações das pesquisas na área e Dourish considera duas possíveis definições para contexto (DOURISH, 2004).

Na primeira, o termo contexto estaria relacionado aos problemas de representação, considerando que os Sistemas Computacionais são representacionais, sendo natural que as preocupações sobre contexto levem a como contexto é codificado e representado. Para Schilit e Theimer, contexto pode ser definido como "a localização e a identificação de pessoas e objetos próximos à interação" (SCHILIT; THEIMER, 1994), já Pascoe et al. sugere contexto como sendo "a localização, identidade, ambiente e tempo" (PASCOE et al., 2000). A partir de uma extensa investigação e englobando os diferentes significados para contexto dentro da Computação Ubíqua, Dey et al. sugere uma definição mais geral, onde contexto pode ser entendido como "qualquer informação que possa ser usada para caracterizar a situação de entidades", entidades essas que de um modo mais elaborado são "tipicamente a localização, a identidade e o estado de pessoas, grupos, e objetos físicos e computacionais" (DEY et al., 2001). Reunindo essas definições e considerando a interação entre usuário e aplicação, chega-se a seguinte definição:

"Contexto é qualquer informação que pode ser usada para caracterizar a situação de uma entidade. Uma entidade é uma pessoa, lugar, ou objeto considerado relevante para a interação entre um usuário e uma aplicação, incluindo o usuário e a aplicação em si." 
Nessa definição, é responsabilidade do projetista da aplicação decidir quais informações podem ser consideradas como contexto. Considerando essas definições é possível observar quatro aspectos que formam a base para a noção de contexto apresentada:

- Contexto é informação. Do ponto de vista computacional, ele pode ser codificado e representado.

- Contexto é delimitado para um conjunto de aplicações ou requisitos de aplicação, existindo um limite para as informações contextuais suportadas.

- Contexto é estável. Embora os elementos que são usados em uma representação contextual possam variar de aplicação para aplicação, não existe uma variação de instância para instância de uma atividade ou evento.

- Por fim, contexto e atividade são entidades distintas. A atividade acontece junto com um contexto, onde o contexto descreve características do ambiente onde uma atividade acontece, mas que são separadas da atividade em si (DOURISH, 2004).

A segunda definição considera contexto como sendo um problema de interação, não existindo uma preocupação com o modo que o contexto é representado, interessando apenas como e porque durante uma interação as pessoas obtêm e mantêm um entendimento mútuo do contexto das ações que foram realizadas (DOURISH, 2004). Usando os quatros aspectos observados na primeira definição, é possível entender as diferenças dessa abordagem:

- Contexto não é considerado informação, mas uma propriedade da informação ou de objetos, ou seja, uma propriedade relacional. Ao invés de pensar em algo como sendo ou não contexto, mas sim que ele seja ou não contextualmente relevante para determinada atividade.

- Também não existe uma delimitação, ou seja, não é antecipado o que será considerado contexto, mas como contexto é tratado como um problema de interação, o alcance das características contextuais é definido dinamicamente.

- Nessa abordagem, contexto não é estável, sendo particular a cada momento de uma atividade ou ação. Portanto, contexto seria uma propriedade casual relevante apenas a um ambiente em particular, instâncias particulares de uma ação ou partes em particular dessa ação.

- Encerrando, contexto e atividade não seriam duas entidades separadas, sendo o contexto um resultado da atividade, não estando simplesmente ali, mas sendo ativamente produzido, mantido e reproduzido durante o curso de uma atividade em execução (DOURISH, 2004). 
Nessa abordagem, contexto não descreve um ambiente e suas características, mas algo que as pessoas fazem. Segundo Dourish, um modo de entender essa definição é associando contexto à noção de relevância em uma conversa. Como exemplo, considere duas pessoas conversando sobre um livro que acabaram de ler. Alguns pontos da conversa, como a personagem principal e o autor do livro são relevantes para seu contexto, mas em algum momento, assuntos paralelos surgirão como o resultado da final do campeonato brasileiro. Exceto se o livro discutido tenha relação com futebol, o resultado da final é irrelevante, não fazendo parte do contexto da conversa. Seriam consideradas contextualmente relevante às informações que dessem uma visão geral da conversa e auxiliassem em seu fluxo e construção, como as pessoas envolvidas na conversa. Em alguns aspectos, essas informações podem se transformar, o local de uma conversa pode deixar de ser contexto (localidade) para fazer parte do conteúdo, no momento que os participantes da conversa percebem que estão em um ambiente público e precisam de privacidade. Assim, a contextualidade não pode ser definida por antecipação, sendo uma característica emergente da interação, determinada pelo momento e pelas ações em desenvolvimento. Então, para Dourish, contexto e conteúdo (ou atividade) não podem ser separado (DOURISH, 2004).

Considerar contexto como um problema de interação permite ir além da representação, tornando flexível e ampliando seu uso. Mas aplicar a definição de Dourish, computacionalmente falando, é complexo por exigir um esforço adicional na identificação do que é contextualmente relevante a cada momento da interação. Dentro do contexto do presente trabalho, a primeira definição é mais adequada, uma vez que para garantir que o Mecanismo de Decisão seja capaz de identificar os parâmetros de configuração de um fluxo de vídeo mais adequados para um determinado contexto, a informação relacionada a esse contexto deve ser estável e bem representada. Além disso, sem uma delimitação e uma definição clara do que seriam informações contextuais, não existiria uma base definida para o treinamento e teste/validação das técnicas de Aprendizado de Máquina, além de comprometer o desempenho esperado dessas técnicas.

Assim, considerando que para o problema de adaptação de um fluxo de vídeo, a definição de contexto envolve o problema de representação, o próximo passo é definir quais informações podem ser consideradas como contexto, isto é, definir as características de contexto e assim classificar as informações contextuais para encontrar quais dessas informações auxiliarão no processo de adaptação dinâmica de vídeo. 


\subsection{Classificação de Contexto}

Considerando um modo de categorizar os tipos contextuais, Dey \& Abowd propuseram o uso das diretrizes quem (who), onde (where), o quê (what) e quando (when), relacionadas a uma determinada entidade, para a partir dessas diretrizes definir o porquê (why) uma situação esta ocorrendo em um determinado momento (DEY; ABOWD, 2000). Alguns autores ainda definem a diretriz como (how) complementando as informações usadas na definição do porquê (why) e definindo como um determinado dispositivo é usado numa interação ou, no domínio das aplicações de captura e acesso, definindo como será o acesso e captura dos dados (TRUONG et al.., 2001).

A literatura mostra que na prática, algumas informações contextuais podem ser consideradas mais importantes que as demais e por convenção, essas informações são denominadas como contexto primário, compreendendo informações de identidade, localização, atividade e tempo. Essas informações, além de responderem ás questões quem, onde, o quê e quando, atuam como indicadores para outras fontes de informação contextual, como é o caso da identidade de uma pessoa, definindo informações como o endereço, estado civil, número de telefone etc. (ABOWD et al., 2002).

Assim, fica evidente o contexto do Usuário, definindo suas características, necessidades e interesses com relação aos serviços oferecidos (DINOFF et al., 2006). Além do contexto do Usuário, na literatura encontram-se outros tipos contextuais, como o contexto de Infra-Estrutura, de Sistema, de Domínio e de Ambiente (CHALMERS, 2002), (CROWLEY et al., 2002), (DIX et al., 2000).

O contexto de Infra-estrutura representa o estado atual da infra-estrutura de comunicação entre a aplicação e dispositivos indicando, por exemplo, possíveis mudanças de estado, conseqüência de falhas ou da transição de um dispositivo no ambiente (DIX et al., 2000).

Já o contexto de Sistema define as possíveis interações entre dispositivos e/ou aplicações, verificando se um dispositivo está ciente de outros dispositivos próximos e de modo análogo, até onde uma aplicação está ciente de outras aplicações oferecendo serviços. Este argumento é sustentado pelo fato dos dispositivos competirem por recursos afetando o funcionamento uns dos outros e a partir da combinação de dispositivos é possível definir serviços mais avançados ao usuário (DIX et al., 2000), (CHALMERS, 2002), (CROWLEY et al., 2002). No entanto, não existe uma separação clara do contexto de Sistema com o contexto de Infra-Estrutura, uma vez que ambos relacionam aplicações e dispositivos. 
O contexto de Domínio considera os relacionamentos entre os dispositivos e seus usuários e o modo como essas relações podem ser usadas para determinar a natureza da interface ou serviço apresentado, fornecendo informações referentes à semântica do domínio da aplicação. Por exemplo, o nível de segurança da informação e sua privacidade é um aspecto importante do domínio, considerando que nem sempre as informações relacionadas a um determinado usuário, como sua localização e atividade que desempenha, devem ficar disponíveis para os demais usuários (DIX et al., 2000), (ABOWD et al., 2002).

Por último, o contexto de Ambiente descreve as características do ambiente no qual se insere determinada entidade, como por exemplo, a luminosidade, localização ou temperatura. Este contexto não se restringe apenas aos ambientes reais, podendo abranger ambientes virtuais, por exemplo, descrevendo a localização de um arquivo em um computador (DIX et al., 2000).

Para situar seu trabalho que envolveu a definição do contexto de Ambiente, Dix et al. descreveu os tipos contextuais apresentados nesta Seção. Do mesmo modo, Goularte estendeu essa classificação adicionando os tipos contextuais de Usuário e Aplicação, atendendo as necessidades de seu trabalho que envolvia a personalização de conteúdo interativo em relação ao usuário. Assim, Goularte propõe um modo de organizar esses contextos, auxiliando no desenvolvimento de uma representação de contexto (GOULARTE, 2003).

\subsection{Representação de Contexto}

Representar as informações de contexto é um desafio e segundo Abowd et al., sem boas representações, a tendência é de que os desenvolvedores de aplicações optem por esquemas proprietários e limitados para armazenamento e manipulação, dificultando o intercambio desse tipo de informação (ABOWD et al., 2002). Assim, diversos autores procuraram representações que suportem a abstração de informações de contexto, como é o caso do Context Toolkit, uma arquitetura que descreve informações contextuais oriundas de sensores para seu uso em aplicações cientes de contexto (SALBER et al., 1999). No entanto, devido a sua simplicidade, não é definido nenhum vocabulário que garanta uma representação sofisticada, o que dificulta a compreensão de contexto ao compartilhar as informações. Crowley et al. representam contexto como um conjunto de variáveis representando o estado do sistema (CROWLEY et al., 2002). A maioria dos trabalhos que buscam uma representação para as informações contextuais não se preocupa em classificar os tipos de contexto de modo estruturado e abrangente limitando-se em resolver os problemas que necessitam dessa 
representação, além da falta de flexibilidade no compartilhamento de informações de contexto com outras aplicações (GOULARTE, 2003).

Usando a definição de contexto de Dey et al. (DEY et al., 2001), Goularte desenvolveu um arcabouço (framework) que oferece uma representação de contexto; meios para definir entidades contextuais classificadas conforme um modelo contextual (Figura 1); e um conjunto de elementos contextuais pré-definidos em uma biblioteca contextual (GOULARTE, 2003). Nesse arcabouço cada tipo contextual é definido como uma extensão dos contextos primários (identidade, localização, atividade e tempo).

O modelo contextual proposto por Goularte, mostrado na Figura 1, desconsidera os contextos de Ambiente e Domínio. Nele, as entidades que possuem representação própria, isto é, que não dependem de outros contextos na sua formação, são representadas usando retângulos com linha cheia enquanto que as entidades que correspondem a um conjunto de entidades, ou entidades componentes, usam retângulos pontilhados. Esse modelo, por organizar de modo estruturado os diferentes tipos de contexto, permite uma separação clara dos contextos de Sistema e de Infra-Estrutura, além de facilitar o entendimento dos tipos de contexto e, como conseqüência, a criação de representações para informações de contexto (GOULARTE, 2003).

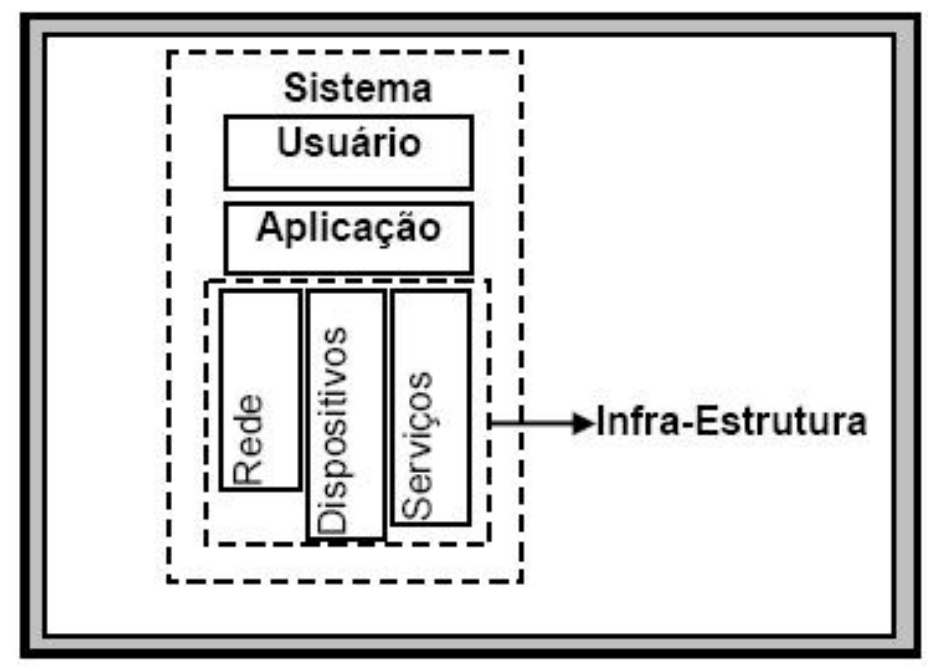

Figura 1: Componentes do contexto do sistema (GOULARTE, 2003)

A representação proposta por Goularte define um tipo abstrato PrimaryContextType que é composto por outros tipos abstratos (IdentityType, LocationType, TimeType e ActivityType), representando os quatro contextos primários. Utilizando essa definição é possível construir entidades contextuais específicas de acordo com o contexto primário. Isso permitiu a criação de uma biblioteca contextual composta por entidades específicas e cada item dessa biblioteca é representado a partir de um XML Schema (LAURENT; 
FITZGERALD, 2005), com as informações relevantes que caracterizam determinada entidade. Para descrever uma entidade contextual, procura-se na biblioteca pré-definida pela informação que melhor caracteriza a entidade. Caso não exista uma representação contextual adequada dentro dessa biblioteca, é possível criar novas representações por meio de extensões do PrimaryContextType. Como exemplo, a Figura 2 mostra a descrição da entidade Usuário a partir do tipo UserType, definido como uma extensão do tipo PrimaryContextType e em conseqüência disso, herdando os elementos definidos, ou seja, toda a biblioteca contextual (GOULARTE et al., 2006).

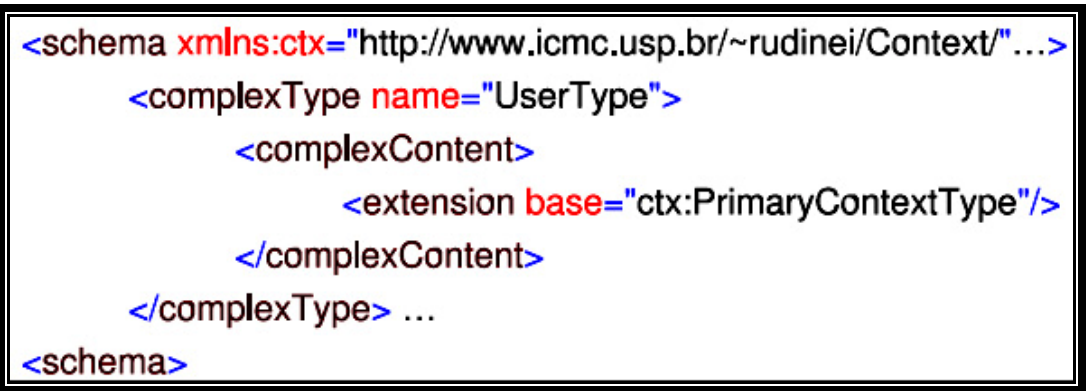

Figura 2 Definindo o tipo UserType como extensão do PrimaryContextType (GOULARTE, 2003)

O desenvolvedor pode escolher quais tipos presentes na biblioteca melhor descrevem um usuário, caracterizando seus interesses. Caso não exista uma biblioteca com a informação desejada, como a representação de um apelido, é possível estender o PrimaryContextType, definindo um novo tipo, como mostrado na Figura 3, onde o novo tipo (NickNameType) é associado a um contexto primário, no caso o IdentityType (GOULARTE et al., 2006).

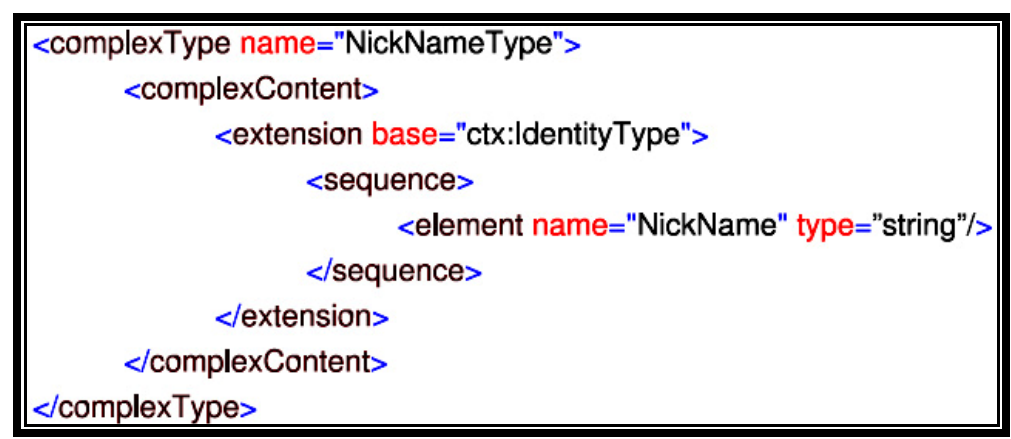

Figura 3 - Exemplo de criação do Tipo NickName (GOULARTE, 2003)

Usando esse modelo de representação, Goularte definiu como exemplo de representação o contexto de Usuário, definindo um conjunto de elementos contextuais classificados de acordo com os tipos de contexto primário. Esses elementos compõem a biblioteca contextual permitindo a representação de informações contextuais relacionadas aos usuários (GOULARTE et al., 2006). Na Tabela 1 encontra-se uma listagem com alguns exemplos de tipos presentes na biblioteca contextual, para cada contexto primário, onde cada tipo corresponde a um elemento. Do mesmo modo que tipos complexos foram construídos a 
partir de tipos simples, é possível usar tipos simples ou complexos na definição de novos elementos, conforme a necessidade da aplicação.

Tabela 1 - Alguns tipos presentes na Biblioteca Contextual (GOULARTE et al., 2006)

\begin{tabular}{|c|l|l|}
\hline Contexto Primário & \multicolumn{1}{|c|}{ Tipos Complexos } & \multicolumn{1}{c|}{ Tipos Simples } \\
\hline Tempo & & $\begin{array}{l}\text { occasionType, dateType, } \\
\text { simpleTimeType, durationType, ... }\end{array}$ \\
\hline Atividade & userActionType, userActivityType \\
\hline Localização & indoorLocationType & $\begin{array}{l}\text { floorType, roomType, corridorType, } \\
\text { gateType, exitType,... }\end{array}$ \\
\cline { 2 - 3 } & postalAddressType & $\begin{array}{l}\text { streetType, numberType, } \\
\text { complementType, cityType, stateType, } \\
\text { countryType, ... }\end{array}$ \\
\hline Identidade & fullNameType & $\begin{array}{l}\text { userIDType, roleType, givenNameType, } \\
\text { simpleNameType,middleNameType, } \\
\text { familyNameType, ... }\end{array}$ \\
\cline { 2 - 4 } & personalInformationType & $\begin{array}{l}\text { ageType, } \\
\text { eyesType, birthDateType, ... }\end{array}$ \\
\hline
\end{tabular}

\subsection{Considerações Finais}

Adaptar conteúdo exige o conhecimento de todos os elementos que possam definir ou influenciar as necessidades do usuário em relação a tal conteúdo. Portanto, definir as informações relevantes e como elas serão apresentadas constituem importantes subsídios à adaptação. Assim, capturar as informações contextuais do ambiente computacional, no qual o sistema e o usuário estão inseridos, é um modo de obter esses subsídios. Por exemplo, na adaptação de vídeo, essas informações contextuais poderiam ser a resolução gráfica do dispositivo usado pelo usuário e a largura de banda disponível na rede, oferecendo subsídios para determinar a taxa e o tamanho dos quadros de um fluxo de vídeo.

Obter e representar essas informações, dando subsídios à adaptação de conteúdo, ainda é um problema em aberto. A Ciência de Contexto, uma subárea da Computação Ubíqua, estuda justamente o uso das informações presentes nas interações entre usuários e aplicações de modo a adaptar os serviços para que atendam as necessidades específicas, no momento em que ocorrem e de modo transparente para o usuário (ABOWD et al., 2002). Existem duas 
maneiras distintas de abordar o termo contexto, seja como um problema de interação, onde não existe uma separação clara entre conteúdo e contexto, não limitando o que é considerado informação contextual, podendo variar a cada momento da interação; ou como um problema de representação, partindo do princípio que os sistemas computacionais são representacionais, ou seja, lidando com contexto como uma informação representável, estável e delimitada (DOURISH, 2004).

Lidar com contexto como um problema de interação cria novas possibilidades, uma vez que uma mesma informação pode ter seu papel alterado conforme o momento, como é o caso de dois agentes secretos discutindo sua missão no saguão de um hotel. Em um primeiro momento, o saguão do hotel representa uma informação contextual (localidade), entretanto, quando esses agentes percebem que o local escolhido pra discussão não garante a privacidade necessária, essa informação deixa de ser contexto e passa a ser parte do conteúdo. Isso permite explorar o problema da adaptação de um modo amplo. Entretanto, a complexidade exigida para lidar com o dinamismo na definição de que uma informação é contexto ou conteúdo, a cada momento da interação, dificulta seu uso prático nos sistemas computacionais atuais. Assim, a abordagem representacional, por trabalhar com contexto como algo representável, delimitado e estável, é possível explorar diversos paradigmas computacionais para a obtenção e manipulação de informação, paradigmas já estabelecidos e apresentando bons resultados em diversos segmentos. Um desses paradigmas envolve o Aprendizado de Máquina (HAYKIN, 2001).

Nem toda informação contextual obtida do ambiente computacional é relevante a uma aplicação. Um sistema que controla a temperatura de uma sala não precisa conhecer, a princípio, a localização desta sala, a menos que esta informação influencie ou auxilie o funcionamento do sistema. O mesmo pode ser dito da adaptação de um conteúdo e para determinar quais informações são necessárias ao processo de adaptação se faz necessário à classificação das informações contextuais. Na literatura, algumas diretrizes são definidas para identificar uma entidade, conhecidas como as cinco dimensões semânticas ou cinco W's: quem (who), onde (where), o quê (what) e quando (when), definindo o porquê (why) determina ação/evento ocorre com essa entidade (DEY; ABOWD, 2000). Em alguns casos específicos, acrescentasse a dimensão como (how) definindo, por exemplo, o dispositivo usado para executar a ação/evento, complementando o porquê (why) (TRUONG et al.., 2001) e a partir dessas dimensões definem-se os contextos primários (identidade, localização, atividade e tempo). Com isso é possível identificar um conjunto de tipos contextuais, como é o caso do Usuário, Infra-Estrutura, Sistema, Domínio e Ambiente (CHALMERS, 2002), 
(CROWLEY et al., 2002), (DIX et al., 2000), (DINOFF et al., 2006), organizado por Goularte em um modelo de representação de contexto que permitiu não apenas uma organização hierárquica e estruturada, mas uma separação clara entre o contexto de Sistema e de InfraEstrutura (GOULARTE, 2003).

Esse modelo permite que o desenvolvedor defina apenas as informações contextuais que considerar relevante, além de ser extensível graças à biblioteca contextual definida com o uso de XML Schema (LAURENT; FITZGERALD, 2005). Entretanto, a biblioteca proposta por Goularte define apenas o Usuário, como exemplo de seu potencial. Assim, para o presente trabalho definiu-se uma extensão dessa biblioteca, considerando os Dispositivos, complementando o trabalho de Goularte (EISINGER et al., 2005). A representação dos dispositivos dentro do modelo proposto por Goularte será discutida em detalhes no Capítulo 5. Com as informações contextuais organizadas e representadas adequadamente, têm-se subsídios suficientes para definir quais dessas informações serão importantes na adaptação do fluxo de vídeo segundo as necessidades de cada usuário.

Para que essas informações sejam aproveitadas da melhor maneira possível, o sistema deve ser capaz de analisar e responder de acordo com as necessidades do usuário. Como já mencionado na Introdução, a adaptação de um conteúdo, como é o caso de vídeo, é um problema típico de classificação, onde a partir de um conjunto de informações esperasse identificar a saída, ou seja, o fluxo de vídeo mais adequado. Assim sendo, técnicas de Aprendizado de Máquina podem ser usadas para resolver esse problema. Para o presente trabalho foram consideradas duas técnicas em particular, as Redes Neurais Artificiais (HAYKIN, 2001), objeto de estudo do Capítulo 3, imitando o funcionamento do cérebro humano, usando um conjunto de unidades simples, os neurônios, que reunidas ganham um grande poder de processamento; e a Inferência Bayesiana (MITCHEL, 1997), uma técnica estatística que usa a probabilidade para inferir a chance de uma hipótese ocorrer, estudada com mais detalhes no Capítulo 4. 
Capítulo 3

Redes Neurais

“Nosso cérebro é o melhor brinquedo já criado: nele se encontram todos os segredos, inclusive o da felicidade”.

\section{Charles Chaplin}

Redes neurais são sistemas computacionais formados pela combinação de inúmeros elementos de processamento (EP), funcionalmente simples e altamente interconectados, trabalhando massivamente em paralelo. Originalmente concebidas com base no estudo do cérebro humano e de suas conexões sinápticas, são radicalmente diferentes de todos os demais modelos computacionais. Em síntese, uma rede neural pode ser resumida como uma função matemática que mapeia um conjunto de padrões de entrada em um conjunto de padrões de saída desejados (HAYKIN, 2001).

O sistema nervoso é uma rede de comunicações eletroquímicas internas do corpo e as principais partes que o compõem são o cérebro e a medula espinhal que formam o sistema nervoso central (SNC), correspondendo ao centro de controle e coordenação do corpo; e os nervos, formados por bilhões de longos neurônios compondo o sistema nervoso periférico responsável por transmitir impulsos nervosos entre o SNC e as demais regiões do corpo.

O cérebro humano, ou encéfalo, intriga por sua complexidade e surpreendente capacidade de processamento e armazenamento de informação. Como centro supervisor do sistema nervoso, sua função é controlar e coordenar a maior parte dos movimentos, comportamentos e funções homeostáticas do organismo, como por exemplo, o batimento cardíaco, temperatura do corpo e concentração dos fluidos internos. Ele é composto primariamente por dois tipos de células: os neurônios, células que cuidam da transmissão de informação e as neuroglias, responsáveis por apoiar e proteger os neurônios. Os neurônios são conectados uns aos outros por meio de sinapses, formando uma grande rede, chamada rede neural. As sinapses transmitem estímulos usando diferentes concentrações de $\mathrm{Na}+$ (Sódio) e $\mathrm{K}+$ (Potássio), e o resultado disto pode ser estendido por todo o corpo humano. A Figura 4 mostra a estrutura básica de um neurônio, composto por três partes: o corpo celular ou soma, definido por um núcleo e um citoplasma onde os estímulos de informação são integrados e a maioria do metabolismo celular é realizada; os dendritos, que recebem os impulsos provenientes dos axônios de outros neurônios e os levam ao corpo celular, para a integração 
das informações, reiniciando novo ciclo, e o axônio, encarregado da transmissão dos impulsos da célula para outros neurônios (KANDEL et al., 2000).

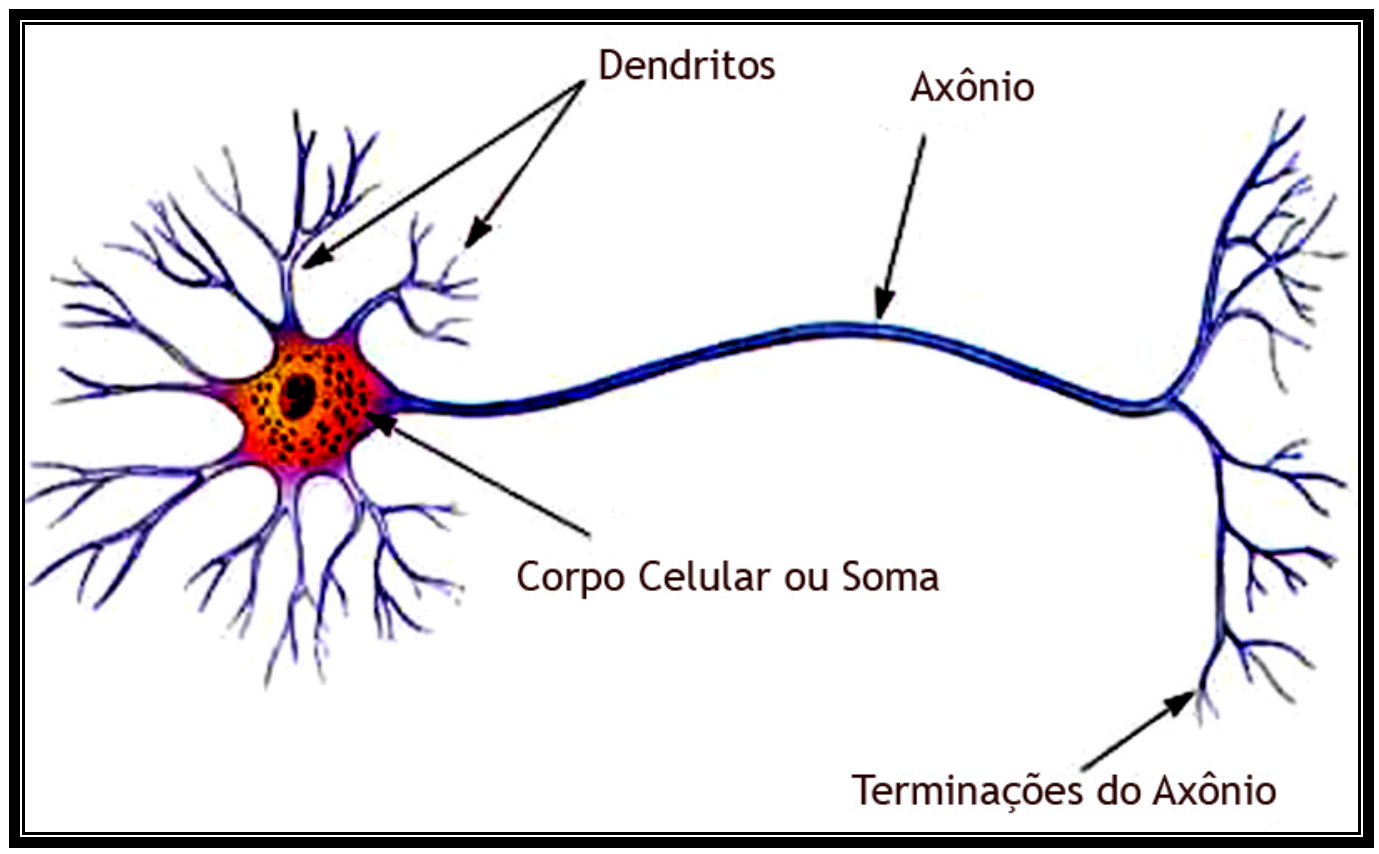

Figura 4: Estrutura Biológica de um Neurônio (KANDEL et al., 2000).

Observando as estruturas biológicas do cérebro e o comportamento de suas células nervosas, vários pesquisadores tentaram desenvolver uma rede formada por unidades com processamento semelhantes aos neurônios biológicos, como a capacidade de operar paralelamente. Em 1943, uma máquina inspirada no funcionamento do cérebro humano, em particular, na sua capacidade de organizar seus componentes estruturais de modo a desempenhar certas funções, como o reconhecimento de padrões, foi sugerida por W. S. McCulloch e W. H. Pitts, iniciando os estudos com Redes Neurais Computacionais (HEATON, 2005). Portanto, as redes neurais artificiais (RNAs) foram concebidas com o objetivo de imitar em um computador a estrutura e funcionalidade do cérebro, para isso os pesquisadores tiveram que buscar alternativas para modelar o neurônio biológico, tanto na sua estrutura como na sua funcionalidade, conectividade e interatividade dos neurônios. O modelo matemático de um neurônio artificial idealizado pelos pesquisadores W. S. McCulloch e W. H. Pitts compõe-se basicamente de conexões e pesos de entrada simulando os dendritos e sinapses, de uma função de mapeamento como referencia ao corpo celular, e uma saída que seria equivalente ao axônio, conforme exemplificado na Figura 5 (MCCULLOCH, 1943). 


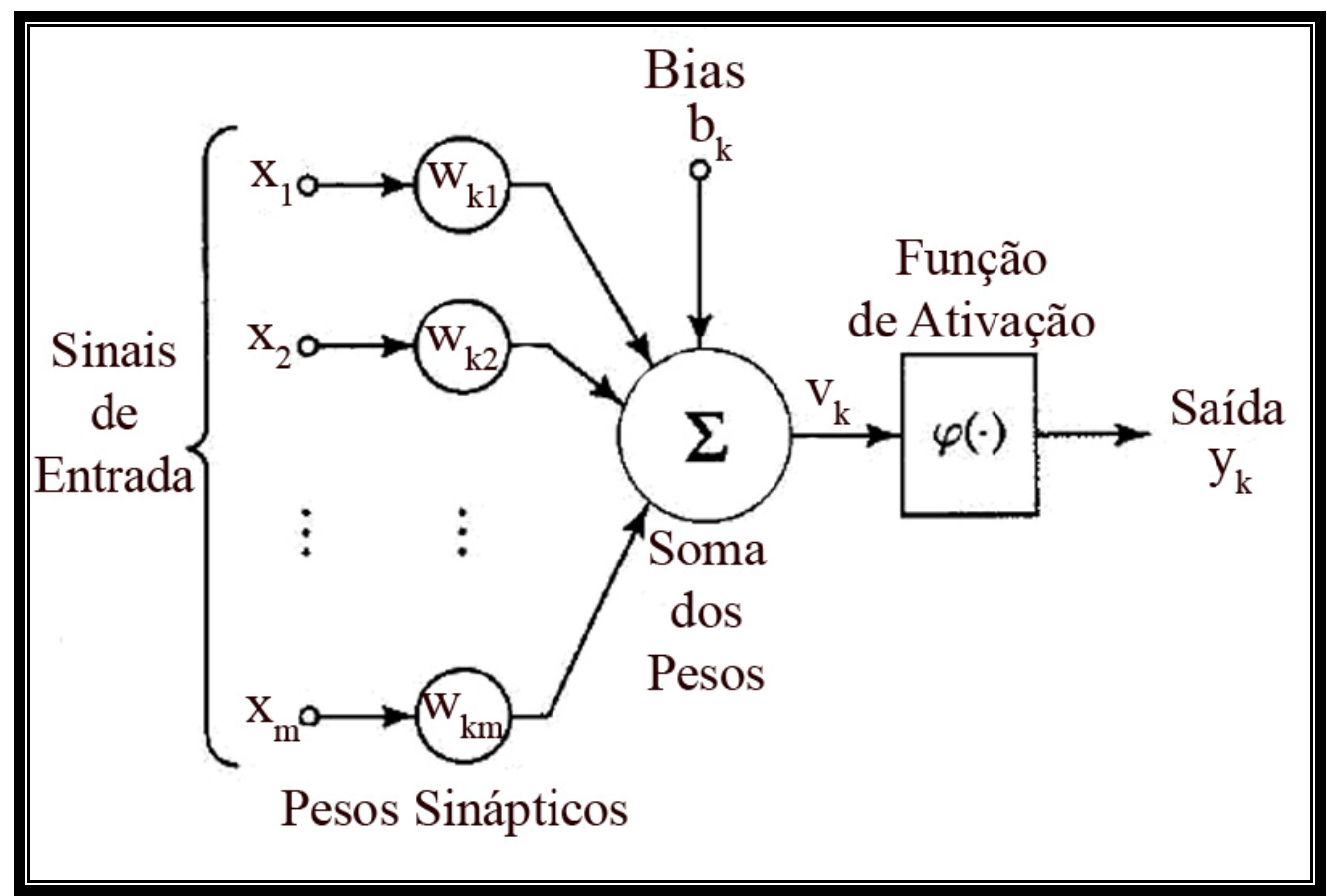

Figura 5: Modelo de Neurônio sugerido por McCulloch e Pitts (MCCULLOCH, 1943)

O modelo de neurônio usado atualmente nas RNAs teve sua estrutura básica inspirada na interpretação do funcionamento de um neurônio biológico realizada pelo físiologista Warrem McCulloch, sendo composto basicamente pelos seguintes elementos:

1. Entradas, tendo como origem as saídas de outros neurônios da RNA ou entradas externas, como os dados a serem analisados.

2. Combinação das Entradas, a soma de todas as entradas multiplicadas por seus respectivos pesos sinápticos.

3. Função de Ativação, que determina o estado (ou saída) do neurônio, tendo como base o resultado da combinação das entradas.

A diferença entre algumas ou às vezes todas as entidades envolvidas em um problema levou os pesquisadores a desenvolverem diferentes estruturas de redes neurais. Essa variedade de estruturas permitiu que as redes neurais fossem aplicadas com sucesso em problemas nas mais diferentes áreas de conhecimento, a maioria envolvendo a Classificação ou Reconhecimento de padrão; Processamento de imagem e visão; Identificação de sistema e controle e Processamento de sinais. A adaptação de um fluxo de vídeo, de modo automático e dinâmico, enquadra-se como um problema de Classificação ou Reconhecimento de Padrão, onde a partir das informações contextuais obtidas do ambiente, representando as necessidades do usuário e restrições do sistema, define-se qual padrão para o fluxo de vídeo é mais adequado. 
O presente trabalho usa a capacidade de extração e classificação de conhecimento das redes neurais como cérebro do Mecanismo de Decisão, analisando as informações contextuais e obtendo a configuração mais adequada para o fluxo de vídeo. Este Capítulo investiga as Redes Neurais e seu potencial como parte do Mecanismo de Decisão, organizado de modo a esclarecer esse potencial. A Seção 3.1 identifica as principais características das Redes Neurais, destacando-se para o presente trabalho a capacidade de generalização a partir de uma amostra do ambiente. Já a Seção 3.2 apresenta os processos de aprendizado considerando como os exemplos são apresentados à rede durante seu treinamento e os dois principais paradigmas de treinamento: Supervisionado e Não-Supervisionado. Os diferentes tipos de Redes Neurais são relacionados na Seção 3.3, destacando-se a rede definida para o presente trabalho, a Multi-layer Perceptron (MLP). O Capítulo encerra com a Seção 3.4, resumindo o que foi apresentado e justificando a escolha da rede MLP na adaptação dinâmica de vídeo.

\subsection{Características das Redes Neurais}

O poder computacional de uma RNA deve-se basicamente a dois fatores, sua estrutura paralela massivamente distribuída e sua habilidade de aprender e, por conseqüência, generalizar. Uma RNA dispensa o uso de modelos precisos da realidade física do problema, possuindo grande capacidade de adaptação e precisando apenas de uma arquitetura paralela com algoritmos adequados na fase de "aprendizado" e alta capacidade de processamento. Dentre as principais vantagens têm-se sua tolerância à falhas; seu uso em aplicações de tempo real; sua alta capacidade de auto-adaptação; e a capacidade de resolver problemas práticos sem a necessidade da definição de listas de regras ou de modelos precisos (HAYKIN, 2001).

As RNAs oferecem a melhor abordagem na resolução de problemas que envolvam o reconhecimento de padrões, classificação de padrões, associação de padrões, identificação, resistência ao ruído, aproximação de funções e aprendizado; sendo aplicados quando não é difícil criar modelos precisos da realidade ou em problemas com freqüentes mudanças no ambiente (HAYKIN, 2001). Em uma rede neural artificial todos os parâmetros de entrada devem ser convertidos em valores numéricos para que possam ser processados pela rede, ou seja, uma rede neural é eminentemente numérica. Assim, Haykin sugere algumas características relevantes das RNAs, discutidas nas subseções a seguir (HAYKIN, 2001). 


\subsubsection{Possibilidade de considerar o comportamento não-linear dos fenômenos físicos apresentados na entrada}

Um neurônio pode ser linear ou não-linear, dependendo da Função de Ativação usada como saída. Por conseqüência, uma RNA composta por interconexões de neurônios nãolineares é uma rede não-linear e essa não-linearidade é distribuída por toda a rede considerando, por exemplo, sinais de entrada inerentemente não-lineares, como um sinal de voz.

\subsubsection{Necessidade de pouco conhecimento estatístico sobre o ambiente onde a rede encontra- se inserida}

Diferente da análise estatística tradicional, as redes neurais não precisam ter um prévio conhecimento sobre a distribuição dos dados para analisá-los. Basta que exista uma relação implícita entre os dados, mesmo que não seja conhecida sua representação analítica e/ou estatística.

\subsubsection{Capacidade de aprendizagem}

As Redes Neurais armazenam em seus pesos sinápticos o conhecimento adquirido a partir de um conjunto de exemplos que caracterizem bem o ambiente. Isso é possível graças a um processo de aprendizado envolvendo a modificação desses pesos. No aprendizado supervisionado, descrito na Seção 3.2, esses exemplos são representados por um conjunto de entradas e a saída esperada para esses dados, os pesos sinápticos são modificados de modo a minimizar a diferença entre a resposta desejada, ou a saída esperada, e a resposta atual da rede, isto é, a saída obtida a partir da configuração atual dos pesos sinápticos. O processo é repetido até se atingir um erro aceitável ou que não haja mudanças significativas nos pesos. Como conseqüência as Redes Neurais conseguem aproximar qualquer mapeamento entrada/saída de natureza continua dependendo da arquitetura de rede escolhida e do algoritmo de aprendizado usado.

\subsubsection{Capacidade de Adaptação e Generalização}

As RNAs têm a capacidade de aprender rapidamente padrões complexos e qualquer tendência presente nos dados, sendo ágeis ao adaptarem-se as mudanças, tornando-as ferramentas extremamente flexíveis em um ambiente dinâmico. Essa capacidade também permite que a rede tenha desempenho satisfatório mesmo com um dado de entrada desconhecido, procurando na vizinha dos dados usados no treinamento uma saída mais adequada, em outras palavras, generalizando, tendo como base as informações usadas no 
treinamento. Essa generalização depende do quanto é representativa a amostra do ambiente usada no treinamento.

\subsubsection{Tolerância a Falha}

A perda de alguns neurônios, assim como no cérebro, não afeta totalmente o desempenho de uma RNA, continuando a apresentar resultados satisfatórios. Cada neurônio é potencialmente afetado pela atividade global dos demais neurônios na rede, assim o conhecimento é representado pela própria estrutura da RNA e seu estado de ativação. Em outras palavras, os neurônios da vizinhança de um neurônio defeituoso podem substituir seu funcionamento, ainda que com uma pequena perda. Isso também mostra outro aspecto interessante, o modo como o conhecimento é armazenado em uma RNA, o que faz com que as informações contextuais sejam tratadas com naturalidade.

\subsection{Processos de Aprendizado}

Aprender com o ambiente e melhorar seu desempenho por meio desse aprendizado é a propriedade mais significativa de uma RNA. Dentro do contexto de Redes Neurais, Haykin apresenta a seguinte definição para aprendizado:

“Aprendizagem é um processo onde os parâmetros livres de uma RNA são adaptados por meio de estímulos do ambiente no qual a rede está inserida. O tipo de aprendizado é determinado pela forma com a qual é efetuada a mudança nos parâmetros (HAYKIN, 2001)”.

Adotando critérios específicos no aprendizado é possível encontrar um conjunto de parâmetros livres que possibilite um desempenho adequado da rede, usando um processo interativo e iterativo. Normalmente esses critérios envolvem a mudança nos parâmetros livres a partir de estímulos do ambiente e com essa mudança a rede passa a responder ao ambiente de uma nova maneira. O ideal é que esse conhecimento do ambiente no qual a rede neural esta inserida aumente a cada iteração no processo de aprendizagem, em outras palavras, a cada mudança, espera-se que a rede se aproxime da resposta esperada para esses estímulos.

Do ponto de vista computacional, essas mudanças são realizadas a partir de um algoritmo de aprendizado. Na literatura existem dois tipos de paradigmas de aprendizado adotados para esses algoritmos aqueles que utilizam a ajuda de um tutor, ou seja, um Aprendizado Supervisionado; ou sem o uso de um tutor, definindo um Aprendizado NãoSupervisionado. Alguns autores consideram ainda um terceiro paradigma, o Aprendizado por Reforço, fazendo uso de um crítico ou árbitro (HAYKIN, 2001). 


\subsubsection{Modos de Aprendizado}

O processo de aprendizado envolve o ajuste dos parâmetros livres ou pesos sinápticos e o modo como esse ajuste é feito influencia o desempenho de uma RNA. Assim, existem dois modos de atualização são usualmente utilizados por um algoritmo de aprendizado:

- Batch, onde os parâmetros são ajustados somente ao final de cada época (epoch), isto é, o processamento de todo o conjunto de observações ou exemplos usados no treinamento. Nesse modo, a RNA é menos influenciada pela ordem em que os exemplos são apresentados no treinamento, sendo menos suscetível às oscilações no aprendizado, ao custo de uma velocidade de aprendizado, ou convergência, em geral mais baixa.

- Incremental, com os parâmetros sendo ajustados ao final do processamento de cada observação, ou seja, a cada exemplo ajustam-se os parâmetros da rede. A ordem da apresentação dos padrões influencia a velocidade de aprendizado da rede e, em alguns casos, deve-se reorganizar esta ordem, o que permite acelerar o treinamento. O problema dessa abordagem é encontrar a ordem que o conjunto de exemplos deve ser apresentado para acelerar o aprendizado, alguns trabalhos utilizam algoritmos genéticos para isso. (HAYKIN, 2001).

\subsubsection{O Aprendizado Supervisionado}

Neste paradigma o conhecimento é representado como um conjunto de pares, composto por entradas e saídas. O treinamento consiste em apresentar as entradas de um par à rede neural, processando-as e assim obtendo uma ou mais saídas. O treinamento consiste em comparar as saídas obtidas nesse processamento com as saídas esperadas para aquele conjunto de entradas, definidas previamente pelo tutor. A diferença entre a saída esperada e a saída obtida define o erro que será usado no ajuste dos pesos sinápticos da rede, procurando minimizar esse erro. O processo é repetido até que a RNA responda próximo o suficiente da saída esperada, dentro de uma margem de tolerância definida previamente. A Figura 6 mostra um diagrama de blocos deste tipo de aprendizado, onde as informações do Ambiente definem o Tutor e a comparação entre a resposta esperada e a resposta obtida pelo definem um sinal de erro, utilizado no ajuste dos parâmetros livres ou pesos sinápticos do Mecanismo de Aprendizado (HAYKIN, 2001). 


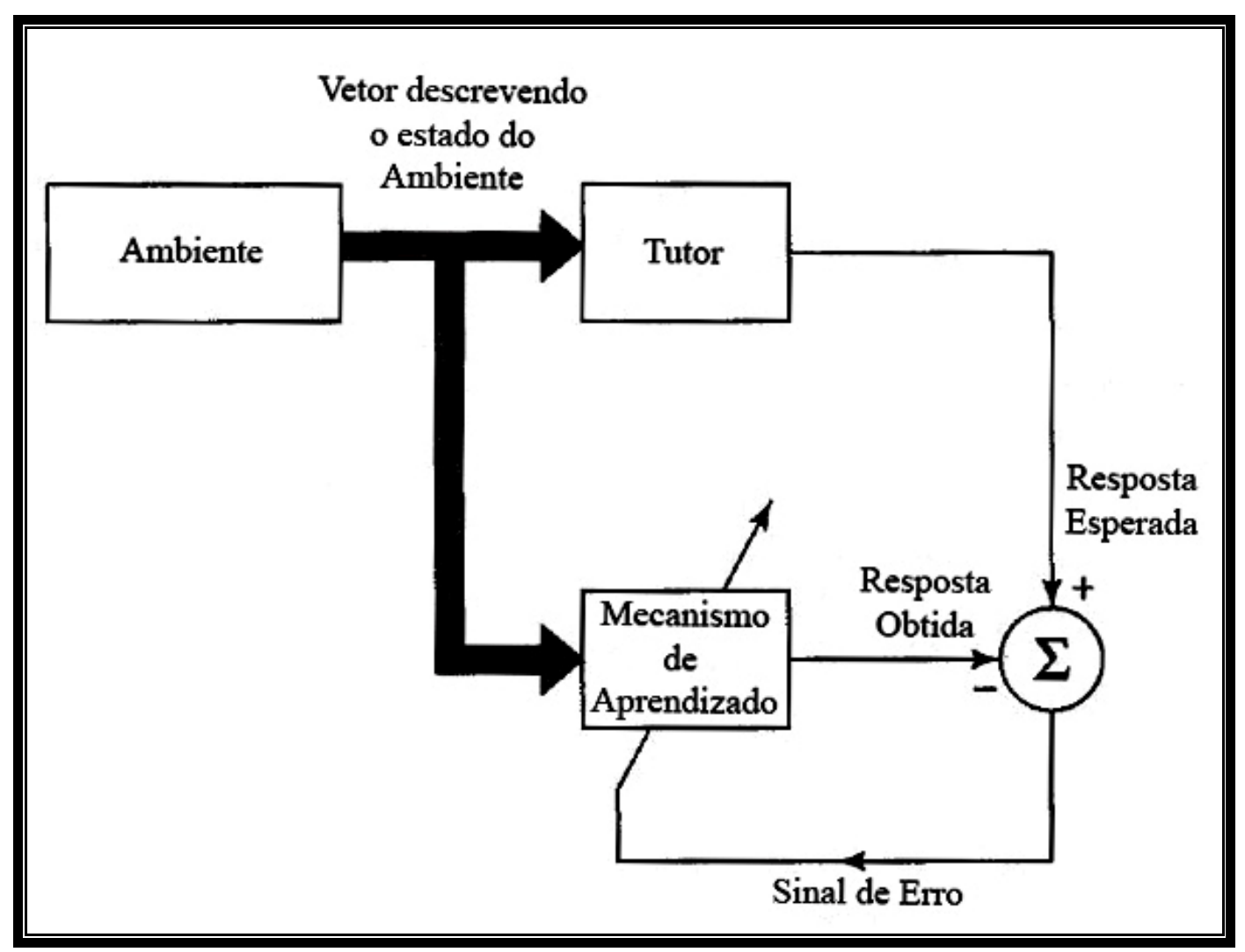

Figura 6: Diagrama de Blocos do Aprendizado supervisionado (HAYKIN, 2001).

O processo básico do aprendizado supervisionado pode ser sumarizado com os seguintes passos, considerando um treinamento em modo Incremental:

- Passo 01: Escolha dos pesos iniciais, geralmente assumindo valores pequenos e aleatórios.

- Passo 02: Apresentação de uma entrada cuja saída correspondente é conhecida.

- Passo 03: Cálculo da saída a ser gerada pela rede.

- Passo 04: Cálculo do erro (saída desejada vs. saída gerada).

- Passo 05: Ajuste dos pesos.

- Passo 06: Verificação do erro médio encontrado, se satisfatório, termina o processamento da rede, caso contrário retorna ao Passo 02.

\subsubsection{Aprendizado não-supervisionado}

O aprendizado não-supervisionado, também conhecido como aprendizado autoorganizado, é usualmente utilizado na resolução de problemas de classificação, quando os padrões não são conhecidos previamente, possuindo a capacidade de agrupá-los em grupos com características similares. A rede é treinada a partir de excitações do ambiente ou padrões de entrada e esta arbitrariamente organiza esses padrões em categorias. Diferente do 
aprendizado supervisionado, o aprendizado auto-organizado dispensa a ajuda de tutores e árbitros (HAYKIN, 2001).

Durante o treinamento, quando uma entrada é aplicada à rede, uma resposta é fornecida, indicando a classe correspondente e se o padrão de entrada não corresponde às classes existentes, uma nova classe é gerada. A Figura 7 mostra o diagrama de blocos do aprendizado auto-organizado, basicamente indicando que o Mecanismo de Aprendizado pega os padrões do Ambiente e sozinho, sem um tutor, identifica a saída esperada.

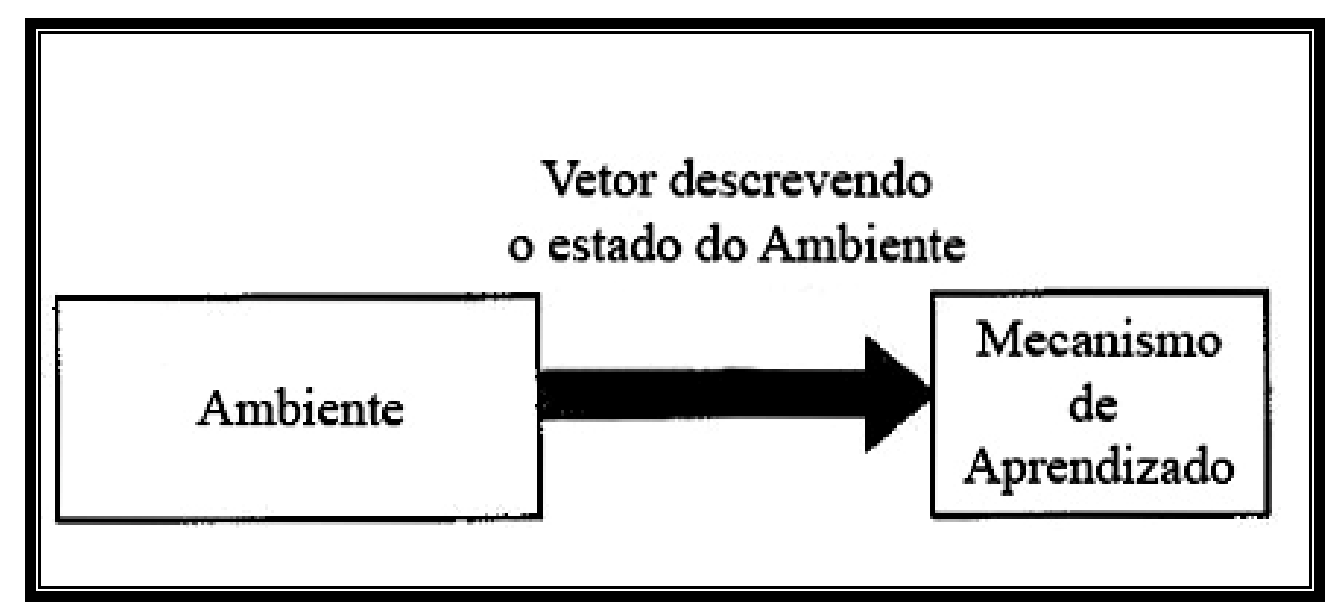

Figura 7: Aprendizado sem tutor ou não-supervisionado (HAYKIN, 2001).

\subsection{Tipos de Redes Neurais:}

As RNAs são exploradas na resolução dos mais variados problemas e pela diferença entre algumas ou às vezes todas as entidades envolvidas, diferentes estruturas de redes neurais tem sido encontrada na literatura. Um modo de classificar essas estruturas é separando-as com base nos paradigmas de aprendizado, dividindo em dois grupos, as Redes Feed-Forward, ou de aprendizado supervisionado e as Redes Recorrentes, ou auto-organizáveis. Alguns modelos de RNAs são mostrados na Figura 8, separadas conforme esses dois grupos.

Dentro das Redes Recorrentes, citam-se as Redes Competitivas, onde todos os neurônios recebem a mesma informação de entrada, competindo até definir um único neurônio ativo para aquela entrada, isto é, cada neurônio torna-se especialista em uma informação; as Redes de Kohonen, um tipo particular de Rede Competitiva, onde as entradas são apresentadas em seqüência e os neurônios disputam quem será o vencedor a cada iteração, terminando o processo assim que todas as entradas são reconhecidas; as Redes de Hopfield, ou Redes de Pesos Simétricos, apresentam uma topologia onde todos os neurônios estão conectados e depois de treinada e uma entrada é apresentada à rede passa por diversos ciclos até estabilizar e a saída será o padrão obtido para essa entrada; e como ultimo exemplo, os 
Modelos ART, que diferem dos demais modelos de redes neurais pela capacidade de adquirir um novo conhecimento sem perder aquele que já foi adquirido enquanto que nos demais modelos sempre que uma nova informação precisa ser adicionada, é necessário um novo treinamento (HAYKIN, 2001).

Como exemplos de Redes Feed-Forward citam-se o Perceptron Simples, um dos primeiros modelos de redes neurais que, como será explicado mais adiante, limita-se a problemas linearmente separáveis; e as Redes Perceptron Multicamadas, ou Multi-Layer Perceptron (MLP), uma evolução do Perceptron Simples que a partir do uso de várias camadas, consegue resolver problemas não-lineares, sendo uma das redes neurais mais usadas na literatura; a rede de Função de Base Radial, ou Radial Basis Function (RBF), aproxima os resultados a partir de respostas localmente sintonizadas, selecionando um intervalo finito no intervalo de entradas.

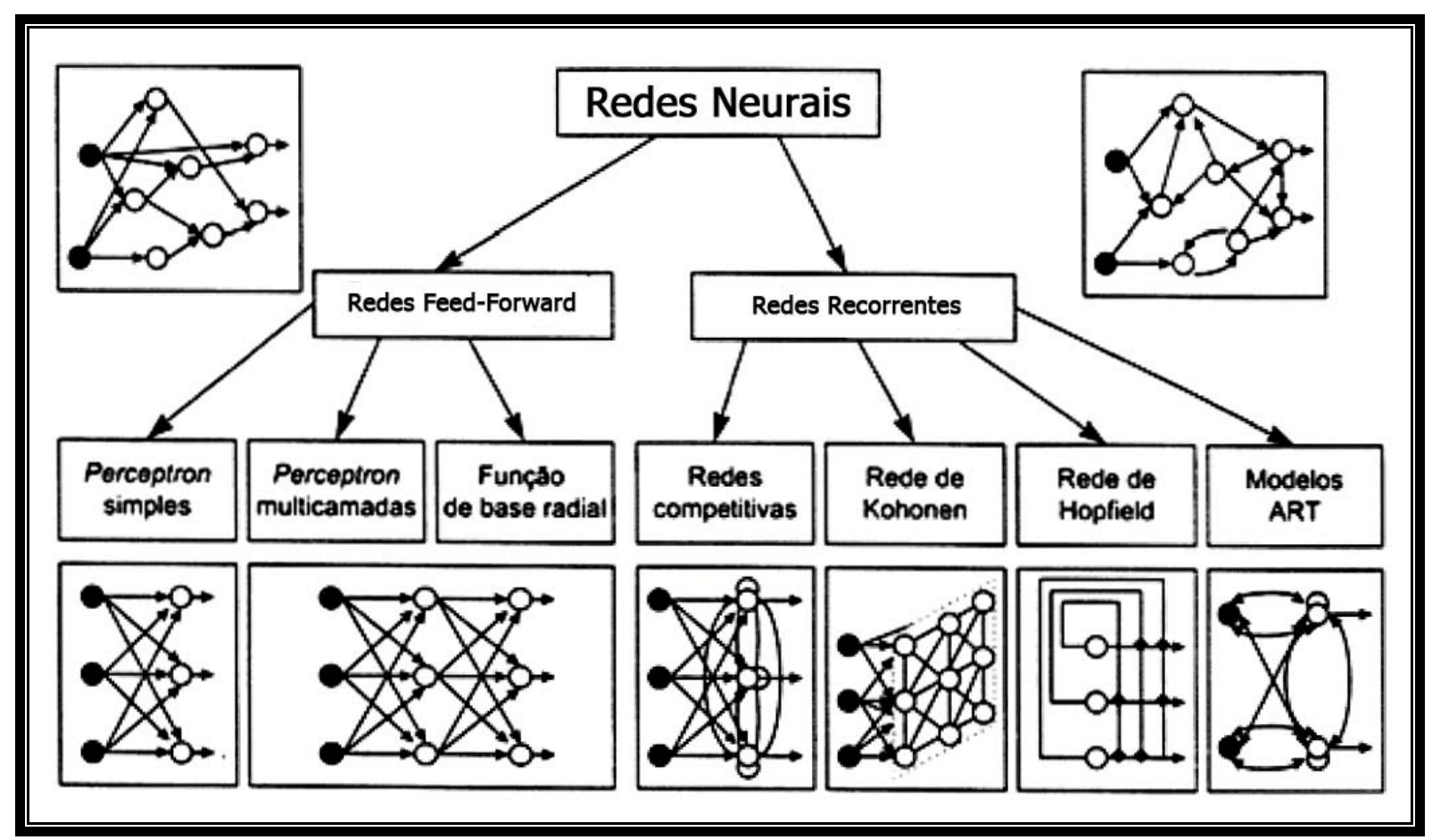

Figura 8: Tipos de Redes Neurais (HAYKIN, 2001).

Em outra classificação é considerada a estrutura dessas redes dividindo-as em Redes Estáticas, ou seja, cujas conexões e o número de neurônios são constantes ao longo do processo de treinamento; ou Redes Dinâmicas, onde esse número pode variar. Do ponto de vista estrutural, essas redes podem ser classificadas como tendo uma única camada ou múltiplas camadas de neurônios. Outra classificação considera o modo como os neurônios são conectados, existindo redes com conexões estritamente no sentido de ida, bilaterais (ida e volta), lateralmente conectadas, topologicamente ordenadas ou híbridas. Por último, considerando sua aplicação, as redes neurais podem ser usadas para o Reconhecimento de 
padrões e Classificação; Processamento de imagem e visão; Identificação de sistema e controle e Processamento de sinais, embora se deva deixar claro que uma aplicação que use rede neural não precisa necessariamente ser classificada em uma única classe, dentre as classes acima apresentadas (HAYKIN, 2001).

A melhor abordagem para a adaptação dinâmica de um fluxo de vídeo é a adoção de técnicas de aprendizado supervisionado, usando Redes Feed-Forward. Essa escolha é justificada considerando que é possível representar o problema a partir de uma amostragem do ambiente, usando este conjunto para treinar uma rede que responda, satisfatoriamente, a qualquer entrada que faça parte do espaço amostral adotado. O uso de Redes Recorrentes poderia ser considerado, mas alguns fatores as tornam inadequadas, como o fato das Redes Auto-organizáveis separarem suas saídas em categorias abstratas, por encontrarem as saídas com base na similaridade entre as entradas usadas no conjunto de exemplo, sem definir um parâmetro de saída mais adequado. No caso de um fluxo de vídeo, as saídas esperadas são conhecidas, o que permite delimitar e estabelecer uma relação entre um conjunto de entradas e uma ou mais saídas, o que torna mais adequado o treinamento utilizando um tutor.

Dentre as diferentes Redes Feed-Forward, a rede MLP de longe é a mais utilizada, sendo aplicada em diferentes áreas e possuindo um histórico bem sucedido na maioria dos casos em que foi aplicada. Assim, a próxima seção explica como funciona uma rede MLP, adotada como uma das candidatas a fazer parte do Mecanismo de Decisão proposto no presente trabalho.

\subsection{Perceptron de Múltiplas Camadas (Multi-Layer Perceptron)}

$\mathrm{Na}$ Universidade de Cornell, ao final da década de 1950, Rosenblatt criou uma rede de múltiplos neurônios do tipo discriminadores lineares e chamou esta rede de perceptron. Um perceptron é uma rede formada por neurônios dispostos em camadas sendo considerado um dos primeiros modelos de redes neurais. Um perceptron aprende conceitos usando os exemplos apresentados na etapa de treinamento, respondendo com verdadeiro (1) ou falso (0) dependendo das entradas apresentadas. Isso é feito com o ajuste dos pesos, que produzem um vetor de saída que corresponda ao vetor de entrada apresentado.

A Figura 9 apresenta a arquitetura básica de um perceptron, mostrando a função de ativação e a regra de propagação. A soma do produto entre pesos $\left(\mathrm{w}_{\mathrm{m}}\right)$ e entradas $\left(\mathrm{x}_{\mathrm{m}}\right)$ alimenta cada neurônio de saída, e se o resultado desta operação exceder determinado limiar, geralmente zero, o neurônio atribui à saída (y) o valor um; se o resultado for inferior ao limiar, o neurônio assume zero na saída. O treinamento de um perceptron usa um algoritmo 
simples de aprendizagem, calculando o erro entre a saída obtida e a saída desejada. Essa diferença é usada para ajustar os pesos e o processo é repetido até se atingir uma margem de erro aceitável (DRYFUS, 2005).

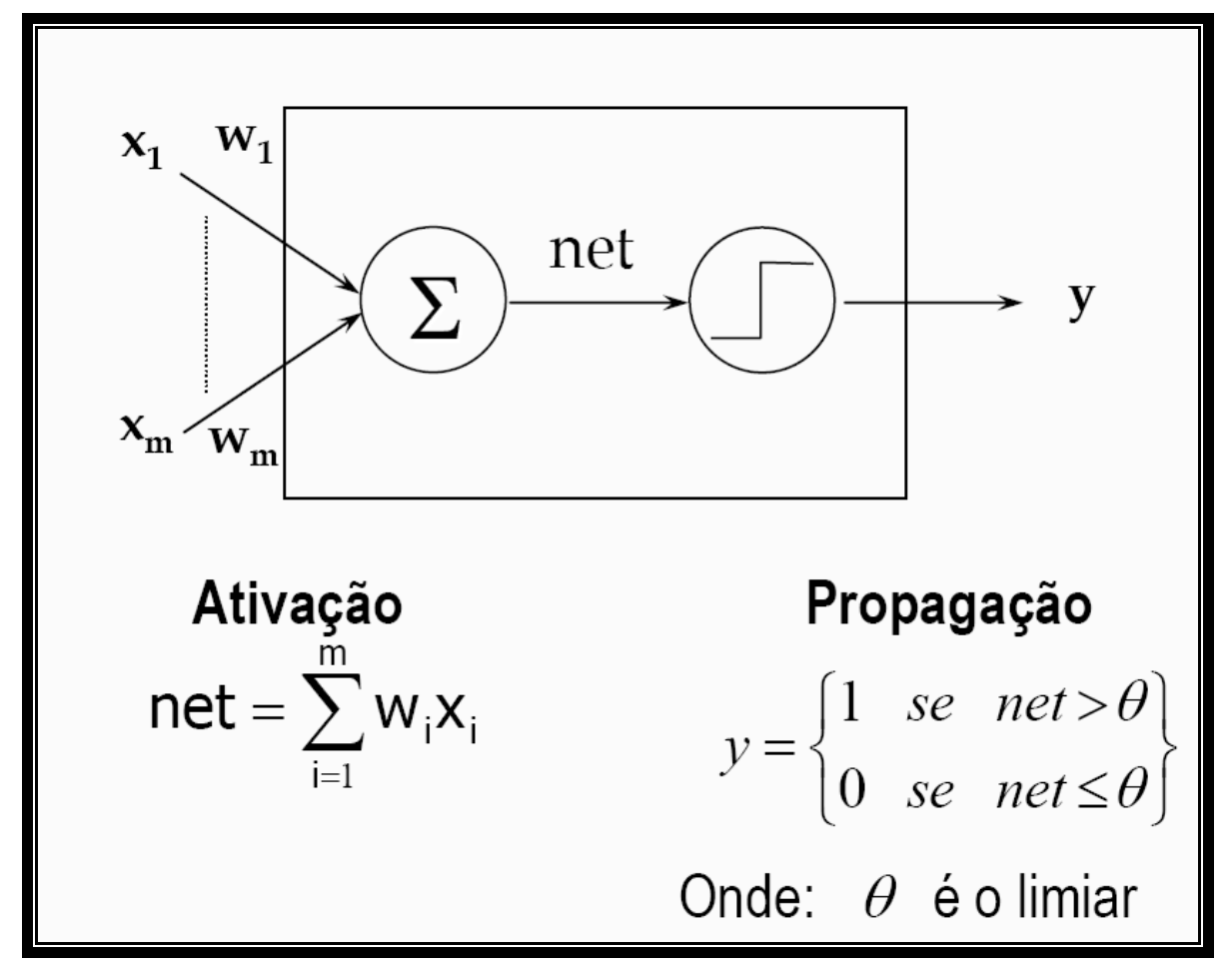

Figura 9 - Arquitetura Básica de um Perceptron (DRYFUS, 2005).

Em 1969, Minsky e Papert publicam um estudo sobre o Perceptron no qual concluem que ele é incapaz de solucionar problemas não linearmente separáveis e que com mais de uma camada teriam dificuldades de aprendizado, problemas de espaço de memória e tempo de processamento. Para entender o que seria um problema não linearmente separável, a Figura 10 mostra dois exemplos, no caso do problema linearmente separável, ele pode ser resolvido usando uma reta para separar o conjunto de soluções, já no problema não linearmente separável isso não é possível. (DRYFUS, 2005). 


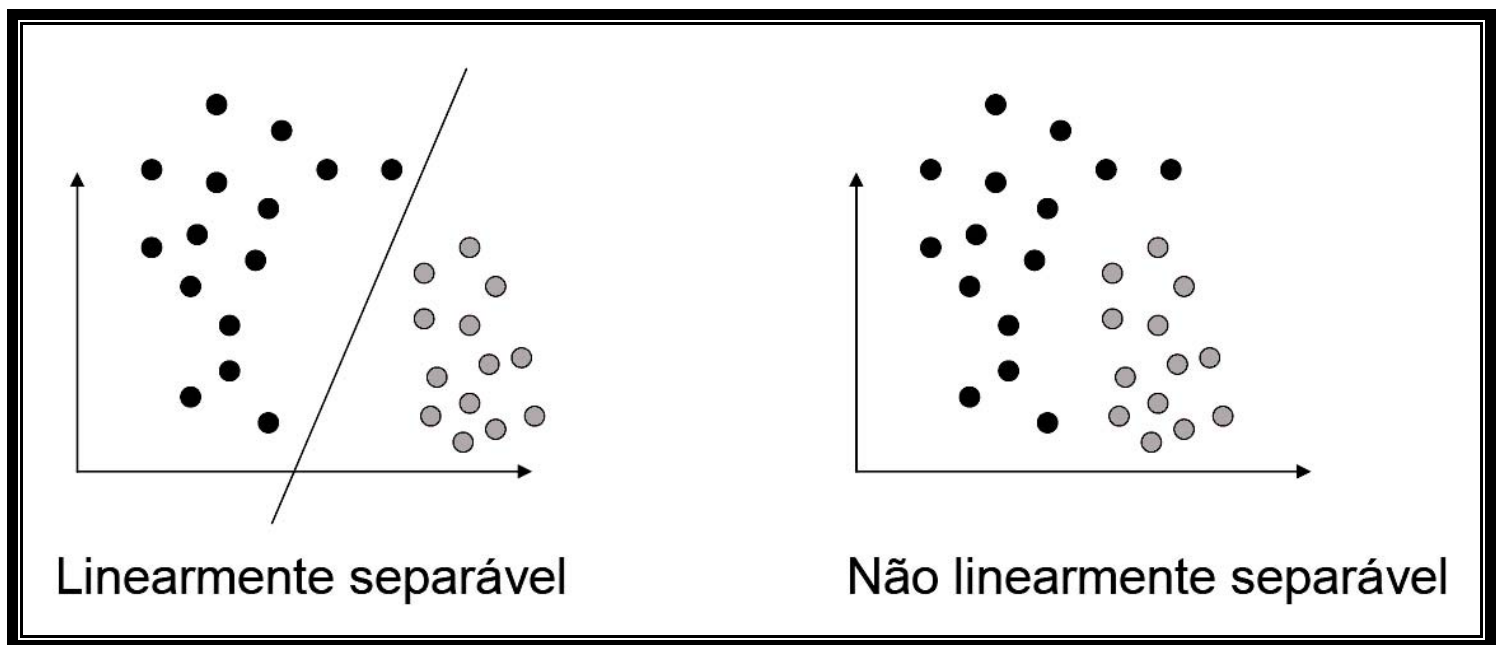

Figura 10 - Dois exemplos de conjunto de amostras (DRYFUS, 2005).

Isso enfraqueceu o interesse pelo estudo das Redes Neurais até que em 1982 Hopfield apresenta um modelo eficiente de rede relacionando-a com sistemas físicos e, em 1986, Rumelhart, Hinton e Williams apresentam o algoritmo "Back-Propagation" solucionando o problema de aprendizado do Perceptron Multicamadas. Este algoritmo é uma generalização da regra de aprendizado "Widrow-Hoff", apresentada por Bernard Widrow \& Marcian Hoff em 1960-1962 para redes do tipo Feed-Forward Perceptron. A regra de aprendizado "Widrow-Hoff" também é conhecida como "Regra Delta", de Minimização do Erro Médio Quadrático ou Least Mean Squares (LMS), ajustando os pesos das conexões entre os neurônios da rede de acordo com o erro, ou seja, essa regra tem como objetivo encontrar um conjunto de pesos e polarizações que minimizem a função erro, como é mostrado em (1):

$$
\mathrm{E}=\frac{1}{2} \sum_{\mathrm{p}=1}^{\mathrm{R}} \sum_{\mathrm{i}=1}^{\mathrm{S}}\left(\hat{\mathrm{y}}_{\mathrm{p}, \mathrm{i}}-\mathrm{y}_{\mathrm{p}, 1}\right)^{2}
$$

Onde,

$\mathrm{R}$ = número de padrões ou vetores de entrada;

$\mathrm{S}$ = número de neurônios de saída — dimensão do vetor de saída;

$\mathrm{y}_{\mathrm{p}, \mathrm{i}}=$ saída desejada no i-ésimo neurônio, quando o p-ésimo padrão é apresentado;

$\hat{y}_{\mathrm{p}, \mathrm{i}}=$ saída obtida pela rede no i-ésimo neurônio, quando o p-ésimo padrão é apresentado.

Os pesos $\left(\mathrm{W}_{\mathrm{i}, \mathrm{j}}\right)$ da regra de "Widrow-Hoff” são alterados seguindo o cálculo mostrado em (2), onde a principal restrição na minimização do erro, no sentido do gradiente 
descendente, é que a função de transferência do neurônio tem que ser monotônica e diferenciável em qualquer ponto.

$$
\Delta W_{i, j}=-\eta \frac{\partial E}{\partial W_{i, j}}
$$

Onde,

$\eta=$ parâmetro da taxa de aprendizado;

$\frac{\partial E}{\partial W_{i, j}}=$ derivada parcial do erro em relação ao peso da respectiva conexão, o

gradiente.

O algoritmo "Back-Propagation” (BP) refere-se a uma regra de aprendizagem onde os pesos e polarizações da rede são ajustados por meio da retro propagação do erro encontrado na saída. A minimização do erro é conseguida realizando-se continuamente - a cada iteração - a atualização dos pesos e das polarizações da rede no sentido oposto ao do gradiente da função no ponto corrente, ou seja, proporcionalmente ao negativo da derivada do erro quadrático em relação aos pesos correntes (2). Trata-se, portanto, de um algoritmo de treinamento supervisionado, determinístico e de computação local que implementa o método do gradiente descendente na soma dos quadrados dos erros. A topologia da arquitetura da rede que utiliza esta regra de aprendizagem é formada, geralmente, por uma ou mais camadas escondidas, ou intermediárias, de neurônios não-lineares, isto é, com função de propagação sigmoidal, e uma camada de saída de neurônios lineares. O algoritmo para treinamento incremental de uma rede MLP pode ser descrito pelos seguintes passos:

- Passo 01: Inicialização dos pesos, das polarizações e dos demais parâmetros de treinamento.

- Passo 02: Apresentação de um padrão de entrada do conjunto de treinamento e a computação de a sua saída pela rede.

$$
\mathrm{e}_{\mathrm{k}}=\left(\mathrm{y}_{\mathrm{k}}-\hat{\mathrm{y}}_{\mathrm{k}}\right)
$$

Onde,

$\mathrm{Y}_{\mathrm{k}}=$ saída desejada;

$\hat{\mathrm{Y}}_{\mathrm{k}}=\mathrm{a}$ saída real (saída gerada pela rede).

- Passo 03: Cálculo do erro dos neurônios da camada de saída, subtraindo a saída desejada da saída calculada, como mostra a equação (3). 
$\Delta w_{i}^{o}(k+1)=-\frac{\partial e_{k}^{2}}{\partial w_{i}^{o}(k+1)}$

$\Delta w_{i}^{o}(k+1)=\eta \cdot\left(y_{k}-\hat{y_{k}}\right) \cdot p^{\prime}\left(n e t^{0}(k)\right) \cdot a^{\prime}\left(w_{i}^{o}(k), O_{i}^{1}(k)\right)$

Onde,

$p$ = função contínua derivável, comumente uma sigmoidal;

$\eta=$ taxa de aprendizagem,

net $=$ estado de ativação;

$O_{i}^{1}=$ entrada do neurônio.

- Passo 04: Cálculo do ajuste nos pesos da camada da saída usando a equação (4).

$$
\begin{aligned}
& \Delta w_{j, i}^{1}(k+1)=-\frac{\partial e_{k}^{2}}{\partial w_{j, i}^{1}(k+1)} \\
& \Delta w_{j, i}^{1}(k+1)=\eta \cdot\left(y_{k}-\hat{y}_{k}\right) p^{\prime}\left(n e t^{\circ}\right) \cdot \frac{\partial a}{\partial O_{j}^{1}(k)}\left(w_{j}^{o}(k), O_{j}^{1}(k)\right) \cdot p^{\prime}\left(n e t_{j}^{1}\right) \cdot \frac{\partial a}{\partial w_{j, i}^{1}(k)}\left(w_{j, i}^{1}(k) .\right.
\end{aligned}
$$

- Passo 05: Retro propagação do erro para as camadas escondidas. Como não existe uma saída desejada para os neurônios das camadas escondidas, deve-se calcular o erro destes a partir do erro dos neurônios pertencentes à camada de saída e das conexões que os interligam, como mostra a equação (5), com o cálculo do ajuste de pesos para a camada escondida mais próxima à saída.

- Passo 06: Cálculo do erro acumulado da rede. Nesta etapa, deve ser verificado se o erro total sobre todos os padrões de entrada pode ser considerado desprezível, isto é, se caiu abaixo de um limiar de aceitação. Se assim for o caso, o algoritmo deve parar, caso contrário, deve-se voltar ao Passo 02.

Usando múltiplas camadas de neurônios não-lineares, uma rede MLP aprende relações lineares e não-lineares existentes entre os valores de entrada e saída. Em teoria, são capazes de realizar a aproximação de qualquer função matemática, sendo ainda bastante utilizadas na associação e classificação de padrões. A Figura 11 mostra a arquitetura típica de uma rede MLP, com as camadas de entrada, escondida e de saída. 


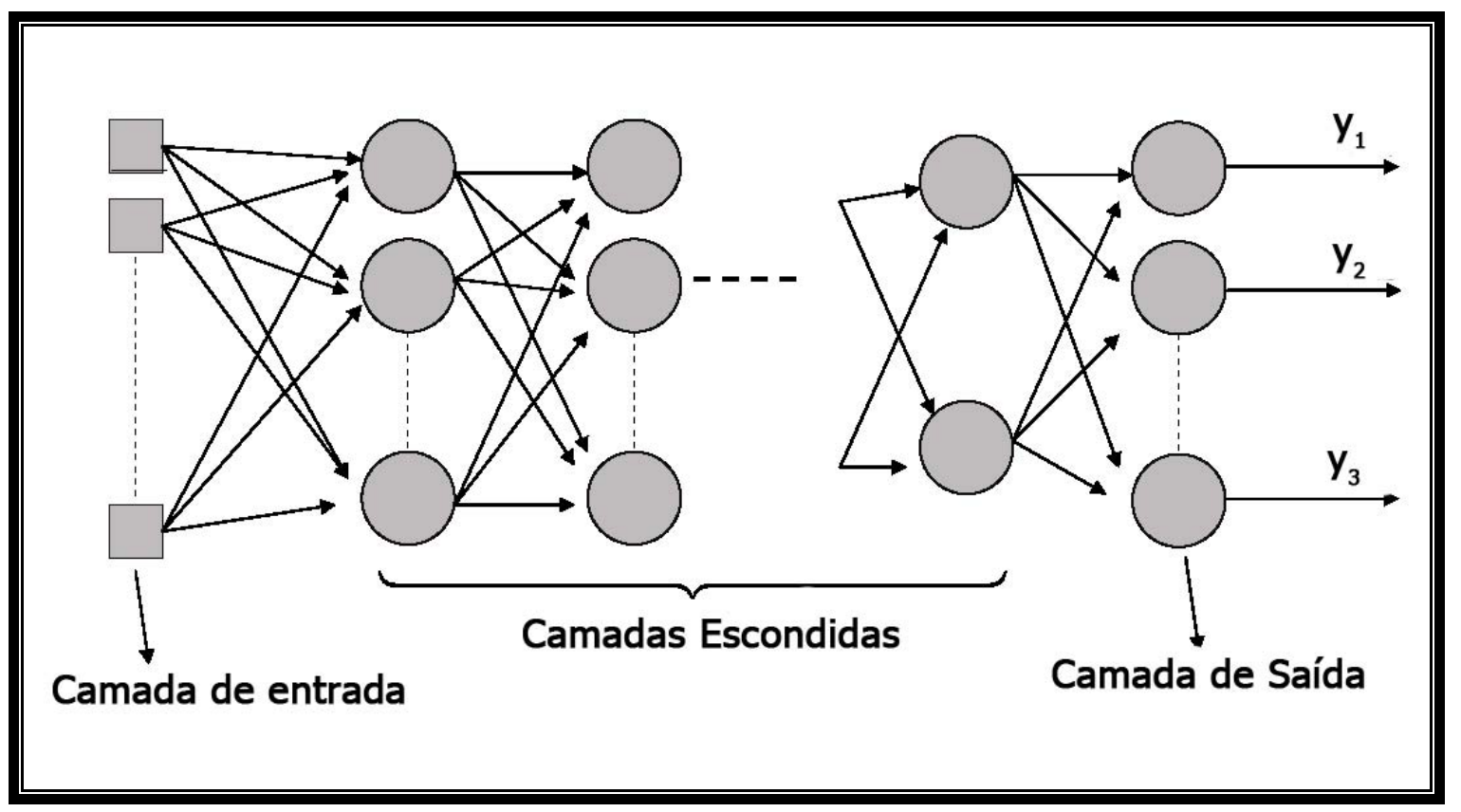

Figura 11 - Arquitetura Típica de uma MLP (DRYFUS, 2005).

\subsection{Considerações Finais}

O Mecanismo de Decisão deve ser capaz de identificar o fluxo de vídeo mais adequado a partir das necessidades do usuário e das características e restrições do sistema. A Ciência de Contexto permite modelar e representar essa informação, restando apenas definir como usar essa informação no processo de adaptação. Considerando que a adaptação de um fluxo de vídeo enquadra-se como um problema de Classificação, onde a partir de informações contextuais espera-se encontrar o padrão que melhor satisfaça as necessidades do usuário, técnicas para classificação podem ser utilizadas como é o caso das Redes Neurais e a Inferência Bayesiana. Assim, o presente capítulo apresentou conceitos sobre as Redes Neurais, identificando o tipo de rede mais adequado à resolução do problema de adaptar um fluxo de vídeo dinamicamente.

A capacidade de aprender com o ambiente, aproximando qualquer mapeamento de entrada/saída de natureza contínua; a exigência de pouco conhecimento sobre a distribuição dos dados ou mesmo sua origem; a tolerância à falhas e a capacidade de se adequar ao ambiente, processando as informações e retornando uma resposta mesmo em situações para a qual não recebeu treinamento são características que justificam o estudo das redes neurais no desenvolvimento desse Mecanismo de Decisão.

Existem dois tipos de redes, considerando o paradigma de aprendizado utilizado: Redes FeedForward e Recorrentes. Optou-se pelas Redes Feed-Forward, uma vez que é possível representar o problema a partir de uma amostragem do ambiente. As Redes Recorrentes 
foram descartadas por agrupar as entradas por suas similaridades em saídas abstratas, ou seja, sem identificar essas saídas. Dentre as Redes Feed-Forward, a rede MLP é amplamente utilizada em diversas áreas, com resultados satisfatórios, o que a torna uma boa candidata para avaliar as Redes Feed-Forward, de um modo geral, na resolução do problema da adaptação de vídeo.

Como o problema pode ser abordado a partir de uma amostragem do ambiente, além das Redes Neurais, é possível considerar também o uso da Inferência Bayesiana, uma abordagem estatística que utiliza o teorema de Bayes para inferir qual hipótese para um determinado evento é mais provável de ocorrer, dado um ou mais eventos. A Inferência Bayesiana é o assunto do próximo Capítulo. 
Capítulo4

\section{Inferência Bayesiana}

“Por bilhões de anos, o sol tem nascido depois que ele se pôs. O sol já se pôs hoje à noite. Então, com uma grande probabilidade o sol irá nascer amanhã. E com uma probabilidade baixa o sol não nascerá amanhã.”

Do mesmo modo que as Redes Neurais, outro método de aprendizado de máquina que pode ser considerado relevante para o presente trabalho é o Aprendizado Bayesiano, ou Inferência Bayesiana, que utiliza a probabilística na inferência de resultados. Para Mitchell, existem duas razões que justificam isso. A primeira considera os algoritmos de aprendizado Bayesiano uma abordagem prática na resolução de certos tipos de problemas de aprendizado, como a classificação, ao calcularem as probabilidades explícitas das hipóteses, isto é, considerando um conjunto de hipóteses, eles determinam a probabilidade de cada uma dessas hipóteses ocorrerem, cada hipótese representando um padrão para o qual os conjuntos de dados serão classificados (MITCHEL, 1997). Um exemplo é a classificação de documentos textos, como notícias on-line, sendo o classificador naive-Bayes, um dos vários algoritmos de Inferência Bayesiana, um dos mais efetivos na resolução deste problema. O classificador naive-Bayes também é usado como filtro de spam em e-mails. Ou seja, o desempenho desses algoritmos é competitivo na maioria dos casos, comparado com outras técnicas de aprendizado de máquina, chegando a ter um desempenho superior em alguns casos.

A outra razão é que o estudo dos métodos Bayesianos oferece uma perspectiva útil na compreensão de algoritmos de aprendizado que não manipulem explicitamente usando probabilidades, isto é, que indiretamente se aproximem de um resultado probabilístico, como é o caso do "FIND-S” e o “CANDIDATE-ELIMINATION”, identificando as condições necessárias para que esses algoritmos encontrem a hipótese mais adequada, considerando os dados de treinamento. Além disso, é possível justificar porque os algoritmos de aprendizado das Redes Neurais, aproximando do resultado esperado a partir da minimização do erro quadrático médio. Em outras palavras, além do fato do Aprendizado Bayesiano ser um método competitivo, como no caso da classificação, ele permite compreender e caracterizar diferentes algoritmos usados no Aprendizado de Máquina (MITCHEL, 1997).

A Inferência Bayesiana utiliza aspectos dos métodos científicos, como a coleta de evidências que podem ser consistentes ou não com determinada hipótese. À medida que novas 
evidências sobre os dados se acumulam o grau de crença de uma hipótese muda, ou seja, a chance de uma hipótese ocorrer pode ser alta ou baixa se houver evidência suficiente para isso. Assim, com uma base lógica razoável é possível considerar que para discriminar hipóteses conflitantes, a hipótese que tiver um maior grau de confiança (crença) deve ser aceita como verdadeira e a de menor grau de confiança, como falsa. A frase no início deste Capítulo é um exemplo típico de Inferência Bayesiana. Como existe uma forte evidência de que sol já vem nascendo e se pondo por bilhões de anos e considerando a hipótese de que ele nascerá ou não no dia seguinte, é com alto grau de confiança que se pode considerar como hipótese verdadeira que o sol deve nascer.

Para a Estatística, a informação sobre uma quantidade de interesse $\theta$ é fundamental e mesmo que o verdadeiro valor de $\theta$ seja desconhecido, é interessante reduzir esse desconhecimento. A intensidade da incerteza a respeito de $\theta$ pode assumir diferentes graus. Do ponto de vista Bayesiano esses diferentes graus de incerteza são representados usando modelos probabilísticos para $\theta$. Assim, é natural que diferentes pesquisadores possam ter diferentes graus de incerteza sobre $\theta$ considerando modelos distintos, não existindo nenhuma distinção entre quantidades observáveis e os parâmetros de um modelo estatístico, sendo consideradas quantidades aleatórias (MITCHEL, 1997).

A necessidade de um conhecimento inicial das diversas probabilidades é a maior dificuldade na aplicação de um método Bayesiano. Quando essas probabilidades não são conhecidas de antemão é preciso estimá-las usando como base as informações existentes (background data), ou seja, os demais dados disponíveis, assumindo valores a partir de sua distribuição básica. Outro problema é o custo computacional necessário para determinar a hipótese Bayes ótima no caso geral. Entretanto, considerando situações especializadas, o custo computacional pode ser reduzido drasticamente (MITCHEL, 1997).

Dentre as características da Inferência Bayesiana podem ser citadas:

- Cada exemplo de treinamento observado pode aumentar ou reduzir a probabilidade estimada de uma determinada hipótese ser correta, permitindo uma abordagem flexível para o aprendizado, comparado com algoritmos que eliminam completamente as hipóteses que são consideradas inconsistentes com qualquer simples exemplo.

- O conhecimento prévio pode ser combinado com os dados observados para determinar a probabilidade de uma hipótese. Na Inferência Bayesiana, esse conhecimento prévio pode ser definido assumindo uma probabilidade prévia 
para cada hipótese candidata e/ou a partir da distribuição de probabilidade dos dados observados para cada possível hipótese.

- Novas instâncias podem ser classificadas combinando as previsões de múltiplas hipóteses, balanceadas por suas probabilidades.

- Mesmo quando os métodos Bayesianos são comprovadamente inadequados computacionalmente, eles servem como padrão para comparação com outros métodos práticos, permitindo medir seu desempenho.

Assim, a capacidade da Inferência Bayesiana em estimar a tendência esperada para um conjunto de hipóteses torna-a uma opção tão atraente como as redes neurais, considerado cada padrão de configuração do fluxo de vídeo como um conjunto de hipóteses e definindo qual hipótese é mais provável de atender adequadamente as necessidades do usuário. O presente Capítulo investiga o uso da Inferência Bayesiana no Mecanismo de Decisão, definindo seu funcionamento e como ela foi aplicada neste trabalho. A Seção 4.1 apresenta o teorema de Bayes, definindo também as hipóteses de máxima verossimilhança e a probabilidade de máximo "a posteriori”. Alguns algoritmos que usam esse teorema são relacionados na Seção 4.2, como o classificador ótimo Bayes (Bayes optimal classifier), o algoritmo de Gibbs e o classificador naive-Bayes (naive-Bayes classifier). A Seção 4.3 é dedicada as Redes de Crença Bayesiana (Bayesian Belief Network), o algoritmo adotado no presente trabalho, encerrando com as considerações finais na Seção 4.4.

\subsection{O Teorema de Bayes}

Publicado postumamente com o título de "Ensaio Voltado à Solução de um Problema na Doutrina do Acaso" (Essay Towards Solving a Problem in the Doctrine of Chances, 1764), o teorema que leva o nome de Thomas Bayes (1702-1761) é o resultado de um estudo que relata a distribuição probabilística, condicional e marginal de variáveis aleatórias (BARNARD, 1958). Em algumas interpretações de probabilidade, o teorema de Bayes sugere um modo de atualizar ou revisar a crença em uma hipótese a luz de uma nova evidência: a posteriori.

A probabilidade de que um evento A condicional a outro evento B é geralmente diferente da probabilidade condicional de B em A, entretanto, existe uma relação entre os dois eventos e o Teorema de Bayes define essa relação. A probabilidade Bayesiana contrasta com a probabilidade Freqüentista em sua origem, a primeira derivada das freqüências observadas em distribuições definidas e a segunda a partir de proporções na população. A diferença entre as interpretações Bayesianas e Freqüentistas da probabilidade tem importantes conseqüências 
para a estatística prática. Para os Freqüentistas, a probabilidade para eventos aleatórios é atribuída de acordo com sua freqüência de ocorrência ou para um subconjunto da população, sendo proporcional a todo o conjunto. Por sua vez, para os Bayesianos esta probabilidade é atribuída para hipóteses que são incertas.

Considerando por exemplo o problema do efeito de um tratamento médico, as abordagens Freqüentistas e Bayesianas para a análise de dados representam dois caminhos distintos na inferência do tratamento mais efetivo. A abordagem Freqüentista assume que um dado estudo pode hipoteticamente ser repetido um número infinito de vezes e o efeito de um tratamento em particular observado no estudo realizado na verdade é apenas uma de todas as possíveis observações, escolhida ao acaso. Na abordagem Bayesiana para estatística, o analista especifica em termos quantitativos sua crença, ou certeza nessa crença, sobre o tamanho do efeito do tratamento em investigação e as observações realizadas em um estudo particular modificado pela crença do analista.

Um freqüentista, no final da análise de dados, especifica uma estimativa do tamanho do efeito do tratamento, baseando-se apenas nos dados que foram estudados, apresentando ainda um valor-p equivalente a um intervalo de confidência de 95\%. Este intervalo de confidência descreve estatisticamente o intervalo no qual o verdadeiro efeito do tratamento gira em torno de 95 entre 100 repetições hipotéticas do experimento. Como a maioria dos estudos não pode ser repetida diversas vezes, essa suposição na qual essa estatística é baseada não pode ser verificada diretamente. Por outro lado, um Bayesiano, ao final da análise de dados, especifica uma estimativa do tamanho do efeito do tratamento e um intervalo no qual o analista acredita que com 95\% de certeza o verdadeiro efeito do tratamento reside. Esta aproximação é validade pela crença subjetiva do analista, uma das controvérsias que provocam resistência ao uso da estatística bayesiana na ciência.

Entretanto, essa crença subjetiva baseada no conhecimento do analista sobre o comportamento dos dados, é um modo de lidar com as incertezas permitindo inferir resultados além dos limites dos dados obtidos. No caso da adaptação de um fluxo de vídeo, como será explicado no Capítulo 6, o conjunto de exemplos é construído considerando uma necessidade em particular do usuário, como garantir o número de quadros transmitidos ou a qualidade da imagem transmitida, em outras palavras, o comportamento do conjunto de dados é conhecido.

A equação (1) mostra o teorema de Bayes, relacionando a probabilidade marginal e condicional dos eventos estocásticos A e B (ALPAYDIN, 2004). 


$$
\operatorname{Pr}(A \mid B)=\frac{\operatorname{Pr}(B \mid A) \operatorname{Pr}(A)}{\operatorname{Pr}(B)}
$$

Onde,

$\operatorname{Pr}(\mathrm{A})=$ probabilidade a priori ou marginal de A. A priori, porque não leva em consideração nenhuma informação relativa ao evento B;

$\operatorname{Pr}(\mathrm{B})=$ probabilidade a priori ou marginal de $\mathrm{B}$, agindo como uma constante de normalização;

$\operatorname{Pr}(\mathrm{A} \mid \mathrm{B})=$ probabilidade condicional de $\mathrm{A}$, dado $\mathrm{B}$. Também é conhecida como probabilidade a posteriori, porque é derivada ou depende do valor definido para B;

$\operatorname{PR}(\mathrm{B} \mid \mathrm{A})=$ probabilidade condicional de $\mathrm{B}$, dado $\mathrm{A}$.

Considerando um espaço de hipóteses $\mathrm{H}$, o teorema de Bayes tem por objetivo encontrar a hipótese mais provável dentro desse espaço considerando os exemplos de observação D e algum conhecimento inicial. É um método direto de calcular essas probabilidades, usando a sua probabilidade anterior, as probabilidades observadas em vários dados, e os próprios dados. Assim, a equação pode ser reescrita, considerando os dados observados (D) e a hipótese a ser analisada (h), como na equação (2) (ALPAYDIN, 2004).

$$
P(h \mid D)=\frac{P(D \mid h) P(h)}{P(D)}
$$

Considerando que o objetivo é encontrar a hipótese mais provável $\mathrm{h}$, tendo observado D (maximum a posteriori), tem-se a equação (3.1). Aplicando o teorema de Bayes para cada hipótese do conjunto H é possível determinar a hipótese $\mathrm{h}_{\mathrm{MAP}}$. Como $\mathrm{P}(\mathrm{D})$ é independente de h, pode ser considerado como uma constante e retirado da equação. Assim, se cada hipótese for igualmente provável, $\mathrm{P}(\mathrm{h})$ também pode ser considerado constante, portanto a equação (3.2) é uma alternativa para maximizar h (ALPAYDIN, 2004).

$$
\begin{gathered}
\mathrm{h}_{\mathrm{MAP}} \equiv \underset{\mathrm{h} \in \mathrm{H}}{\operatorname{argmax}} \mathrm{P}(\mathrm{h} \mid \mathrm{D}) \\
\mathrm{h}_{\mathrm{MAP}}=\mathrm{h}_{\mathrm{ML}}=\underset{\mathrm{h} \in \mathrm{H}}{\operatorname{argmax}} \mathrm{P}(\mathrm{D} \mid \mathrm{h})
\end{gathered}
$$

Onde,

$\mathrm{h}_{\mathrm{MAP}}=$ probabilidade da hipótese maximum a posteriori (map);

$\operatorname{argmax}=$ hipótese $\mathrm{h}$, dentro do conjunto $\mathrm{H}$, com a maior probabilidade $\mathrm{P}$, ou seja, o argumento de P que o maximiza. 
$\mathrm{O}$ teorema pode ser aplicado a qualquer conjunto $\mathrm{H}$ de proposições mutuamente exclusivas cujas soma das probabilidades é igual a um. Por exemplo, considerando o conjunto de cores, duas hipóteses podem ser assumidas quanto ao vermelho, se ele é ou não uma cor. Não existe um meio termo, existindo 0.5 de chance para cada uma dessas probabilidades.

\subsection{Algoritmos Conhecidos}

Considerando o problema da classificação, diversos algoritmos foram desenvolvidos usando o teorema de Bayes como base. A seguir são descritos os principais algoritmos conhecidos na literatura.

\subsubsection{Classificador Ótimo Bayes}

Considere um espaço de hipóteses contendo três hipóteses, $\mathrm{h}_{1}, \mathrm{~h}_{2}$ e $\mathrm{h}_{3}$. Suponha que a probabilidade a posteriori dessas hipóteses, considerando os dados de treinamento, é $0.4,0.3 \mathrm{e}$ 0.3 respectivamente e $h_{1}$ é a hipótese MAP (maximum a posteriori). Se uma nova instância $\mathrm{x}$ é encontrada e classificada como positiva por $h_{1}$, mas negativa para $h_{2}$ e $h_{3}$. Considerando todas as hipóteses, a probabilidade de $\mathrm{x}$ ser positivo é 0.4 , a probabilidade de $\mathrm{h}_{1}$, e a probabilidade de ser negativo é 0.6. A classificação mais provável (negativo) é diferente do que a hipótese MAP considera, para este caso. A classificação mais provável de uma nova instância é obtida combinando as previsões de todas as hipóteses, tendo como peso as probabilidades à posteriori. Se uma possível classificação do novo exemplo pode assumir qualquer valor $\mathrm{v}$ contido em um conjunto $\mathrm{V}$, então, a probabilidade $\mathrm{P}(\mathrm{v} \mid \mathrm{D})$ pode ser definida pela equação (1.1), onde v é a classificação mais adequada para a nova instância. Assim, a classificação ótima da nova instância é o valor v para o qual $\mathrm{P}(\mathrm{v} \mid \mathrm{D})$ é máximo, definindo um classificador ótimo Bayes (Bayes optimal classifier) como mostra a equação (1.2) (MITCHEL, 1997).

$$
\begin{array}{ll}
P(v \mid D)= & \sum_{h_{i} \in H} P\left(v \mid h_{i}\right) P\left(h_{i} \mid D\right) \\
\underset{v \in V}{\operatorname{argmax}} & \sum_{h_{i} \in H} P\left(v \mid h_{i}\right) P\left(h_{i} \mid D\right)
\end{array}
$$

Qualquer sistema que classifique novas instâncias usando essa equação é considerado um classificador ótimo Bayes e nenhum outro método de classificação que use o mesmo espaço de hipóteses e o mesmo conhecimento a priori podem superar o desempenho desse método, em média. Este método maximiza a probabilidade de que uma nova instância seja 
classificada corretamente, dado as informações disponíveis, um espaço de hipóteses e as probabilidades a priori para essas hipóteses.

Uma curiosa propriedade do método é a capacidade de realizar previsões que correspondem a uma hipótese que não existe no espaço H. Este método considera hipóteses contidas em um espaço H' que efetivamente inclui hipóteses obtidas a partir da comparação entre a combinação linear das previsões feitas para as diversas hipóteses contidas em H (MITCHEL, 1997).

\subsubsection{Algoritmo de Gibbs}

O classificador ótimo Bayes consegue o melhor desempenho considerando os dados de treinamento fornecidos, no entanto, seu custo computacional é elevado, conseqüência do algoritmo computar a probabilidade a posteriori para cada hipótese em $\mathrm{H}$, além de combinar as previsões de cada hipótese para classificar uma nova instância. Como alternativa, existe o algoritmo de Gibbs, que oferece um método com um desempenho inferior ao classificador ótimo, mas a um custo computacional menor. Ele é definido como segue: uma hipótese h do conjunto $\mathrm{H}$ é escolhida ao acaso, de acordo com a distribuição de probabilidades a posteriori sobre H, essa hipótese então é usada para prever a classificação da próxima instância de x.

Considerando a nova instância a ser classificada, o algoritmo de Gibbs simplesmente aplica uma hipótese definida ao acaso de acordo com a atual distribuição das probabilidades a posteriori e, em certas condições, o erro esperado na classificação para o algoritmo de Gibbs é apenas duas vezes o erro do classificador ótimo Bayes. Sendo mais preciso, o valor esperado é obtido usando os conceitos desejados, definidos ao acaso de acordo com a distribuição de probabilidades a posteriori assumida pelo mecanismo de aprendizado. Nessas condições, o valor esperado para o erro do algoritmo de Gibbs será, no pior caso, duas vezes o valor esperado para o classificador ótimo Bayes (MITCHEL, 1997).

\subsubsection{Classificador naive-Bayes}

O classificador naive-Bayes (naive Bayes classifier) é um dos métodos mais práticos de aprendizado Bayesiano e dependendo do domínio seu desempenho é comparável as redes neurais e ao aprendizado por árvores de decisão. Costuma ser aplicado em atividades de aprendizado onde cada instância x é descrita como a conjunção dos valores de atributo e uma função objetivo $\mathrm{f}(\mathrm{x})$, que pode assumir qualquer valor para um conjunto finito $\mathrm{V}$. Para o treinamento da função desejada, um conjunto de exemplos é provido e uma nova instância é apresentada, descrita pela tupla de atributos $\left(a_{1}, a_{2} \ldots a_{n}\right)$. O mecanismo de aprendizado é induzido a prever o valor desejado para esta nova instância, ou seja, classificando esse valor. 
A aproximação Bayesiana para a classificação dessa nova instância assume o valor desejado mais provável, $v_{\text {MAP }}$, dado os valores dos atributos $\left(a_{1}, a_{2} \ldots a_{n}\right)$ que descrevem essa instância, correspondendo à equação (2.1). A mesma equação pode ser reescrita, usando o teorema de Bayes, resultando na equação (2.2) (MITCHEL, 1997).

$$
\begin{gathered}
\underset{v_{j} \in V}{\operatorname{argmax}} P\left(x \mid v_{j}\right) \cdot P\left(v_{j}\right) \\
\underset{v_{j} \in V}{\operatorname{argmax}} P\left(a_{1}, a_{2}, \cdots, a_{n} \mid v_{j}\right) \cdot P\left(v_{j}\right)
\end{gathered}
$$

Para estimar cada probabilidade $\mathrm{P}\left(\mathrm{v}_{\mathrm{j}}\right)$ basta calcular a freqüência da ocorrência, nos dados de treinamento, de cada valor desejado $\mathrm{v}_{\mathrm{j}}$. Entretanto, é impraticável estimar os diferentes termos $\mathrm{P}\left(\mathrm{a}_{1}, \mathrm{a}_{2} \ldots \mathrm{a}_{\mathrm{n}} \mid \mathrm{v}_{\mathrm{j}}\right)$ sem ter um grande conjunto de treinamento, uma vez que o número desses termos é igual ao número de possíveis instâncias vezes o número de possíveis valores desejados. Além disso, para obter estimativas confiáveis é preciso observar cada instância no espaço de instâncias diversas vezes. O classificador naive-Bayes baseia-se na suposição de que o valor de cada atributo é condicionalmente independente de um valor específico desejado. Em outras palavras, dado o valor desejado da instância, a probabilidade de observar a conjunção $a_{1}, a_{2} \ldots a_{n}$ é definida pelo produto das probabilidades de cada atributo individual como na equação (3.1) e a aproximação usada em um classificador naive-Bayes é definida pela equação (3.2) (MITCHEL, 1997).

$$
\begin{aligned}
& P\left(a_{1}, a_{2}, \cdots, a_{n} \mid v_{j}\right)=\prod_{i=1}^{n} P\left(a_{i} \mid v_{j}\right) \\
& v_{N B}=\underset{v_{j} \in V}{\operatorname{argmax}} \prod_{i=1}^{n} P\left(a_{i} \mid v_{j}\right) P\left(v_{j}\right)
\end{aligned}
$$

$\mathrm{O}$ número de termos $\mathrm{P}\left(\mathrm{a}_{\mathrm{i}} \mid \mathrm{v}_{\mathrm{j}}\right)$ distintos que são estimados a partir dos dados de treinamento é igual ao número dos valores de atributos distintos vezes o número dos valores distintos desejados, um número bem menor do que se fosse estimado $\mathrm{P}\left(\mathrm{a}_{1}, \mathrm{a}_{2} \ldots \mathrm{a}_{\mathrm{n}} \mid \mathrm{v}_{\mathrm{j}}\right)$.

Comparado com os demais algoritmos, o classificador naive-Bayes possui uma diferença interessante. Não existe um método explicito de busca no espaço das possíveis hipóteses, isto é, o espaço dos possíveis valores que podem ser definidos para os diversos termos $\mathrm{P}\left(\mathrm{v}_{\mathrm{j}}\right)$ e $\mathrm{P}\left(\mathrm{a}_{\mathrm{i}} \mid \mathrm{v}_{\mathrm{j}}\right)$. Ao contrário, as hipóteses são obtidas sem uma busca, simplesmente contando as freqüências das diversas combinações de dados contidos nos exemplos de treinamento (MITCHEL, 1997). 


\subsection{Redes de Crença Bayesiana}

Como foi dito anteriormente o classificador naive Bayes usa de forma significativa a suposição de que o valor dos atributos $a_{1} \ldots a_{n}$ são condicionalmente independentes, dado um valor desejado v. Essa suposição permite uma drástica redução da complexidade de aprendizado da função objetivo, chegando inclusive a ultrapassar em alguns casos o desempenho do classificador ótimo Bayes. Entretanto, nem todos os casos permitem o uso dessa suposição e, de fato, para alguns casos ela é claramente restritiva.

Uma rede de crença Bayesiana, também conhecida como rede Bayesiana ou modelo gráfico de probabilidade (Bayesian Belief Networks, Bayesian Network, Graphical Probability Model) descreve a distribuição de probabilidade que governa um conjunto de variáveis, definindo um conjunto de suposições condicionalmente independentes junto com um conjunto de probabilidades condicionais. Enquanto o classificador naive-Bayes assume que todas as variáveis são condicionalmente independentes, dado um valor de uma variável desejada, as redes Bayesianas permitem definir suposições condicionalmente independentes que são aplicáveis a subconjuntos de variáveis. Em outras palavras, as redes Bayesianas definem uma solução intermediaria que é menos restritiva que a suposição global de independência condicional feita pelos classificadores naive-Bayes, mas mais aceitável que ignorar todas as suposições de independência condicional (MITCHEL, 1997).

Em geral, uma rede Bayesiana descreve a distribuição de probabilidade sobre um conjunto de variáveis, considerando um conjunto arbitrário de variáveis aleatórias $\mathrm{Y}_{1} \ldots \mathrm{Y}_{\mathrm{n}}$, onde cada variável $\mathrm{Y}_{\mathrm{i}}$ pode assumir um conjunto de possíveis valores $\mathrm{V}\left(\mathrm{Y}_{\mathrm{i}}\right)$. Assim, o espaço conjunto (joint space) do conjunto de variáveis $\mathrm{Y}$ pode ser definido como o produto escalar (cross product): $\mathrm{V}\left(\mathrm{Y}_{1}\right) \times \mathrm{V}\left(\mathrm{Y}_{2}\right) \times \ldots \mathrm{V}\left(\mathrm{Y}_{\mathrm{n}}\right)$, ou seja, cada item no espaço conjunto corresponde a uma das possíveis atribuições para os valores das tuplas de variáveis $\left(\mathrm{Y}_{1} \ldots \mathrm{Y}_{\mathrm{n}}\right)$. Em resumo, uma rede Bayesiana descreve a distribuição de probabilidades conjunta para um conjunto de variáveis (MITCHEL, 1997).

\subsubsection{Independência Condicional}

$\mathrm{Na}$ teoria da probabilidade dois eventos A e B são condicionalmente independentes em relação a um terceiro evento $\mathrm{C}$ se a ocorrência ou não de $\mathrm{A}$ e B são eventos independentes em sua distribuição de probabilidade condicional dado C, como mostrado na equação (1.1), ou de modo equivalente na equação (1.2).

$$
\operatorname{Pr}(A \cap B \mid C)=\operatorname{Pr}(A \mid C) \operatorname{Pr}(B \mid C) .
$$




$$
\operatorname{Pr}(A \mid B \cap C)=\operatorname{Pr}(A \mid C) .
$$

Duas variáveis aleatórias X e Y são condicionalmente independentes em relação a um evento $\mathrm{C}$ se elas são independentes em sua distribuição de probabilidade condicional, dado C. Duas variáveis $\mathrm{X}$ e $\mathrm{Y}$ são condicionalmente independentes, dado uma terceira variável aleatória $\mathrm{W}$, se para qualquer conjunto $\mathrm{S}$, dos possíveis valores de $\mathrm{W}, \mathrm{X}$ e $\mathrm{Y}$, for condicionalmente independente em relação ao evento [W $\mathrm{S}$ ]. A independência condicional para mais de dois eventos ou mais de duas variáveis aleatórias é definida de forma análoga (MITCHEL, 1997). Isso pode ser ilustrado a partir do seguinte exemplo: supondo que Carlos e José joguem cada um uma moeda para ver se obtém cara ou coroa. Assumindo como A, a variável que define o resultado de Carlos e $\mathrm{B}$, relacionada ao resultado de José, ambas variáveis podendo assumir dois valores (Cara ou Coroa). Não há dúvidas de que A e B são independentes. Nenhuma evidência sobre B afeta o resultado de A. No entanto, se Carlos e José jogarem a mesma moeda e, além disso, existir a possibilidade da moeda ser viciada de modo a obter apenas Cara como resultado. Neste caso, A e B não podem ser considerados independentes. Se o resultado observado em B for Cara, aumenta a possibilidade do resultado de A também ser Cara, uma vez que ambas são condicionalmente dependentes de uma terceira variável C, a moeda é viciada, assumindo dois valores (Verdadeiro ou Falso).

\subsubsection{Representação}

Como mencionado, uma rede Bayesiana representa a distribuição de probabilidade conjunta para um conjunto de variáveis. Assim, o exemplo mostrado na Figura 12 representa uma distribuição de probabilidades conjuntas sobre o conjunto de variáveis booleanas: "Tempestade", "Campistas", "Relâmpago", "Fogueira de Acampamento", "Incêndio na Floresta" e "Trovão".

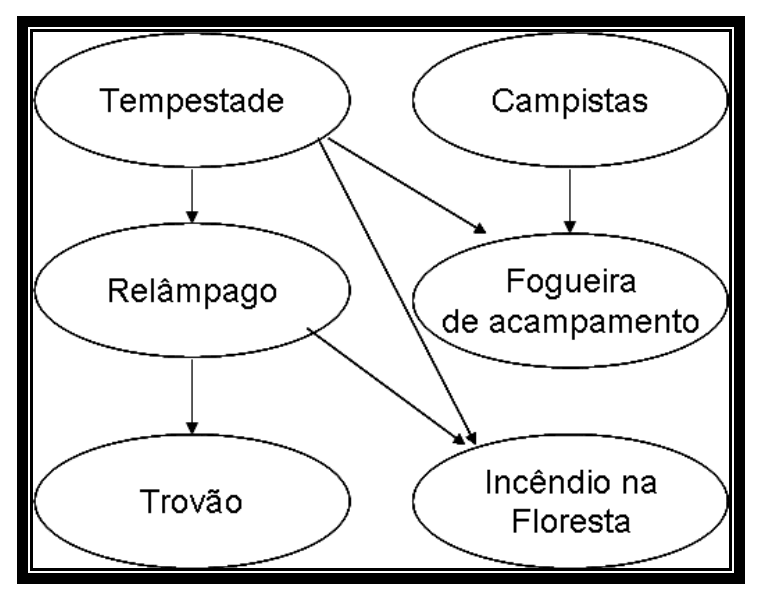

Figura 12 - Exemplo de Rede Bayesiana (MITCHEL, 1997). 
Em geral, uma rede Bayesiana representa uma distribuição de probabilidades conjunta, especificando um conjunto de suposições de independência condicional junto com um conjunto de probabilidades condicionais locais. Essas suposições são representadas como um grafo direto acíclico e dentro do espaço conjunto cada variável é representada como um nó sendo compostas por duas informações. Primeiro, as arestas da rede, que representa a afirmação de que cada variável é condicionalmente independente de seus não-descendentes na rede, dado seu imediato predecessor. Assim, X é descendente de Y quando existe um caminho direto de Y para X. Segundo, uma tabela de probabilidades condicionais é definida para cada variável, descrevendo a distribuição de probabilidades para esta variável, dado os valores de seus predecessores imediatos. A probabilidade conjunta para qualquer atribuição de valores $\left(\mathrm{y}_{1}, \ldots, \mathrm{y}_{\mathrm{n}}\right)$ e para a tupla de variáveis da rede $\left(\mathrm{Y}_{1}, \ldots ., \mathrm{Y}_{\mathrm{n}}\right)$ pode ser determinada pela equação (2) (MITCHEL, 1997).

$$
\mathrm{P}\left(\mathrm{y}_{1}, \ldots, \mathrm{y}_{\mathrm{n}}\right)=\prod_{i=1}^{n} \mathrm{P}\left(\mathrm{y}_{\mathrm{i}} \mid \operatorname{Pais}\left(\mathrm{Y}_{\mathrm{i}}\right)\right)
$$

Onde,

Pais $\left(\mathrm{Y}_{\mathrm{i}}\right)=$ conjunto de predecessores imediatos de $\mathrm{Y}_{\mathrm{i}}$, em uma rede.

Os valores definidos para $\mathrm{P}\left(\mathrm{y}_{\mathrm{i}} \mid \mathrm{Pais}\left(\mathrm{Y}_{\mathrm{i}}\right)\right)$ correspondem exatamente aos valores definidos na tabela de probabilidades condicionais associada ao nó $\mathrm{Y}_{\mathrm{i}}$.

Assim, considerando o nó "Fogueira no Acampamento" mostrado na Figura 12, os nós e arestas que representa a afirmação de que "Fogueira no Acampamento" é condicionalmente independente de seus não-descendentes são "Relâmpago" e "Trovão", considerando que seus pais imediatos são "Tempestade" e "Campistas". Em outras palavras, assim que é conhecido o valor das variáveis "Tempestade" e "Campistas", os valores de "Relâmpago" e "Trovão" deixam de fornecer informação adicional sobre "Fogueira no Acampamento", considerando os valores da tabela de probabilidade condicional associada a "Fogueira no Acampamento", como mostrado na Tabela 2. Assim, a afirmação $\mathrm{P}(\mathrm{F}=$ Verdade $\mid \mathrm{T}=$ Verdade, $\mathrm{C}=$ Verdade $)$ = 0,4 implica em dizer que a probabilidade de que exista uma "Fogueira no Acampamento" (F), considerando que no momento está ocorrendo uma "Tempestade" (T) e existem “Campistas" (C) acampando é de 0,4.

Esta tabela mostra apenas as probabilidades condicionais relacionadas com a variável "Fogueira no Acampamento", considerando as variáveis-pais "Tempestade" e "Campistas". A distribuição de probabilidade conjunta da rede é definida pelo conjunto com as probabilidades 
condicionais locais para todas as variáveis junto com o conjunto de suposições condicionalmente independentes descritas pela rede.

Tabela 2 - Tabela de Probabilidades Condicionais (MITCHEL, 1997).

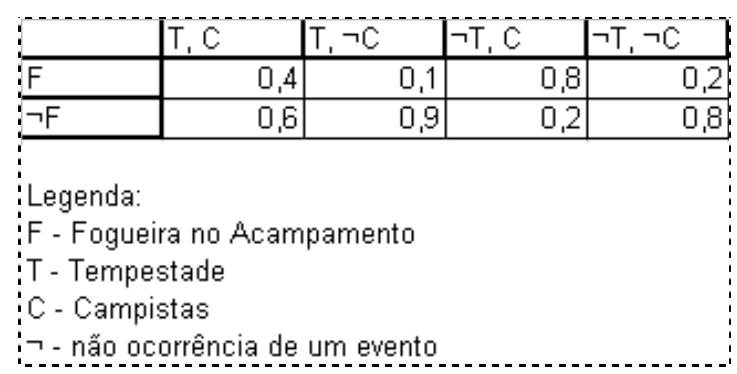

A capacidade de representar de modo conveniente o conhecimento casual é um dos atrativos de uma rede Bayesiana. Por exemplo, considerando o fato de um "Relâmpago" ser a origem do "Trovão", pela terminologia de independência condicional, o "Trovão" é condicionalmente independente de outras variáveis da rede, considerando o valor de "Relâmpago", fato que é endossado considerando as arestas da Figura 12 (MITCHEL, 1997).

Por representarem um modelo completo das variáveis e seus relacionamentos, as redes Bayesianas podem responder questões probabilísticas sobre seus elementos, encontrando o conhecimento do estado atual de um subconjunto de variáveis, a partir da observação das demais variáveis. Considerando o exemplo da Figura 12, as variáveis "Tempestade" e "Campistas" permitem inferir o estado da variável "Fogueira no Acampamento".

Assim, uma rede Bayesiana pode ser considerada um modelo que permite estender o teorema de Bayes para problemas mais complexos, onde a independência condicional só é definida para um subconjunto dentro do modelo. No caso da adaptação de um fluxo de vídeo, dentre os algoritmos aqui mostrados, a rede Bayesiana é a mais adequada, uma vez que ao definir o modelo que considera as variáveis que influenciam nesse fluxo, ou seja, as variáveis que definem as características e restrições do sistema; e as variáveis que configuram esse fluxo, como o tamanho e a taxa de quadros, essas variáveis que configuram o fluxo não serão condicionalmente independentes, considerando variáveis externas, que definem as necessidades ou expectativas do usuário para esse fluxo. Isso inviabiliza o uso do classificador naive-Bayes, cujas variáveis devem ser condicionalmente independentes e os demais algoritmos, por seu custo computacional elevado ou uma taxa de erro não aceitável.

\subsection{Considerações Finais}

Do mesmo modo que as Redes Neurais, problemas de classificação podem ser resolvidos com a ajuda da Inferência Bayesiana, como é o caso da adaptação de um fluxo de vídeo. Algoritmos, como o naive-Bayes, permitem um bom desempenho na classificação e 
identificação de padrões, como é o caso da classificação de documentos ou o filtro de spams em e-mails (MITCHEL, 1997).

Dentre os diferentes algoritmos desenvolvidos com base no Teorema de Bayes, optouse pelas Redes Bayesianas, uma vez que no problema estudado neste trabalho, as variáveis envolvidas no processo de adaptação são influenciadas por variáveis externas, não sendo possível definir o conjunto de variáveis como sendo condicionalmente independente. Isso será explicado em detalhes no Capítulo 6, quando a definição do conjunto de treinamento e teste for abordada, considerando as necessidades do usuário e as restrições e características do sistema (Redes e Dispositivos).

Com isso, define-se o processo de obtenção, representação e processamento das informações, de modo a obter os subsídios necessários a identificação da melhor configuração para um fluxo de vídeo, considerando as necessidades do usuário. Definido como a informação contextual será tratada na adaptação, resta definir o processo de adaptação em si. O próximo Capítulo aborda esse processo, especificamente tratando da adaptação de vídeo. 
Capítulo 5

\section{Adaptação de Vídeo}

"O homem sensato se adapta ao mundo. O homem insensato insiste em tentar adaptar o mundo a si. Sendo assim, qualquer progresso depende do homem insensato.”

Bernard Shaw

Em um dicionário, a palavra adaptação assume diferentes significados e três deles definem o contexto considerado para a adaptação dentro do presente trabalho:

Adaptação: [De adaptar + -ção.] Substantivo feminino.

1. Ação ou efeito de adaptar (-se); Adaptar: verbo bitransitivo. Ajustar ou acomodar (uma coisa a outra); Tornar (-se) apto a; demonstrar capacidade de ajustamento, acomodar-se, amoldar-se; ajustar-se a um ambiente, a um meio; ambientar-se;

2. Biologia: Ajustamento de um organismo, particularmente do homem, às condições do meio ambiente: A respiração pulmonar é uma adaptação à vida aérea, assim como a transpiração é uma adaptação ao calor;

3. Uso de utensílio, objeto, peça, etc., para um fim diverso daquele ao qual se destinava: Este pé de lâmpada é adaptação de um antigo moinho de café; reutilização.

Acomodar e torna-se parte do ambiente, responder a uma mudança desse mesmo ambiente e o reuso de informação são três facetas da adaptação de conteúdo. No contexto computacional, adaptar um conteúdo pode ser definido como ajustar um conteúdo às condições atuais do Usuário, considerando restrições como o Domínio, Ambiente e InfraEstrutura (EISINGER et al., 2005).

Há aproximadamente dez anos, a maior preocupação de sistemas que adaptavam conteúdo multimídia na Internet era a restrição de banda. Um trabalho pioneiro nesse sentido foi o InfoPyramid (MOHAN et al., 1999) definindo um arcabouço para a adaptação de documentos hipertexto compostos por texto, imagem, áudio e vídeo, com o objetivo de reduzir a banda utilizada por esses recursos. Hoje em dia, a tecnologia evoluiu permitindo que dispositivos móveis, como celulares, sejam capazes de receber vídeo com relativa qualidade. É natural, portanto, que as pesquisas na área busquem meios de adaptar um conteúdo 
multimídia para os mais variados dispositivos, em especial, os dispositivos móveis por suas restrições.

Para tornar isso possível, ou seja, para que uma variedade de dispositivos, móveis ou não, possam ter acesso a um rico conteúdo interativo, as aplicações precisam conhecer o contexto do sistema (ABOWD et al., 2002). Assim, usando informação contextual para adaptar o comportamento do sistema é possível oferecer serviços personalizados aos usuários. Essas informações são obtidas a partir das interações usuário-sistema, como a identidade, localização e preferências do usuário, e sistema-sistema, como o estado da rede, largura de banda disponível e a resolução gráfica do dispositivo usado pelo usuário.

No entanto, conhecer essas informações não é suficiente para adaptar o comportamento do sistema sendo necessário, a partir dessas informações, identificar o comportamento mais apropriado. Em outras palavras, o projetista do sistema deve definir como essas informações serão analisadas e processadas para obter o comportamento desejado. Um caminho é definir cláusulas ou regras para essa adaptação, por exemplo, criando faixas e condições para que determinado comportamento ocorra. Assim, considerando um fluxo de vídeo, um exemplo de regra seria assumir que o fluxo tenha a taxa de bits configurada para $100 \mathrm{kbit} / \mathrm{s}$ se a largura de banda disponível no cliente estiver entre $100 \mathrm{kbit} / \mathrm{s}$ a $200 \mathrm{kbit} / \mathrm{s}$ e a qualidade esperada definida como média. No entanto, essa abordagem embora prática e fácil de ser utilizada, limita o funcionamento do sistema as regras pré-definidas. Assim, se a banda disponível no cliente for de $201 \mathrm{kbit} / \mathrm{s}$ e o sistema não definir uma regra para valores acima de $200 \mathrm{kbits} / \mathrm{s}$ ou ainda existir essa regra, mas uma regra geral definida para todas as exceções, o sistema não responderá do melhor modo possível.

Embora pareça um problema de simples solução considerando um aumento na complexidade do sistema, quando duas ou mais variáveis influenciam em seu comportamento a dificuldade em implementar essas regras aumenta significativamente, exigindo que o projetista conheça o ambiente no qual o sistema encontra-se inserido. O Aprendizado de Máquina permite simplificar essa tarefa, definindo essas regras indiretamente, a partir das informações contextuais obtidas do ambiente. Para o presente trabalho, consideraram-se duas técnicas em particular: as Redes Neurais, utilizando uma rede MLP, e a Inferência Bayesiana, com uma rede Bayesiana. Essas duas técnicas permitem classificar as informações do ambiente, definindo o comportamento ou a configuração mais adequada para o fluxo de vídeo, indiretamente encontrando a regra que define qual o melhor padrão de saída para o sistema. 
Ao combinar Ciência de Contexto com o Aprendizado de Máquina definem-se subsídios para a obtenção, representação e processamento das informações do ambiente, sobrando apenas à definição do processo de adaptação em si, em outras palavras, o funcionamento do Mecanismo de Decisão e como ele interage com um Servidor de Vídeo. A Seção 5.1 descreve aplicações que utilizam ou poderiam utilizar a adaptação de vídeo. O estado da arte da adaptação de um fluxo de vídeo, com as técnicas e sistemas encontrados na literatura, é abordado na Seção 5.2. O processo de adaptação adotado no presente trabalho, utilizando as informações contextuais e o Aprendizado de Máquina, é o assunto da Seção 5.3 e a Seção 5.4 encerra o Capítulo.

\subsection{Aplicações Usando Vídeo Digital}

O avanço na tecnologia móvel permite vislumbrar um novo cenário, onde um ambiente cada vez mais heterogêneo estende o alcance das redes de informação criando um novo potencial para as mais diferentes aplicações envolvendo vídeo digital distribuído. Para ilustrar esse novo cenário, três aplicações envolvendo vídeo digital serão apresentadas junto com uma descrição do uso potencial da adaptação dinâmica de vídeo.

\subsubsection{Medicina Móvel (m-Health)}

Os avanços nas tecnologias de informação e comunicação oferecem oportunidades sem precedentes para melhorar a saúde pública no mundo. Cenários que há dez anos eram inconcebíveis hoje são realidade graças a eMedicina (eHealth): pacientes na África recebendo tratamento a distância, na maioria dos casos por médicos em outro país ou continente, graças a telemedicina; profissionais da área de saúde melhorando suas habilidades com a ajuda do aprendizado a distância, sem a necessidade de deixar seus países; ou uma rede eletrônica de registros médicos disponibilizando todo o histórico de seus pacientes a partir de qualquer centro médico, permitindo o suporte apropriado a seu tratamento (WHO, 2006). A integração de diferentes mídias em um único sistema, combinando telecomunicações, videoconferência e transferência de dados em tempo real têm revolucionado a telemedicina. O poder da Internet para a medicina foi sentido pela primeira vez em um seminário realizado em Abril de 1995, quando um estudante chinês que sofria de uma doença desconhecida e aparentemente grave, enviou um e-mail de SOS pela Internet, pedindo auxilio internacional. Esse foi o primeiro diagnóstico documentado usando a Internet. Hoje em dia já é rotineiro o envio de imagens médicas pela Internet ou a realização de demonstrações ao vivo e consultas remotas usando videoconferência. 
$\mathrm{Na}$ medicina, estar um passo a frente pode significar a diferença entre a vida e a morte de um paciente. O recente e rápido avanço de tecnologias como a computação e telefônica móvel e de rede abriu novas oportunidades para novos meios de distribuir cuidados médicos, usando as tecnologias emergentes de redes sem fio. As tecnologias de celulares $3 \mathrm{G} / 4 \mathrm{G}$, a nova geração de rede "ad hoc" e WLAN têm estendido a área de cobertura da informática médica. Nesse cenário, o maior desafio é empregar a transmissão sem fio e técnicas de compressão de vídeo como ferramentas de auxilio a um tratamento médico (JONES, 2006).

A adaptação de vídeo tem um papel crítico para a informática médica, definindo meios para distribuir um fluxo de vídeo em diferentes dispositivos. Entretanto, é crucial considerar como esse vídeo será adaptado. Buchinger e Hlavacs, da Universidade de Viena, Áustria, observaram a partir de estudos experimentais a influência da taxa de quadros de um vídeo na qualidade subjetiva de um vídeo digital, e considerando uma taxa de bits fixa, e os resultados práticos desses estudos sugerem que a taxa de quadros ótima, consideração aplicações médicas, deve ser próxima de dez, ou até mesmo cinco, quadros por segundo (JONES, 2006).

Em outras palavras, adaptar não consiste em adequar um fluxo de vídeo as restrições ou características do sistema, reduzindo o tamanho ou mesmo a qualidade do vídeo para atender restrições de banda ou resolução gráfica suportada por um dispositivo. É importante considerar a aplicação para a qual o vídeo se destina, definindo o que se espera, seja a garantia da qualidade de imagem, a captação do movimento ou qualquer outro aspecto, subjetivo ou não, que possa influenciar o processo de adaptação.

\subsubsection{Televisão Interativa}

A televisão representou uma revolução em seu surgimento, graças a seu potencial como fonte de entretenimento, informação e cultura, alcançando todas as faixas etárias, classes sociais, a qualquer horário e em qualquer lugar. Entretanto, o avanço da Internet e seu rico conteúdo interativo tornaram o antigo modelo da televisão obsoleto à medida que as pessoas passam a ter acesso a novos meios de interação com informação e entretenimento. A televisão seguiu então outros meios de comunicação de massa na tendência mundial da convergência digital, isto é, a fusão dos mercados de mídia e Tecnologias de Informação e Comunicação, substituindo suas plataformas analógicas por plataformas e tecnologias digitais interoperáveis, não apenas pela necessidade de melhorar a qualidade de imagem e som, como também um importante passo rumo à interatividade (FERNANDES et al., 2004).

Este passo deu origem a Televisão Interativa (TV-I) definida, segundo alguns autores, como a combinação da televisão com conteúdos enriquecidos, a possibilidade de um canal de 
retorno ou o resultado da união de conceitos computacionais com a TV convencional, permitindo o acesso a um grande número de serviços interativos (DRISCOLL, 2000). Um protótipo para um modelo de Televisão Interativa encontra-se em desenvolvimento no laboratório Intermídia do Instituto de Ciências Matemáticas e Computação (ICMC), da USP. Esse protótipo define uma infra-estrutura, baseada no padrão MPEG-4 (PEREIRA; EBRAHIMI, 2002), para produção, distribuição e consumo de programas seguindo o modelo do TV-Anytime, como ilustra a Figura 13, onde os elementos em azul representam softwares de terceiros, como o Envivio, e aqueles em amarelo representam as aplicações desenvolvidas dentro do projeto (GOULARTE, 2003).

Nesse protótipo de TV-I, o Gerenciador de Serviços obtém as informações de seus clientes utilizando um MPEGlet, aplicações transportadas junto com fluxos de vídeo MPEG-J. Essas informações podem ser as preferências do usuário, como o tipo de vídeo de interesse do usuário, por exemplo, notícias esportivas; ou até mesmo características do dispositivo, o que permite que esse fluxo seja adaptado de modo a atender da melhor maneira possível as necessidades de cada usuário. Entretanto, essa adaptação é realizada de um modo estático, usando regras simples que associam as informações do cliente, como a largura de banda disponível, com a configuração de fluxo de vídeo que melhor atenda as necessidades do cliente. Em outras palavras, esse protótipo é limitado às regras existentes e ao conhecimento do projetista sobre essa relação entre as necessidades do usuário e a configuração que melhor atenda ela.

Outros modelos trabalham com outros aspectos de interatividade, como é o caso do Globo Vídeos ${ }^{5}$, que define diversas categorias como entretenimento, permitindo que o usuário construa sua própria grade de programação, assistindo apenas os programas de seu interesse.

\subsubsection{Educação}

A educação também é beneficiada pelas novas tecnologias, oferecendo meios para melhorar a transmissão de conhecimento. O ensino a distância é um dos paradigmas mais abordados na literatura, aproveitando que as tecnologias interativas evidenciam o que deveria ser o cerne de qualquer processo de educação: a interação e a interlocução entre todos os que estão envolvidos nesse processo. Neste paradigma, o conceito de aula muda, com o tempo e espaço passando a ser um elemento cada vez mais flexível dentro do processo e surgem os conceitos de educação presencial (ou tradicional), semipresencial, misturando as aulas em sala

\footnotetext{
${ }^{5}$ http://video.globo.com/ Visitado pela última vez em: 12/3/2007.
} 
com uma parte virtual ou à distância, e a educação à distância ou virtual (BATES; BATES, 2005).

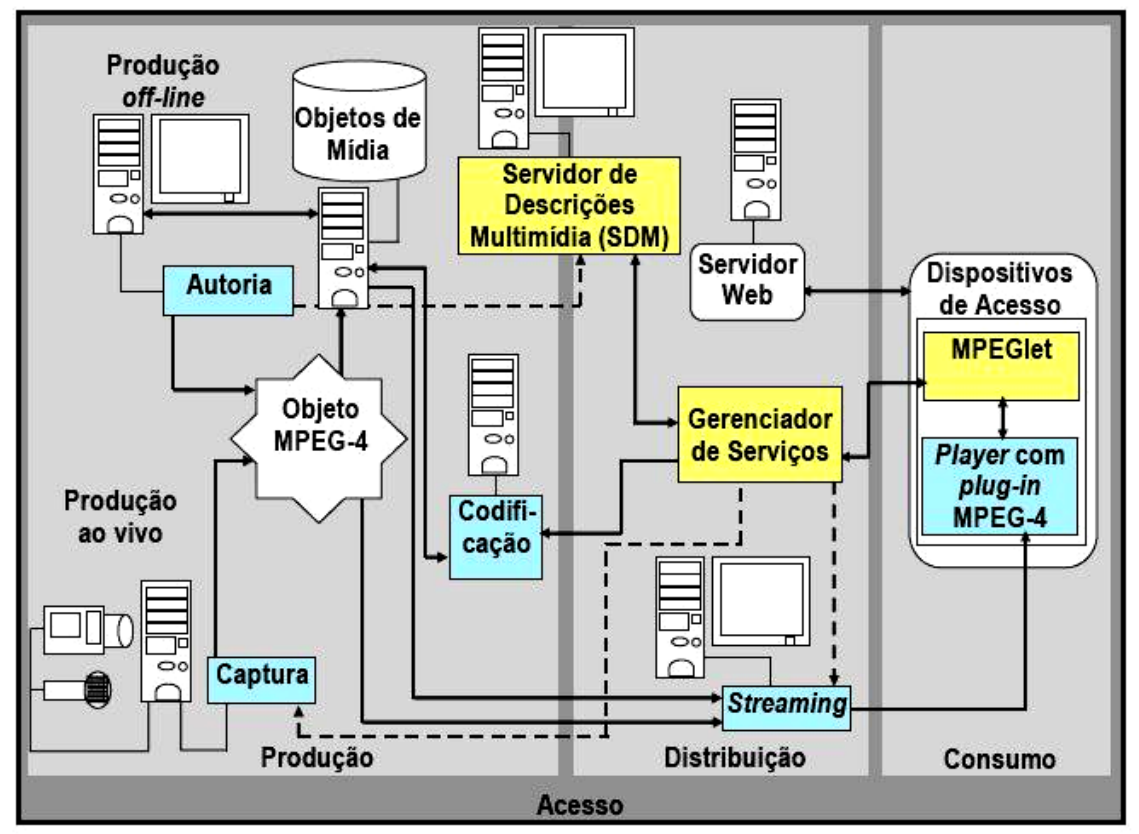

Figura 13: Infra-estrutura do protótipo de TV-I (Goularte, 2003)

Outro conceito importante é o da educação continuada, onde o processo de aprendizado continua mesmo depois que o aluno sai da sala de aula. Nesse âmbito, surgem sistemas como o iClass que tem como propósito a captura de informações de ambientes convencionais, produzindo automaticamente documentos hipermídia com o conteúdo capturado e apresentando esse material por meio da Web (SANTE et al., 2004). O iClass é composto por duas infra-estruturas: uma de hardware, para uma sala de aula instrumentada essa infra-estrutura consiste tipicamente de uma lousa eletrônica (whiteboard), projetores, microfones e câmera de vídeo; e outra de software, cuidando do gerenciamento, captura e apresentação, por exemplo. O iClass segue as fases sugeridas por Abowd para a estruturação do problema de captura e acesso: pré-produção, gravação "ao vivo", pós-produção e acesso, como é ilustrado na Figura 14 (BROTHERTON; ABOWD, 2004).

O objetivo do sistema iClass é preservar todos os detalhes de uma aula, permitindo que um aluno reviva sua experiência na sala de aula em qualquer lugar onde seja possível acessar a Internet e do modo mais completo quanto possível. Apenas o processo de captura das anotações, da apresentação e do áudio são apresentados na Figura 14, mas existem trabalhos que incorporaram a capacidade de captura, armazenamento e distribuição de vídeo ao sistema iClass, considerando o acesso em qualquer lugar ou dispositivo (MANZATO; GOULARTE, 2006). No entanto, a adaptação desse vídeo distribuído ainda é realizada de 
modo estático, do mesmo modo que na TV-I, a partir de regras associando características de rede e do dispositivo ao padrão de configuração mais adequado ao fluxo de vídeo.

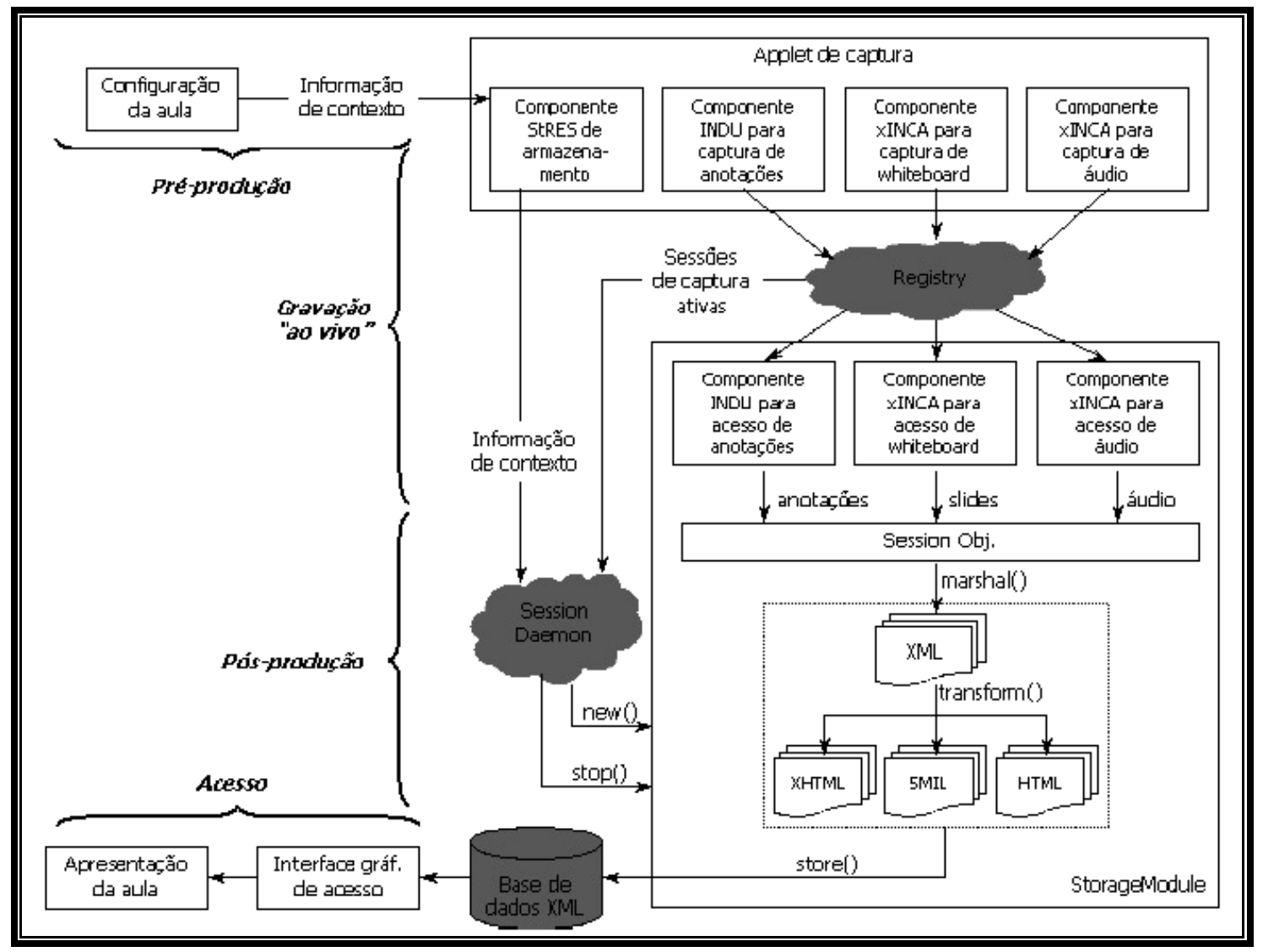

Figura 14 - Arquitetura do Sistema iClass (SANTE et al., 2004).

Outras áreas poderiam ser beneficiadas com a adaptação de um fluxo de vídeo, como a segurança, onde um vigia pode acessar as imagens de uma câmera de vídeo remotamente, a partir de um PocketPC, por exemplo. Diferentes trabalhos tentam definir como essa adaptação é realizada, principalmente depois dos recentes avanços da tecnologia sem fio, e a avaliação dos principais trabalhos na área é o assunto da próxima Seção.

\subsection{Estado da Arte}

A adaptação de vídeo é um campo de estudo emergente demandando ainda mais estudos. Um sistema ou ferramenta de adaptação de vídeo deve ser capaz de, a partir de um ou mais vídeos, gerar uma nova apresentação que atenda as necessidades dos usuários. Essa nova apresentação pode ser um novo vídeo ou mesmo outro tipo de mídia, como um áudio ou um conjunto de imagens estáticas. Em sistemas pervasivos o papel da adaptação de vídeo é atender requisições de diferentes dispositivos, adaptando-se conforme o contexto (CHANG; VETRO, 2005). 
$\mathrm{Na}$ literatura, boa parte dos trabalhos aborda a adaptação de vídeo considerando apenas o problema da largura de banda disponível (bandwidth) e as condições da rede. É o caso do NetMoVie (BOURGEOIS et al., 2003), uma arquitetura intermediária baseada em um protocolo de tempo real que permite adaptar fluxos de mídia às restrições de um canal de rede sem fio. Ele trabalha com codificação de vídeo escalável (scalable vídeo coding), isto é, um tipo de codificação que divide o fluxo de vídeo em várias camadas, com uma camada básica (Basic Layer), definindo a menor qualidade avaliável para o fluxo, sendo necessária para a decodificação de uma seqüência de vídeo e as camadas de aprimoramento (Enhancement Layer), que, quando decodificadas, permitem melhorar a qualidade do vídeo, daí a codificação ser denominada escalável. Assim, o arranjo dessas camadas junto com a camada básica permite obter vários fluxos de vídeo com qualidades distintas. A proposta da arquitetura do NetMoVie é aprimorar o uso da largura de banda em redes sem fio que transmitam dados multimídia, ajustando os fluxos de mídia com base nas informações obtidas nas estatísticas do protocolo RTCP, combinando assim o número adequado de camadas às necessidades do cliente. Entretanto, embora o vídeo escalável resolva o problema da restrição de banda, como já mencionado, um fluxo de vídeo pode ter outras restrições que impeçam seu uso adequado, como é o caso das restrições de dispositivo.

Ainda considerando trabalhos preocupados com o problema da largura de banda, citam-se ainda as tecnologias Real Network SureStream (REAL, 2002) e a Microsoft Intelligent Streaming (BIRNEY, 2003). Elas realizam a adaptação de modo estático, ou seja, definindo previamente um conjunto de versões da mesma mídia, atendendo diversas audiências, em um processo denominado modelo de distribuição por difusão simultânea (Simulcast).

A tecnologia SureStream da Real Networks permite a transmissão de áudio ou vídeo para várias larguras de banda distintas e cada cliente RealPlayer seleciona uma codificação apropriada à sua velocidade de conexão, atendendo diferentes audiências, como o exemplo mostrado na Figura 15, onde um fluxo de vídeo usando a tecnologia SureStream é codificado para atender três clientes distintos $(28,8 \mathrm{Kbps}, 56 \mathrm{Kbps}$ e $112 \mathrm{Kbps})$. Assim, quando um usuário seleciona um vídeo SureStream, o cliente RealPlayer e o servidor RealServer determinam qual dos três fluxos de vídeo é mais adequado, no caso, considerando a largura de banda disponível. É possível inclusive ajustar esse fluxo de modo a compensar variações nas condições da rede, isto é, se a rede estiver sob tráfego intenso, o servidor troca o fluxo de vídeo para uma versão mais leve e vice-versa. 
Funcionando de modo semelhante, a tecnologia Microsoft Intelligent Streaming adapta um fluxo de vídeo conforme a necessidade do usuário, limitado ao número de versões existentes para cada audiência, ou taxa de transmissão esperada. Essa limitação, como já mencionado por Lei (LEI; GEORGANAS, 2005), não garante o melhor compromisso entre a qualidade da mídia e as necessidades reais do usuário, além de não definir meios para adaptar o fluxo as características do dispositivo ou outros aspectos que possam ser importantes na definição da mídia adaptada.

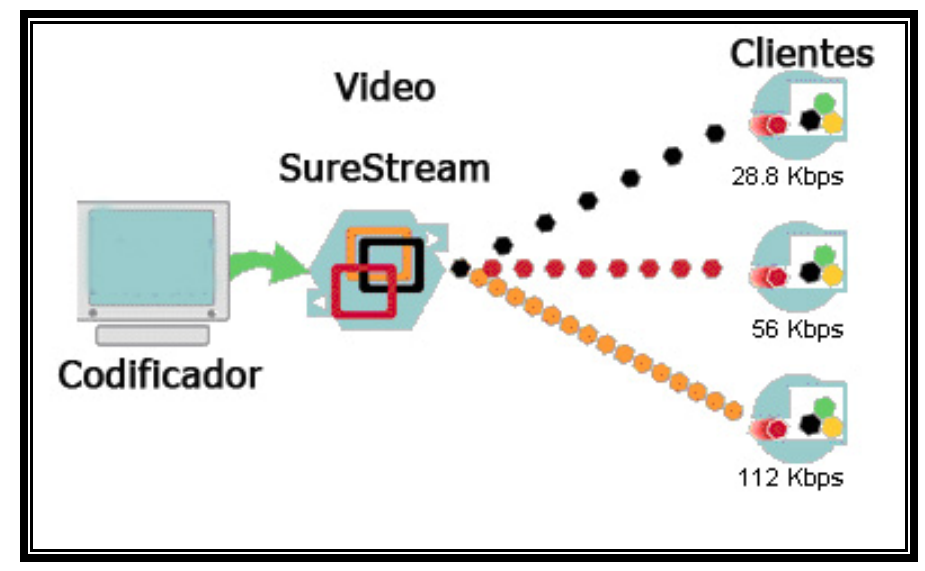

Figura 15 - Tecnologia SureStream da Real Networks (Real, 2002)

Recentemente surgiram trabalhos explorando a adaptação de vídeo sem se restringir apenas à largura de banda e às condições da rede, como é o caso do trabalho de Kim e Chang (KIM et al., 2003), (CHANG; VETRO, 2005), (WANG et al., 2003). Tais trabalhos afirmam que o problema de adaptação de vídeo envolve a identificação da entidade que representa o conteúdo de vídeo e três espaços: adaptação, recursos e utilidade. O termo "espaço" é usado pra definir a múltipla dimensionalidade de cada um desses três conceitos. Utilizando uma função de utilidade (UF) para descrever a relação desses três espaços e os valores que essa função assume definem o operador de adaptação (Adaptation Operator), isto é, um ponto para transcodificação do sinal. Usando técnicas de Aprendizado de Máquina, como o algoritmo “K-Harmonic Means", na predição da função de utilidade, recondicionando o fluxo de vídeo conforme a UF encontrada. Essa função relaciona o tipo de adaptação, os recursos e a utilidade esperada, como mostra a Figura 16, o que permite relacionar diferentes recursos como a banda disponível, energia, capacidade gráfica do dispositivo, com as utilidades que podem ser as qualidades subjetivas ou objetivas, satisfação do usuário.

No caso do trabalho de Kim e Chang, eles usam como exemplo a adaptação da largura de banda utilizada por um fluxo de vídeo, considerando a quantidade de quadros eliminados (frame drop) e o coeficiente que define essa eliminação (coefficient of dropping). Entretanto, 
a geração dos dados da função de utilidade exige um grande consumo de tempo e é limitada á aproximação analítica aplicável apenas a codecs específicos, como por exemplo, o MPEG-4 com controle de taxas TM5. Além disso, o trabalho demonstra apenas a adaptação considerando a largura de banda, deixando em aberto como definir uma função de utilidade que relacione outras restrições, como é o caso das características de dispositivo.

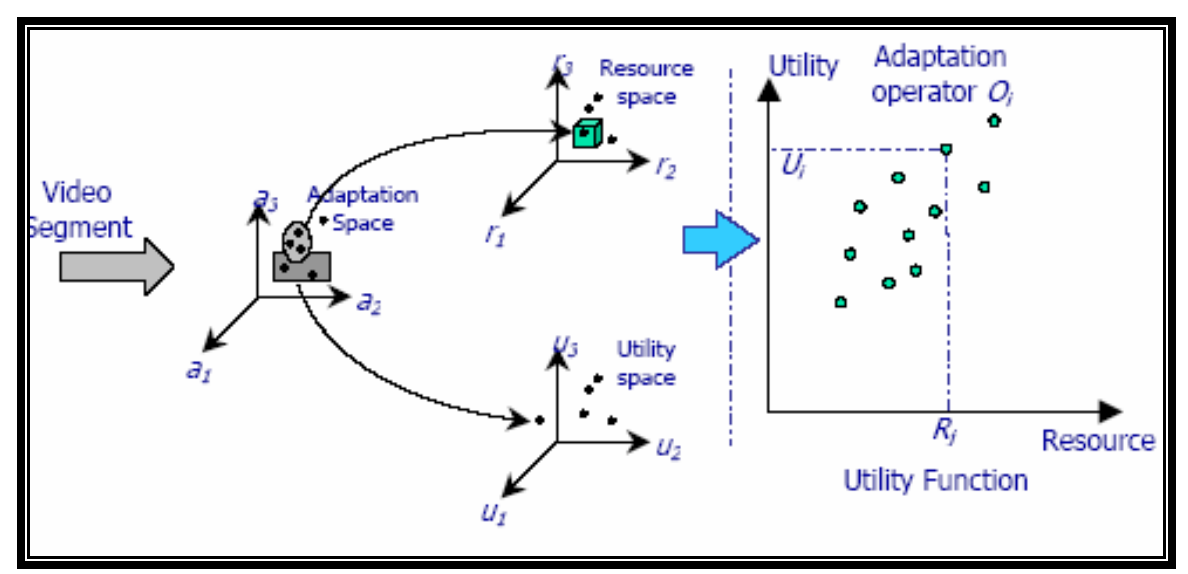

Figura 16 - Função de Utilidade (Wang et al., 2003)

Com o recente avanço da computação móvel, as pesquisas na área de adaptação de vídeo têm explorado outras restrições, como as limitações do dispositivo, surgindo à necessidade de representar essas informações para melhor explorá-las. A maioria dos trabalhos utiliza uma representação própria, entretanto, surge uma iniciativa para definir um acesso multimídia universal, surgindo o UMA, que combina os padrões MPEG-7 e MPEG-21 na definição de um arcabouço para adaptação multimídia (PRANGL et al., 2006), (JANNACH et al., 2006), (THANG et al., 2006).

O UMA (Universal Multimedia Access) é um arcabouço que descreve as informações relacionadas a um conteúdo multimídia, na adaptação de um fluxo de vídeo. Proposto pelo MPEG (Moving Picture's Experts Group), ele usa os padrões MPEG-7, que define descritores e estruturas para descritores ou esquemas de descrição e seus relacionamentos, e o MPEG-21, definindo um arcabouço aberto para o transporte e consumo de multimídia. O UMA tem como objetivo permitir o acesso à informação multimídia por qualquer terminal e a partir de qualquer rede, usando pra isso a customização do conteúdo, que pode ser implementada em três diferentes pontos: no servidor de conteúdo, em um servidor Proxy ou na máquina cliente, em outras palavras, o UMA padroniza a adaptação multimídia. Por ser um arcabouço, o UMA não define como é feita essa adaptação e durante o decorrer do presente trabalho ainda não era maduro o suficiente para que fosse considerado como uma alternativa viável ao modelo de representação proposto por Goularte, utilizado como arcabouço na obtenção e representação das informações contextuais (GOULARTE, 2003). 
Um exemplo é o trabalho de Önür et al. que propõe um conversor de mídia usando o padrão MPEG-21 DI (Digital Items), permitindo adaptar recursos multimídia levando em consideração a capacidade do terminal e as preferências do usuário (ÖNÜR et al., 2004). O MPEG-21 DI é um componente do padrão MPEG-21, mais especificamente sua sétima parte, descrevendo quatro conjuntos de descritores: as características do usuário, capacidades do terminal, características de rede e as características do ambiente; sendo usados em ferramentas para adaptação de conteúdo multimídia (CHANG; VETRO, 2005). Composto por dois componentes, um Gerente do Conversor de Mídia (MCM), que determina a melhor representação para o conteúdo multimídia considerando os quatro conjuntos de descritores do padrão MPEG-21 DI; e o mecanismo Conversor de Mídia (MCE), realizando a adaptação do fluxo de bits de acordo com as instruções do módulo MCM. Entretanto, apenas a arquitetura para esse conversor é definida, ou seja, trata-se de uma proposta de aplicação usando UMA, não definindo como essa adaptação será realizada ou mesmo o mecanismo de conversão usado.

Ainda trabalhando com o MPEG-21 DI, Prangl et al. apresentam um protótipo de aplicação para a Difusão Digital de Vídeo (Digital Vídeo Broadcast ou DVB), mapeando os metadados de um fluxo de DVB a partir de um esquema de descrição multimídia (MDS) do MPEG-7, encapsulados usando o padrão MPEG-21 DI, permitindo uma interface aberta e interoperável para o conteúdo multimídia (PRANGL et al., 2006). Nesse protótipo, um fluxo DVB-S é recebido e mapeado para um formato MPEG-21 DI válido, permitindo o acesso a partir de um computador pessoal ou PDA, quando estes dispositivos usam redes baseadas no protocolo IP (Internet Protocol). O protótipo, no entanto, é dependente do hardware utilizado, utilizando um sistema com uma placa DVB-S embutida, que recebe o fluxo de DVB por satélite e extrai os metadados semânticos e sintáticos, como o codec de vídeo utilizado, a resolução espacial, entre outros dados do fluxo. O propósito deste trabalho é a conversão das informações de um fluxo de DVB para o padrão MPEG-7/MPEG21 DI, não descrevendo o processo de decisão, isto é, como é definido o melhor modo de adaptar um fluxo de vídeo, considerando diferentes dispositivos ou mesmo a largura de banda disponível no cliente (PRANGL et al., 2006).

Jannach et al. trabalham com os padrões MPEG-7 e MPEG-21 utilizando uma abordagem baseada no conhecimento, por meio da construção de um serviço de adaptação multimídia extensível, aberto e que possua conformidade com os padrões existentes ou qualquer novo padrão que venha a surgir (JANNACH et al., 2006). A média original é transformada seguindo diferentes passos de adaptação, com o uso de um conjunto de 
ferramentas externas. Quais ferramentas ou passos serão necessários são definidos a partir de um planejamento baseado em inteligência artificial, usando a linguagem Prolog. Convertendo as informações descritas no formato MPEG-7 e MPEG-21 DI em fatos ou conjuntos de dados que são divididos em dois grupos: o conjunto dos recursos multimídia (pool of multimedia resources) e o conjunto das ferramentas de adaptação (pool of adaptation tools). O Prolog é usado para criar regras associando esses conjuntos, isto é, os predicativos que definem o plano de adaptação.

A vantagem dessa abordagem é a possibilidade de estender esse serviço, adicionando novos fatos, como ferramentas ou recursos multimídias, ou predicativos associando de uma nova maneira esses fatos, ou seja, esse serviço permite estender suas funcionalidades quando novos padrões ou ferramentas surgirem. Entretanto, o Prolog exige uma boa representação do conhecimento, isto é, de todos os fatos envolvidos e as regras de relacionamento, para assim inferir um resultado de maneira apropriada. A partir dessa base de conhecimento, é possível encontrar relacionamentos que não estejam "visíveis" ou explícitos para o projetista, como a combinação de duas ou mais regras distintas, aparentemente sem relação. No entanto, o Prolog não permite ir além dessa base de conhecimento, ou seja, ele encontra o melhor plano de adaptação desde que ele esteja implícito nos dados e regras da base de conhecimento elaborada pelo projetista. Diferente de uma Rede Neural, por exemplo, que consegue aproximar um resultado sem necessariamente ter um conhecimento implícito.

Embora não trabalhe diretamente com o UMA, Thang et al. utilizam um arcabouço multimídia MPEG-21 na adaptação de um fluxo de bits SVC (Scalable Vídeo Coding) ou codificação de vídeo escalável. Usando uma ferramenta de descrição do MPEG-21 DIA, o AdaptationQoS, eles definem um modelo de qualidade de serviço (QoS) para a adaptação do SVC. O AdaptionQoS descreve a relação entre os recursos necessários, como a taxa de bits, os operadores de adaptação e as qualidades correspondentes, e dentro desse trabalho são definidos três operadores de adaptação específicos para a estrutura de um fluxo de bits SVC e seguindo as três dimensões que um fluxo pode ser adaptado. O primeiro operador é as Camadas Espaciais (SpatialLayers), lidando com a dimensão espacial, a partir da definição do número de camadas de aprimoramento espacial que serão descartadas do fluxo SVC. O segundo é o operador de níveis temporais (TemporalLevels), considerando a dimensão temporal, realizando o mesmo que o primeiro operador, mas para as camadas temporais. Por fim, o operador de Redução de Qualidade (QualityReduction), indicando a fração de camadas de aprimoramentos qualitativos que serão truncados no fluxo. Utilizando as preferências do usuário e ajustando esses três operadores define-se uma trajetória de adaptação representada 
por uma função de utilidade usando um número finito de pontos discretos e seguindo essa trajetória o fluxo SVC é ajustado (THANG et al., 2006).

Um Mecanismo de Decisão é proposto para pegar as descrições no padrão MPEG-21 DIA, encontrar os valores dos operadores de adaptação e usando um Mecanismo de Escala, eliminando as camadas desnecessárias. Entretanto, apenas a descrição dos operadores e o algoritmo de adaptação são definidos, deixando de lado o processo de decisão, isto é, como definir a melhor combinação, considerando as preferências do usuário (THANG et al., 2006).

O Vídeo Escalável também tem sido utilizado em aplicações de Internet para televisão ou IPTV (Internet Protocol TeleVision). Shen et al. propõem uma arquitetura híbrida que combina vídeo escalável com uma ferramenta de transcodificação, que converte esse vídeo para um formato não escalável, mantendo compatibilidade com sistemas antigos (SHEN et al., 2006). O objetivo é melhorar o uso da banda disponível entre os diferentes canais de vídeo, presentes em um sistema IPTV, atendendo as necessidades de cada usuário. Esta arquitetura considera a adaptação do fluxo de vídeo para diferentes dispositivos, usando um Home Gateway que realiza essa transcodificação. No entanto, essa arquitetura define apenas o processo de adaptação, sem considerar o processo de decisão, isto é, sem identificar as necessidades do usuário e como elas serão atendidas.

Com o passar dos anos, o avanço tecnológico permitiu que o processo de adaptação de um fluxo de vídeo sofresse uma evolução significativa, conseqüência do aumento da largura de banda disponível nos clientes e o aperfeiçoamento da computação móvel, permitindo o uso de aplicações multimídia, ainda que com algumas restrições. Os primeiros trabalhos preocupavam-se apenas em adequar a largura de banda consumida por um fluxo de vídeo, como foi o caso do InfoPyramid, uma dos primeiros arcabouços para adaptação de conteúdo multimídia (MOHAN et al., 1999). Considerando apenas as técnicas de adaptação de vídeo, os trabalhos abordam três linhas: o uso de um modelo de difusão simultânea ou Simulcast (REAL, 2002), (BIRNEY, 2003); aqueles que exploram as vantagens do vídeo escalável (THANG et al., 2006), (BOURGEOIS et al., 2003) e a transcodificação de um fluxo de vídeo (SHEN et al., 2006), (XIN et al., 2005), (VETRO et al., 2003), (MANZATO; GOULARTE, 2006). Lei e Georganas classificam as técnicas de adaptação de vídeo em duas linhas, aqueles que abordam de um modo estático, isto é, definindo previamente as versões adaptadas dos documentos multimídias e aqueles que realizam esse processo de modo dinâmico, adaptando quando surge a necessidade (LEI; GEORGANAS, 2001). O Simulcast e o vídeo escalável são técnicas exclusivamente estáticas, seu conteúdo deve ser preparado previamente. Já a transcodificação ou recodificação de um fluxo de vídeo, 
processo que envolve a conversão de um vídeo, alterando suas características, como por exemplo, a taxa de bits, número de quadros ou mesmo o padrão usado na codificação, permite tanto uma abordagem estática, como dinâmica, por ser realizado no servidor, antes do fluxo de vídeo ser enviado para os clientes.

Definir a melhor configuração para um fluxo de vídeo, atendendo as necessidades de um usuário em determinado instante é um desafio, tanto do ponto de vista do processo de adaptação, como na definição de um processo de decisão que permita encontrar esses parâmetros, sempre que necessário. A próxima Seção dá um passo rumo à solução desse desafio, apresentando um modelo para adaptação dinâmica de um fluxo de vídeo.

\subsection{Adaptação Dinâmica de Vídeo}

O acesso a um rico conteúdo de serviços interativos por uma variedade de dispositivos, móveis ou não, depende do conhecimento que a aplicação tem sobre o contexto do sistema, ou seja, das possíveis interações entre dispositivos e/ou aplicações (DIX et al., 2000), (CHALMERS, 2002), (CROWLEY et al., 2002). Para isso, as informações contextuais precisam ser identificadas e representadas, permitindo que o sistema processe essas informações e ofereça serviços personalizados para os usuários. Como explicado no Capítulo 2, essas informações são obtidas das interações usuário-sistema, por exemplo, a identidade, localização e preferências do usuário; e sistema-sistema, como o estado da rede, largura de banda disponível e a capacidade gráfica do dispositivo usado pelo usuário.

Não basta identificar as informações contextuais relevantes para o processo de adaptação de um fluxo de vídeo, sem que o processo em si seja definido. Para definir esse processo, duas perguntas devem ser respondidas:

De que modo o vídeo será adaptado? Em outras palavras, como será definido o processo de adaptação, por exemplo, as técnicas que serão usadas para a distribuição e adaptação dessa mídia, de acordo com as necessidades de cada usuário. Dependendo da técnica de adaptação escolhida, o sistema terá um comportamento diferenciado. Para um vídeo escalável, a adaptação é feita a partir da eliminação das camadas de aprimoramento, já as técnicas de recodificação ou transcodificação dependem de conhecer os parâmetros de configuração do fluxo de vídeo e da disponibilidade de largura de banda.

Como será definida a adaptação do vídeo? Ou seja, como será o processo de decisão do sistema. A Seção 5.2 mostrou que a maioria dos trabalhos preocupa-se apenas com o modo como um vídeo será adaptado, deixando o processo de decisão em aberto ou definindo regras de adaptação. Definir o processo de decisão é complementar o processo de 
adaptação. Por exemplo, considerando o uso de técnicas de recodificação na adaptação do fluxo de vídeo, o processo de decisão seria responsável por encontrar os parâmetros de configuração do fluxo de vídeo que atendem às necessidades do usuário sem ultrapassar o limite da largura de banda disponível no servidor e, no caso do vídeo escalável, esse processo de decisão definiria as camadas de aprimoramento que serão eliminadas.

O presente trabalho procura responder a segunda pergunta, definindo um Mecanismo de Decisão que apóie um sistema de adaptação de vídeo. Para isso foram consideradas as técnicas de Aprendizado de Máquina, como as Redes Neurais (Capítulo 3) ou a Inferência Bayesiana (Capítulo 4), com o objetivo de definir o "cérebro" desse Mecanismo, obtendo os parâmetros de configuração mais adequados para o fluxo de vídeo.

\subsubsection{Arquitetura do Sistema}

Manzato (MANZATO, 2006) definiu em seu trabalho uma arquitetura para adaptação de vídeo ao vivo ou sob demanda utilizando um algoritmo com regras simples para realizar a adaptação, em outras palavras, a partir de um método estático. Modificando essa arquitetura é possível adicionar o Mecanismo de Decisão, obtendo a arquitetura mostrada na Figura 17. As fases primárias da arquitetura original definida por Manzato continuam as mesmas, como segue: “Captura Multimídia e Codificação”, “Adaptação”, “Captura de Contexto e Controle de Acesso” e “Acesso”.

O processo envolvendo a captura do sinal de áudio e vídeo do ambiente, sua codificação e transmissão dos dados para o servidor de vídeo definem a fase de "Captura Multimídia e Codificação”. A captura do sinal de áudio e vídeo é realizada a partir de uma câmera de vídeo e de um microfone, acoplados a um computador com o software de difusão ou software difusor, transmitindo os dados do difusor para o servidor de vídeo com o uso do protocolo de tempo real ou RTP (Real Time Protocol). A escolha do protocolo RTP considerou suas diferentes funções para aplicações de tempo real, como a marcação de tempo, numeração de seqüências, a identificação da fonte etc. (WU et al., 2001). As características básicas do vídeo são descritas e disponibilizadas em um arquivo definido a partir do protocolo de descrição de sessão ou SDP (Session Description Protocol) descrevendo, por exemplo, a taxa de bits, resolução espacial, endereço IP (Internet protocol), porta de acesso, entre outras informações do vídeo (HANDLEY; JACOBSON, 1998). Usualmente, este arquivo é obtido a partir do software difusor e disponibilizado no servidor de vídeo (MANZATO, 2006).

O servidor de recodificação ou recodificador é responsável pela “Adaptação”, recebendo os parâmetros de recodificação, adaptando o fluxo e transmitindo de volta o novo 
fluxo gerado para o servidor, junto com um novo arquivo SDP, usado para acessar a versão modificada do vídeo original (MANZATO, 2006). Na versão modificada, os parâmetros de recodificação deixam de ser definidos pelo servidor de acesso, usando para isso o Mecanismo de Decisão.

Um servidor web de acesso é usado na fase de "Captura de Contexto e Controle de Acesso", capturando e processando as informações de contexto no momento que o usuário solicita determinado conteúdo, por exemplo, identificando o dispositivo usado pelo usuário. $\mathrm{Na}$ arquitetura originalmente definida por Manzato a adaptação de vídeo é controlada a partir do servidor de acesso, utilizando as informações de contexto capturadas em um simples algoritmo de decisão composto por uma seqüência de if's aninhados, definindo regras de adaptação (MANZATO, 2006). Entretanto, essa abordagem estática é limitada apenas ao que for definido nas regras de adaptação, ou seja, ao conhecimento previamente definido. $\mathrm{O}$ “Mecanismo de Decisão” permite substituir essa abordagem estática tendo como vantagem o fato de atender as necessidades de cada usuário dinamicamente e por utilizar técnicas de Aprendizado de Máquina, esse mecanismo consegue aproximar resultados, mesmo que não exista um conhecimento pré-estabelecido.

A fase de “Acesso” consiste nas máquinas clientes que enviam requisições de serviço ao Sistema de Adaptação junto com as informações contextuais, recebendo como retorno o fluxo de vídeo que melhor atenda as necessidades de cada usuário.

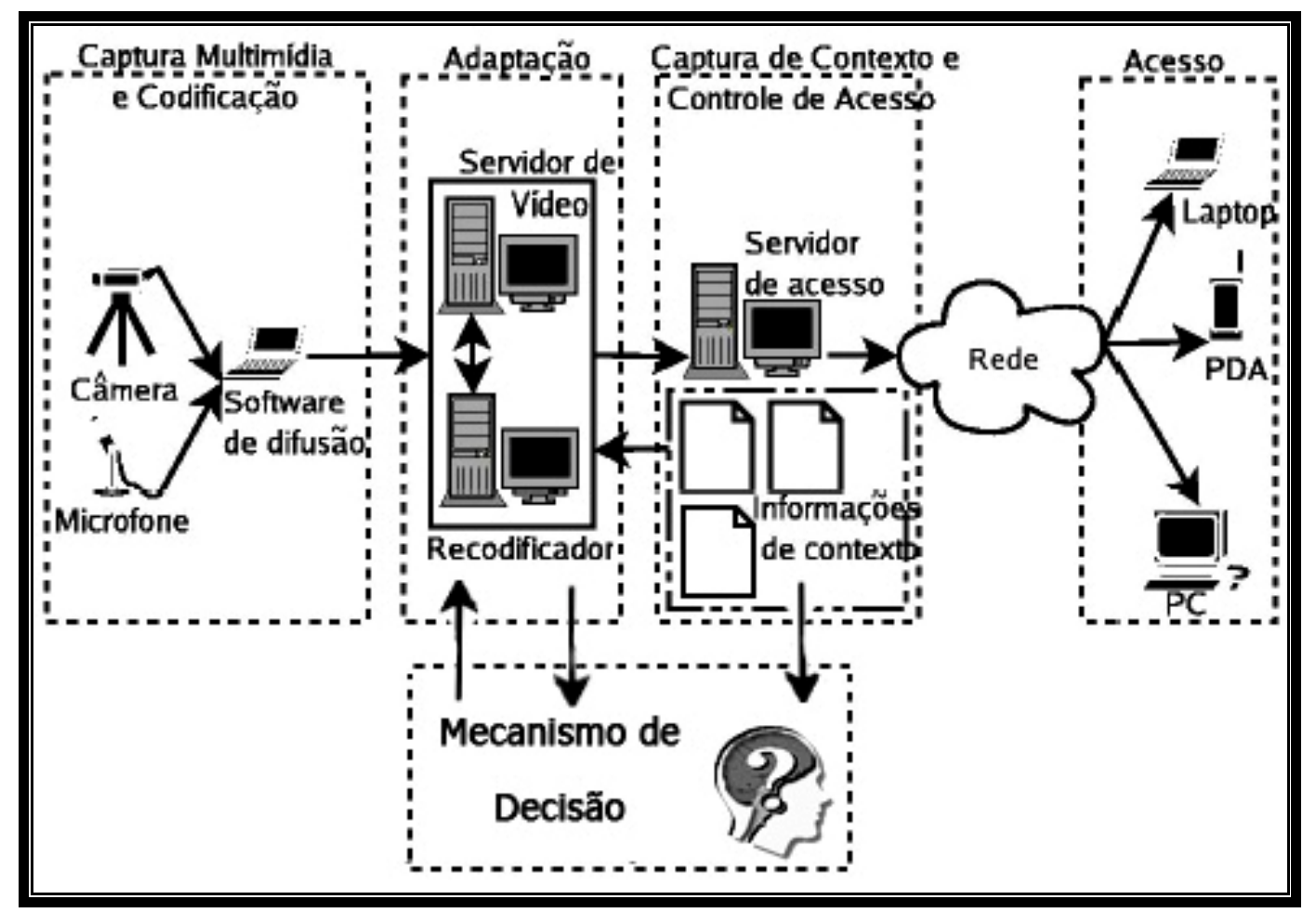

Figura 17 - Arquitetura do Sistema de Adaptação 


\subsubsection{Captura de Informações de Contexto}

Até o presente momento foram apresentados subsídios para a definição e representação das informações contextuais relevantes a um determinado problema, no caso deste trabalho, a adaptação de vídeo. Entretanto, ficou em aberto como essas informações são obtidas do ambiente, ou seja, a definição de um mecanismo para a extração desses dados, de modo automático ou semi-automático.

No caso da arquitetura mostrada na Figura 17, a captura dessas informações é realizada no momento que o usuário requisita um conteúdo ao servidor de acesso, considerando-se duas informações contextuais:

- Largura de Banda: atributo relacionado diretamente a taxa de bits do vídeo. Depende do canal de comunicação utilizado, do tráfego de dados e outros fatores que possam gerar um gargalo na distribuição de vídeo. Adequar à taxa de bits a largura de banda disponível é critico e, como já explicado, é um dos aspectos da adaptação de vídeo mais estudados.

- Capacidade Gráfica do dispositivo: atributo relacionado com a resolução espacial do vídeo. Com a computação móvel ganhando espaço a cada dia, novos dispositivos têm adquirido capacidades multimídia. Dependendo do dispositivo, sua capacidade gráfica torna-se um fator restritivo. É definida pelo número de pontos (pixels) visualizados simultaneamente.

Outras informações contextuais poderiam ser consideradas, mas o propósito do presente trabalho é demonstrar o potencial do Aprendizado de Máquina na adaptação de um fluxo de vídeo e por essa razão, limitaram-se as informações contextuais utilizadas.

A capacidade gráfica do dispositivo é obtida usando informações do navegador utilizado pelo usuário. Isso é possível porque boa parte dos navegadores tem acesso a informações do sistema, como o tipo de sistema operacional, versão do navegador e até a capacidade gráfica. Entretanto, essas informações, por questões de segurança, não são normalmente acessíveis externamente. Um modo de acessá-las é usando um código similar ao mostrado Figura 18, escrito na linguagem Javascript, permitindo obter automaticamente essas informações, usando uma página dinâmica JSP (Java Server Pages) para coletar as informações do cliente e armazená-las no servidor. Isso é possível utilizando o objeto screen, composto pelas propriedades width e height, definindo respectivamente, a largura e a altura da resolução do dispositivo e enviando esse objeto por meio do formulário. É importante lembrar que nem todos os navegadores suportam Javascript e muitos usuários desabilitam seu funcionamento por questão de segurança, exatamente por permitir o acesso remoto a 
informações do sistema. Como alternativa, algumas informações do cabeçalho HTTP podem ser usadas ainda que de modo limitado, como por exemplo, utilizando o campo User-Agent que informa o sistema operacional usado pelo dispositivo do usuário e, em alguns casos, é possível distinguir a resolução de um Pocket PC da resolução de um Computador Pessoal (MANZATO, 2006).

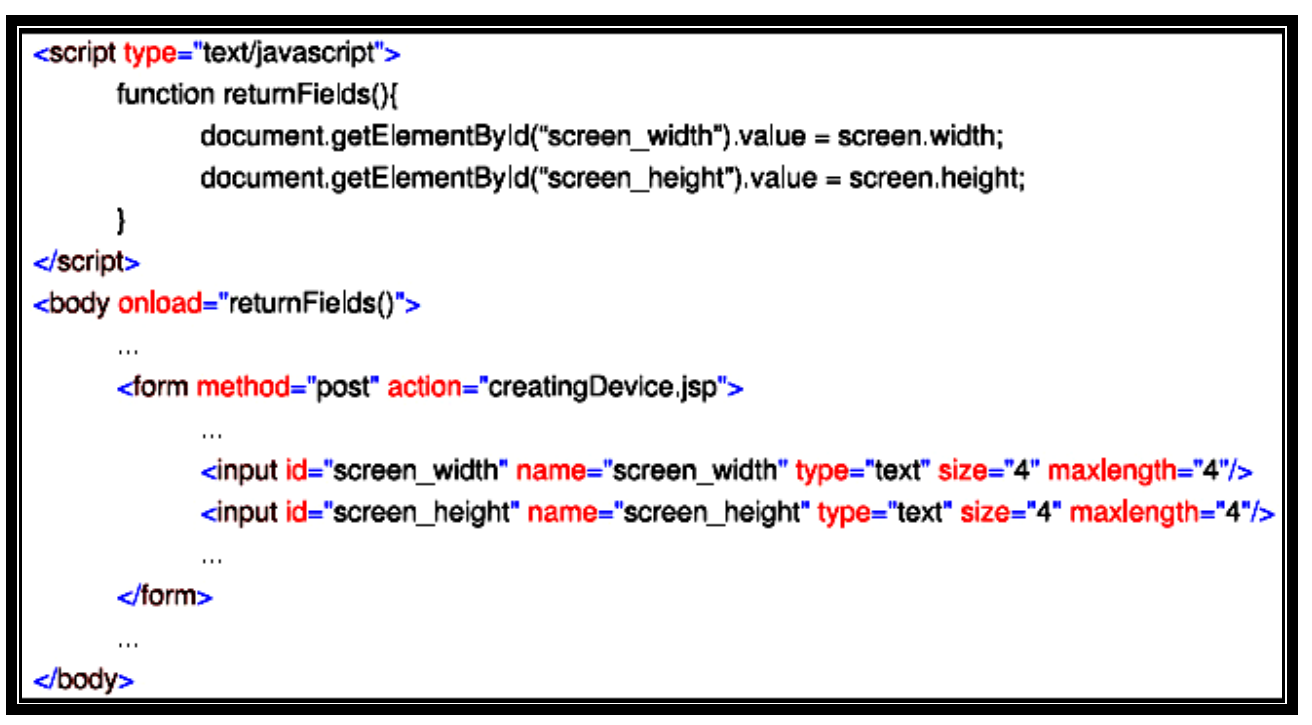

Figura 18 - Captura da Informação de Contexto “resolução do dispositivo” (MANZATO, 2006)

Ferreira e Mello desenvolveram uma ferramenta para avaliar interfaces de comunicação utilizando o modelo LogP (FERREIRA; MELLO, 2004). Essa mesma ferramenta pode ser usada para determinar a Largura de Banda, por meio da troca de mensagens entre um servidor e cliente. Entretanto, para realizar essa troca de mensagens, é necessária a intervenção do usuário, resultando em um processo semi-automático. O usuário instala uma aplicação cliente que conecta ao servidor utilizando uma porta especifica, enquanto que o servidor habilita as portas que serão acessadas e gerencia essa troca de mensagens, obtendo os parâmetros que definem o modelo LogP (FERREIRA; MELLO, 2004), definido como segue:

- L: Latência de transmissão de uma mensagem de um ponto a outro na rede, dependendo da tecnologia e da topologia de rede adotada.

- o: Overhead, consistindo no tempo consumido no empacotamento de uma mensagem, dependendo da capacidade do processamento, do sistema operacional, do protocolo usado e da velocidade de comunicação entre a interface de rede e o barramento de memória do computador.

- g: Gap, o intervalo de tempo entre duas transmissões ou recepções de mensagem consecutivas, considerando uma rede sobrecarregada.

- P: Número de elementos de processamento do sistema. 
Dividindo o tamanho da mensagem pelo gap é possível encontrar a largura de banda disponível. O tamanho da mensagem depende de diversos fatores como, por exemplo, o tipo de rede. Para a rede ethernet, o tamanho da mensagem é de 1460 bytes, desconsiderando o tamanho dos cabeçalhos IP e TCP.

A Figura 19 mostra um exemplo de cliente para estimar a largura de banda no Windows XP. Neste cliente é inserido o endereço e a porta de acesso do Servidor (Host), o usuário então conecta neste servidor que realiza o cálculo, retornando para o cliente uma mensagem informando que a estimativa da largura de banda foi bem sucedida.

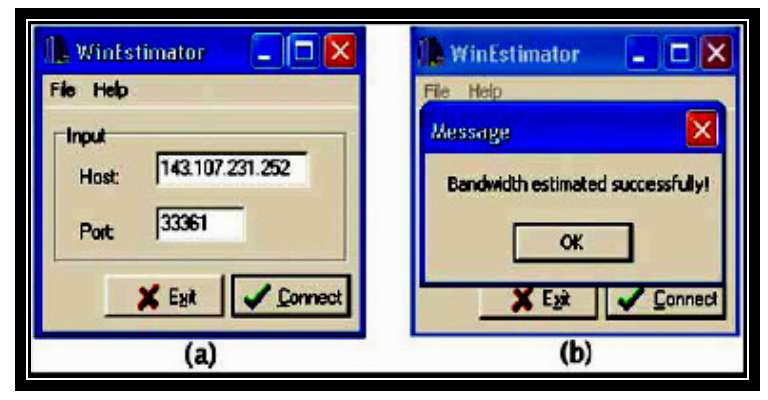

Figura 19 - A estimativa da largura de Banda (MANZATO, 2006)

\subsubsection{Representação de Dispositivos}

Existem na literatura diversos trabalhos abordando a representação e descrição de dispositivos. O mais conhecido é o CC/PP (Composite Capabilities/Preferences Profile), usado para descrever as preferências de usuários e características dos dispositivos. O sistema DELI $^{6}$ é um exemplo de trabalho utilizando o CC/PP, uma biblioteca de código aberto para a distribuição de contexto usando CC/PP e UAProf, usada no processamento de requisições HTTP. Outro trabalho combina CC/PP e os padrões UPS (Universal Profile Schema) e SMIL (Synchronized Multimedia Integration Language) na adaptação de conteúdo para dispositivos móveis (LEMLOUMA; LAYAIDA, 2003). Apesar de popular, alguns autores questionam esse padrão, como é o caso de Indulska et al., argumentando que embora o CC/PP possa ser utilizado na representação contextual, incluindo relacionamentos e dependências, suas limitações impedem que ele seja apropriado para essa tarefa (INDULSKA, J. et al., 2003). A falta de um modelo para representação de dispositivos compostos é um exemplo de limitação do CC/PP, que permite apenas um nível na árvore de representação. Outro exemplo é a inconsistência ao definir atributos em vocabulários e perfis diferentes, o CC/PP não distingue se o mesmo atributo é definido para dois vocabulários distintos (EISINGER et al., 2005).

\footnotetext{
${ }^{6}$ http://delicon.sourceforge.net/
} 
Considerando a adaptação de um fluxo de vídeo, a Seção 5.2 apresentou o UMA, um arcabouço proposto pelo MPEG descrevendo as informações relacionadas a um conteúdo multimídia, como as características do usuário, capacidades do terminal, características de rede e do ambiente (ÖNÜR et al., 2004), (PRANGL et al., 2006), (JANNACH et al., 2006), (THANG et al., 2006). Atualmente existem diversos trabalhos explorando este arcabouço, entretanto, quando o presente trabalho teve início, o UMA não estava amadurecido como padrão e por isso optou-se por estender o modelo de representação de contexto proposto por Goularte (GOULARTE, 2003), adicionando a representação do contexto de Dispositivo.

A Seção 2.3 apresentou um arcabouço para a representação de contexto, onde cada tipo contextual é definido a partir da extensão dos quatro contextos primários: identidade, localização, atividade e tempo (GOULARTE, 2003). Goularte demonstrou seu arcabouço definindo uma biblioteca contextual para descrever o contexto de Usuário, deixando em aberto os demais contextos. Considerando a necessidade de representar diferentes dispositivos para realizar a adaptação de um fluxo de vídeo, os problemas encontrados nos modelos para representação de contexto encontrados na literatura e na contribuição para o trabalho de Goularte, uma nova biblioteca contextual foi adicionada ao arcabouço, descrevendo o contexto dos Dispositivos (EISINGER et al., 2005).

$\mathrm{Na}$ representação definida por Eisinger et al. (EISINGER et al., 2005), cada dispositivo pode ser tratado de dois modos distintos, seja por suas características e/ou como um conjunto de dispositivos, como mostra a Figura 20, cujo modelo de representação foi construído com a ajuda da ferramenta XMLSpy ${ }^{7}$. Por exemplo, um computador pode ser descrito como um dispositivo único, considerando características como sua capacidade de processamento, espaço em disco ou sistema operacional instalado, como também pode ser descrito como um conjunto de componentes, ou seja, outros dispositivos com características próprias como um monitor, teclado, mouse, entre outros componentes (EISINGER et al., 2005). O projetista decide qual representação é mais conveniente para o problema que pretende resolver. Essa abordagem resolve o problema de representação de dispositivos compostos observado por Indulska et al. no CC/PP (INDULSKA, J. et al., 2003).

\footnotetext{
${ }^{7}$ http://www.altova.com/products/xmlspy/xml_editor.html
} 


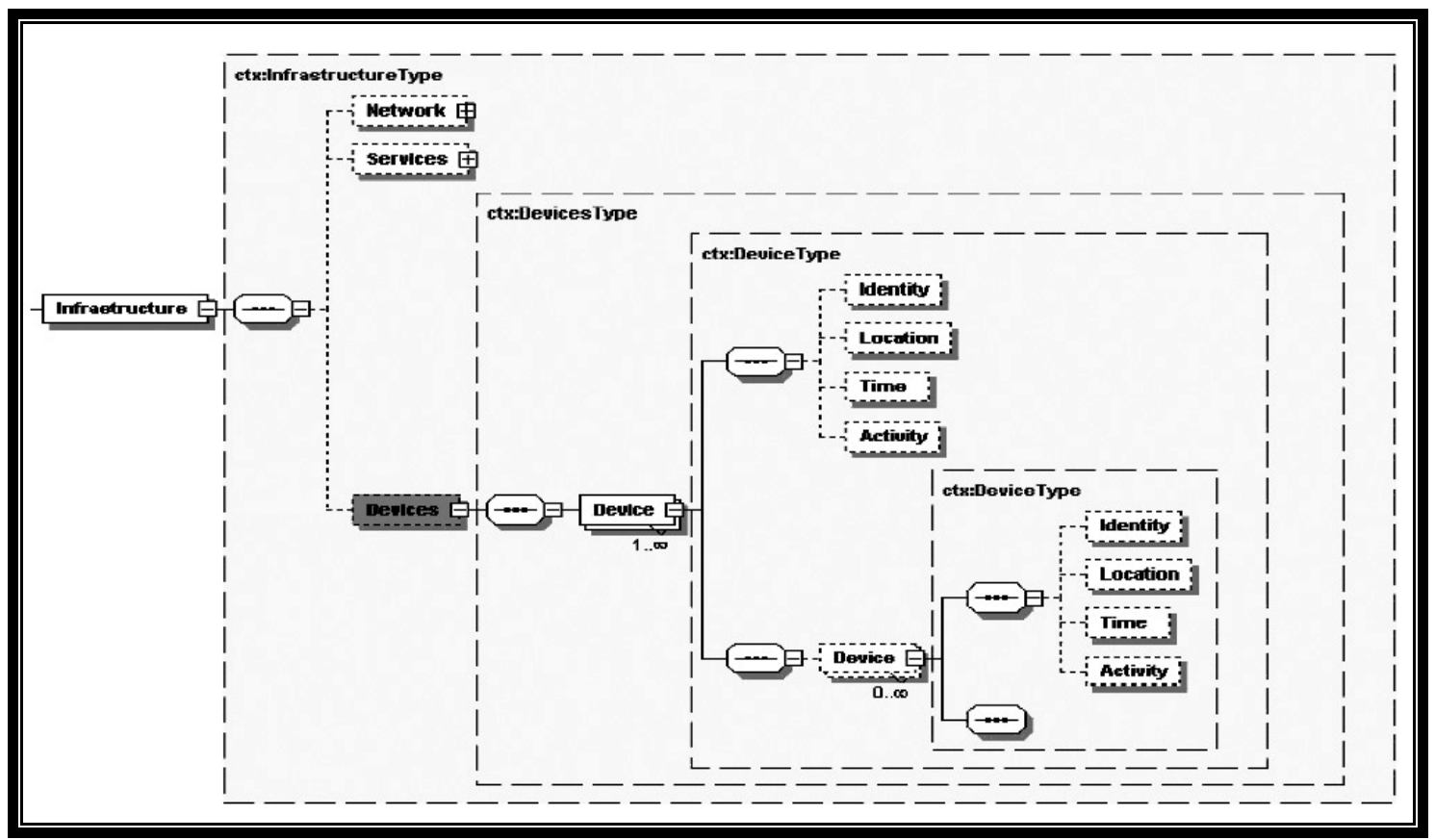

Figura 20 - Representação de Contexto: Dispositivos (EISINGER et al., 2005)

Do mesmo modo que na representação do contexto de Usuário, a descrição de um Dispositivo utiliza os quatro tipos de contexto primário: identidade (Identity), localização (Location), tempo (Time) e atividade (Activity). Com a identidade é possível definir as características de um dispositivo, por exemplo, um telefone celular pode ser identificado por sua marca, tipo de bateria, capacidade da agenda de telefone, presença ou não de vibracall. A localização informa a posição atual do dispositivo, seja física ou virtual, assim uma geladeira pode ser encontrada na cozinha de uma casa e até ter um endereço IP associado, se ela fizer parte de uma casa inteligente. Já o tempo considera os aspectos ligado a sua passagem ou ao momento que um dispositivo é usado, como por exemplo, o número de horas gasta com ligações de um telefone celular. Por fim, a atividade relaciona os demais contextos primários, justificando-os, por exemplo, uma ligação para Angola foi realizada no dia 22 de novembro de 2006, a bateria de um telefone celular precisa ser recarregada por pelo menos 4 horas a cada semana, a geladeira é usada diariamente, pelo menos três vezes por dia ou mesmo que essa geladeira foi transferida para a sala, em conseqüência de uma reforma na cozinha.

Considerando as características de cada dispositivo, é possível agrupá-las facilitando sua classificação e identificação. A Figura 21 mostra um exemplo disso, considerando as diferentes especificações que definem um dispositivo computacional. Os elementos representados com linhas tracejadas são opcionais, ou seja, são identificados apenas se necessário. Os elementos com linhas cheias são obrigatórios, como a identificação do dispositivo (DeviceID). Essas características foram obtidas da avaliação dos principais vendedores de dispositivos computacionais da atualidade, como a HP, Intel, Samsung, IBM, 
dentre outras, obtendo de suas fichas técnicas e especificações de dispositivos, as informações necessárias para definir a biblioteca contextual. No entanto, não foi realizada uma pesquisa abrangente especificando apenas os dispositivos utilizados no presente trabalho, mas, a representação de dispositivo é extensível, permitindo a definição de novos tipos de dispositivos conforme a necessidade da aplicação.

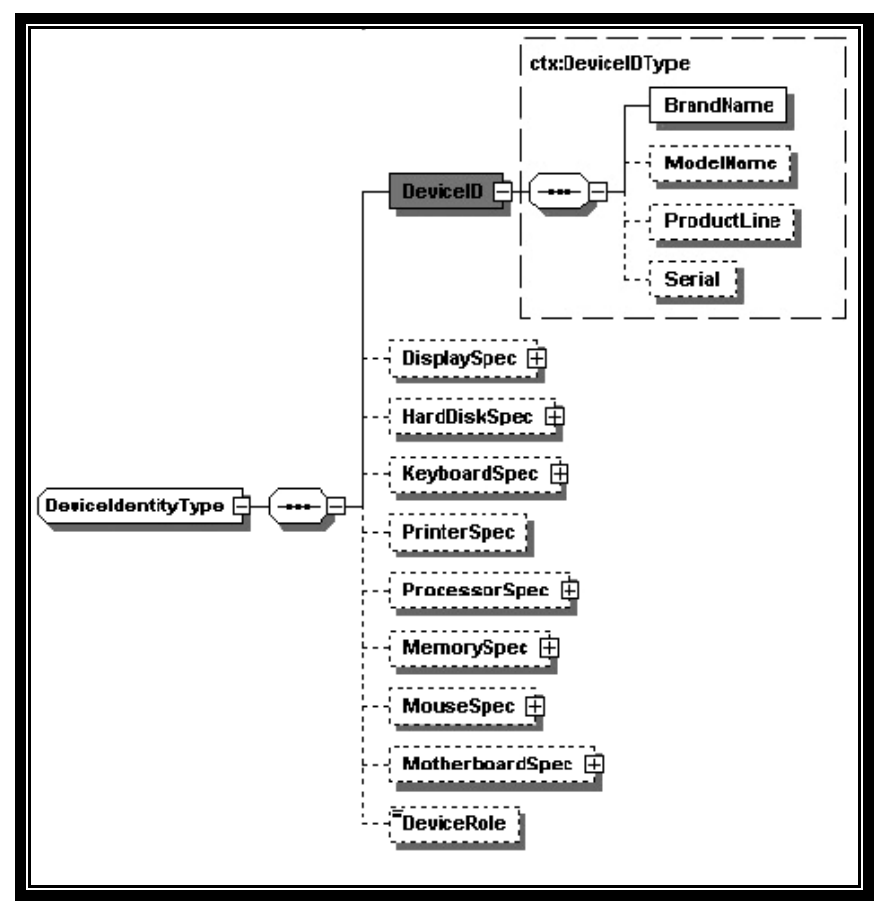

Figura 21 - Especificação de um Dispositivo

A definição de um novo dispositivo é realizada a partir de uma extensão do tipo abstrato DeviceType, como mostra a Figura 22, definindo um novo tipo de dispositivo na biblioteca contextual, no caso esse tipo recebeu o nome de MemoryType, representando dispositivos de memória. As características deste novo dispositivo são descritas utilizando um SpecType, no caso dos dispositivos de memória, definiu-se um MemorySpecType como mostra a Figura 23. Um dos elementos que compõem a definição de um dispositivo de memória, o tipo de memória (MemType), restringe-se a um conjunto definido de valores (DDR, SDRAM etc.). Isso garante a consistência das informações, uma vez que o usuário só pode definir um tipo de memória usando as opções definidas no MemType. Entretanto, se o projetista precisar utilizar um conjunto diferente de valores, ele pode estender a biblioteca definindo seu próprio tipo de memória. 


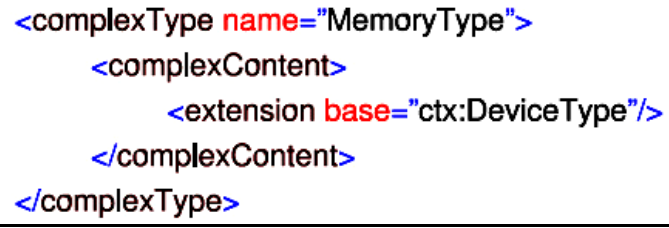

Figura 22 - Definição de um novo dispositivo

O MemType é uma característica especifica de um dispositivo de memória e por isso foi descrito dentro do MemorySpecType, entretanto, a memória possui características que são comuns a outros dispositivos, como sua velocidade (MemSpeed) e a capacidade (MemSize), que podem ser usados por um disco rígido (HardDiskType). Para não repetir essas informações, todos os tipos que podem ser compartilhados são definidos a parte. Assim, para especificar a velocidade da memória, o atributo MemSpeed é tratado como sendo do tipo SpeedType, definido na Figura 24.

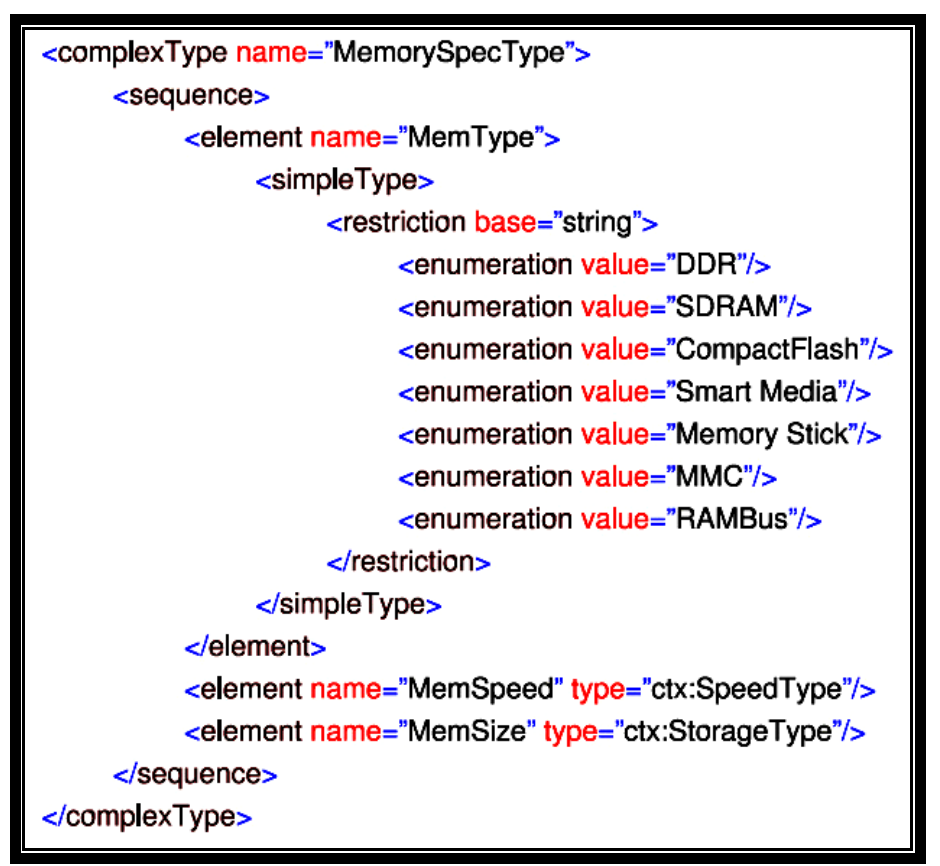

Figura 23 - Especificação de uma Memória usando a biblioteca contextual

A última etapa na definição de um novo tipo de dispositivo é referenciá-lo dentro da biblioteca contextual, como parte do contexto primário de identidade, como mostrado na Figura 25. Como exemplo de uso da representação de dispositivo, a Figura 26 mostra um arquivo XML que descreve um laptop Pavilion ze2010, da HP. Nessa representação é definido o tipo de dispositivo, no caso laptop (LapTopType) composto por sua identificação (BrandName, ModelName e ProductLine) e especificações (ProcessorType). No caso desse exemplo, o laptop é composto por outro dispositivo, o processador, com identificação e características próprias. 


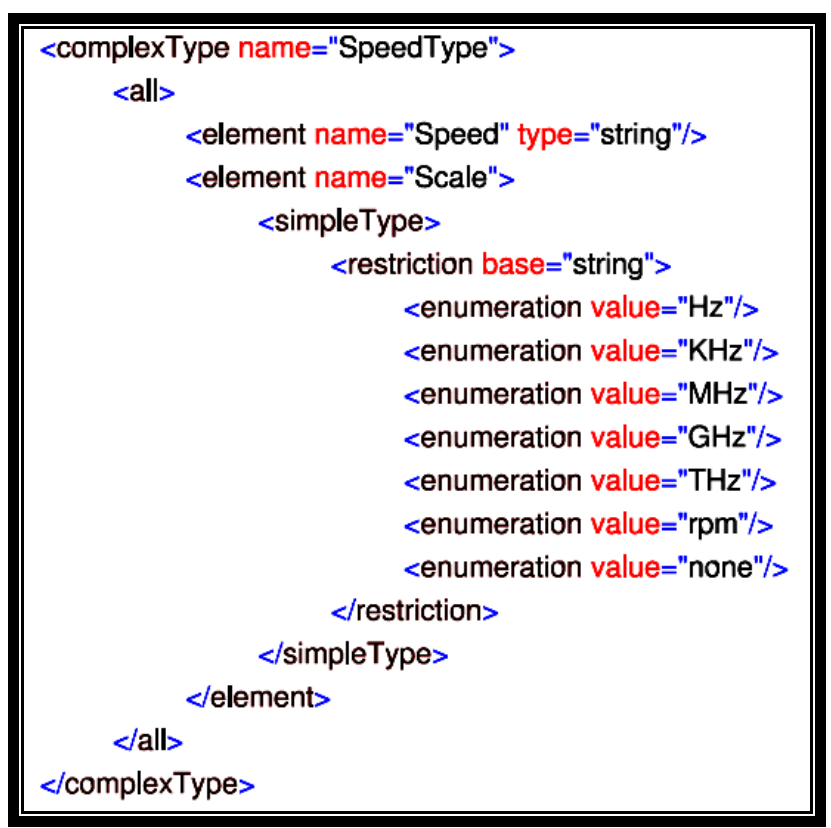

Figura 24 - Especificação do Tipo Velocidade (SpeedType)

\subsubsection{Mecanismo de Decisão}

O último componente do sistema de adaptação de vídeo é o Mecanismo de Decisão, responsável por processar as informações contextuais, encontrar uma configuração para o fluxo de vídeo que melhor atenda as necessidades do usuário e ao mesmo tempo gerenciar o processo de adaptação. Como menciona a Seção 5.3.1 na arquitetura originalmente proposta por Manzato o servidor de acesso era responsável por capturar as informações de contexto e realizar a adaptação do fluxo de vídeo com base nessas informações. Esse processo de adaptação utiliza um simples algoritmo de decisão tendo como base duas regras que envolvem a resolução espacial do fluxo do vídeo. A primeira limita a resolução espacial a capacidade gráfica disponível no dispositivo do usuário, enquanto que a segunda regra limita a resolução espacial conforme a taxa de bits suportada pelo cliente, isto é, a largura de banda disponível, como mostra a Tabela 3 (MANZATO, 2006).

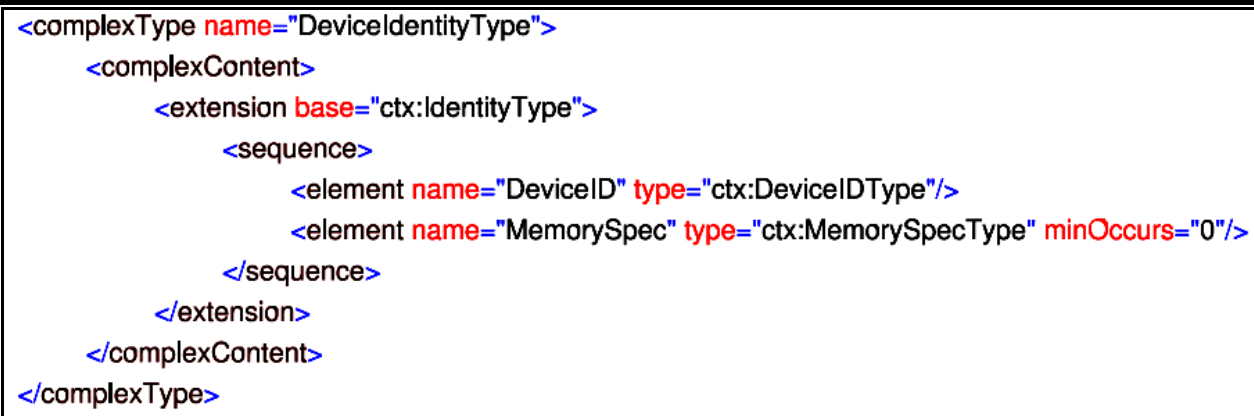

Figura 25 - Adicionando uma nova especificação 


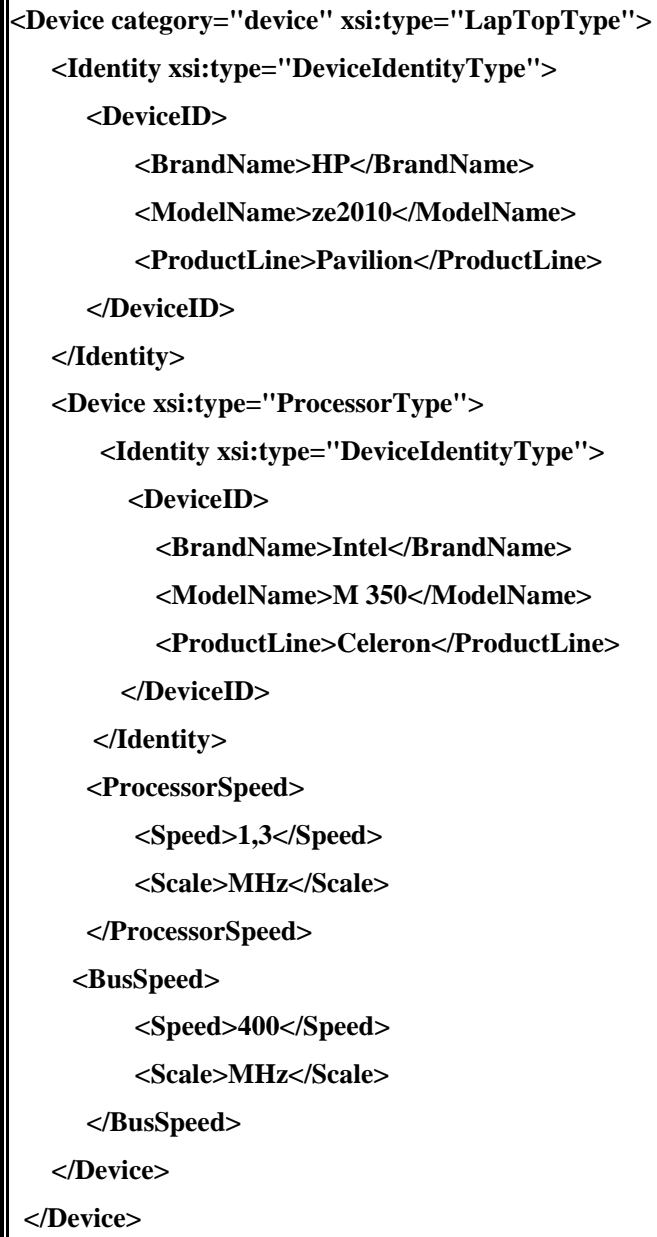

Figura 26 - Representação XML do Dispositivo

O algoritmo retorna a taxa de bits e a resolução espacial, usando essas duas regras como base, como mostra a Figura 27. Entretanto, como foi explicado no início deste Capítulo, regras para adaptação podem ser práticas e simples de colocar em uso, mas são limitadas ao conhecimento representado por elas, no caso dessas regras, supondo que um telefone celular seja capaz de executar fluxos de vídeos e tenha uma capacidade gráfica de 80x60, considerando as regras estabelecidas, o telefone celular não seria capaz de exibir corretamente esse fluxo, considerando que a menor resolução espacial definida pelas regras é de 160x120. É preciso considerar que essa é uma simplificação do ambiente para demonstração do sistema de adaptação de vídeo utilizando informações de contexto, portanto, à medida que aumenta a complexidade do problema a dificuldade em definir novas regras também aumenta, por depender do conhecimento que o projetista tem sobre o problema abordado e o modo como ele define essas regras. 
Tabela 3 - Regra de Decisão limitando a Resolução com base na Taxa de Bits (MANZATO, 2006)

\begin{tabular}{||l|l|}
\hline Taxas de bits & Resolução Espacial \\
\hline Até $120 \mathrm{kbits} / \mathrm{s}$ & $160 \times 120$ \\
\hline de $120 \mathrm{kbits} / \mathrm{s}$ até $600 \mathrm{kbits} / \mathrm{s}$ & $320 \times 240$ \\
\hline de $600 \mathrm{kbits} / \mathrm{s}$ até $12 \mathrm{Mbits} / \mathrm{s}$ & $640 \times 480$ \\
\hline A partir de $12 \mathrm{Mbits} / \mathrm{s}$ & $1280 \times 960$ \\
\hline
\end{tabular}

Ao definir um Mecanismo de Decisão é possível separar a lógica usada na adaptação de um fluxo de vídeo do processo de decisão deixando o Servidor de Acesso com a responsabilidade de servir como interface de comunicação com o usuário, recebendo suas requisições e coletando as informações contextuais necessárias para atendê-las. Assim, o Servidor de Acesso obtém do usuário informações relacionadas às características do dispositivo usado e da rede, respectivamente, a capacidade gráfica do dispositivo e a largura de banda disponível entre o servidor e a máquina do usuário, informações que servem de subsídio ao processo de adaptação.

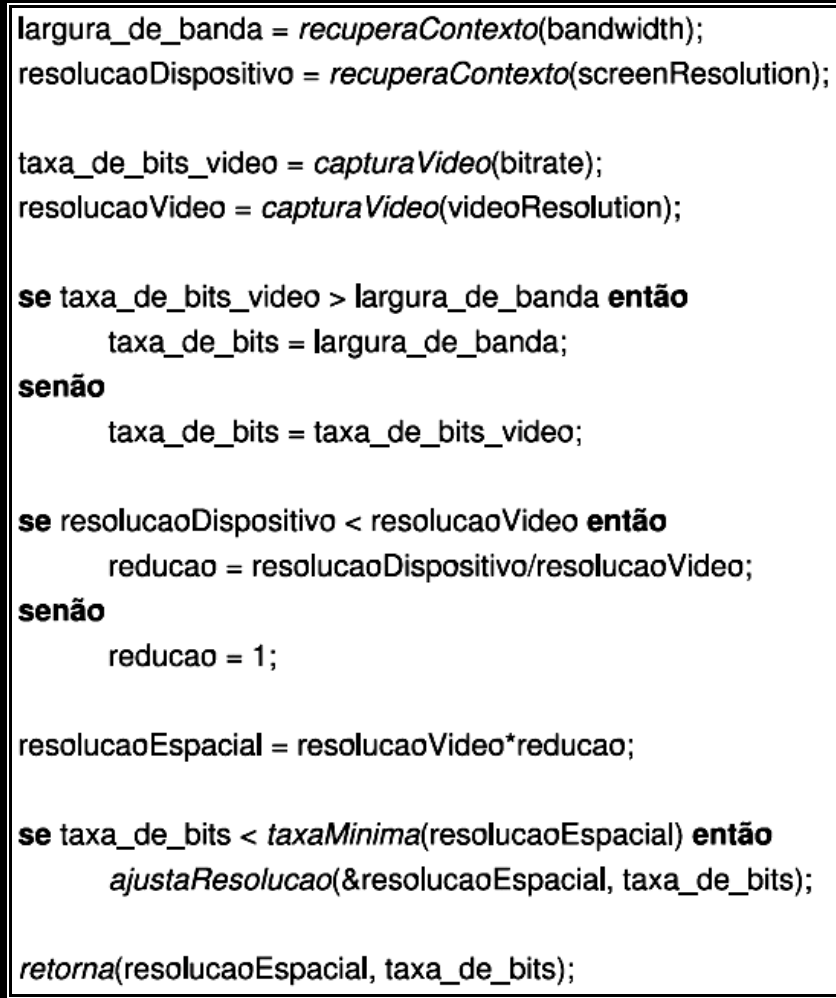

Figura 27 - Algoritmo para adaptação de vídeo definido por Manzato (MANZATO, 2006)

Entretanto, como usar essas informações na adaptação do sistema depende da estratégia adotada pelo projetista. No caso do sistema proposto por Manzato, optou-se por usar duas regras de decisão relacionadas com a resolução espacial (MANZATO, 2006). Como já mencionado, adotar essa abordagem é limitado ao conhecimento que o projetista tem sobre o processo e sua capacidade de identificar todas as regras necessárias, permitindo que o 
sistema seja capaz de reconhecer a partir das informações coletadas, no caso da adaptação de vídeo, a configuração para o fluxo de vídeo que melhor atenda as necessidades do usuário.

Para um sistema ciente de contexto, conhecer os fatores que influenciam ou definem as necessidades de cada usuário é essencial à adaptação de um conteúdo, sendo a base que define o comportamento esperado para o sistema. No entanto, adaptar não se resume a adequar um conteúdo às restrições impostas, outros aspectos precisam ser considerados. $\mathrm{Na}$ adaptação de um fluxo de vídeo uma das restrições consideradas é a largura de banda consumida, ou seja, a taxa de bits produzida por este fluxo. Esta taxa de bits pode ser alterada de diferentes modos, por exemplo, mudando as configurações referentes à resolução espacial ou temporal, assim, alterando parâmetros como o tamanho do quadro ou a quantidade de quadros por segundo, é possível definir diferentes configurações para uma mesma taxa de bits. Embora essa alteração possa ser realizada de modo arbitrário, além de não considerar qual será a aplicação que este fluxo de vídeo se destina, a falta de padronização dificulta o processo automático de adaptação. Por exemplo, se um fluxo de vídeo é utilizado em uma aplicação de babá eletrônica, identificar o movimento do bebê é importante, portanto, a quantidade de quadros por segundo deve ser priorizada. Outra aplicação pode utilizar tecnologia móvel, nesse caso é importante restringir a resolução espacial para ser compatível com a capacidade gráfica do dispositivo usado pelo usuário.

Isso só é possível estabelecendo a relação entre os fatores que influenciam ou definem as necessidades do usuário e o comportamento esperado para o sistema, como é o caso do sistema proposto por Manzato que utiliza regras de decisão para definir essa relação. Essas regras definem implicitamente o conhecimento dessa relação, ou seja, o modo como as informações obtidas do usuário serão usadas na adaptação do sistema. Sem definir esse conhecimento, implícita ou explicitamente, não é possível estabelecer essas relações, portanto, o projetista deve ter um conhecimento prévio do problema a ser solucionado. Como mencionado, depender do conhecimento do projetista limita o processo de adaptação à medida que a complexidade do problema aumenta. Assim, diminuir essa dependência permite um melhor aproveitamento dessas informações e neste sentido uma alternativa é utilizar técnicas de Aprendizado de Máquina.

Enquanto as regras de decisão exigem que o projetista considere todos os casos possíveis, as técnicas de Aprendizado de Máquina dependem apenas do conjunto de treinamento definido pelo projetista, considerando as relações que são esperadas na resolução do problema proposto. No caso do presente trabalho, as duas técnicas que foram utilizadas, as redes MLP e Bayesiana, conseguem obter implicitamente essas relações para todo o espaço 
amostral adotado, no entanto, isso só é possível treinando-as com um conjunto que defina adequadamente essas relações. Depois de treinadas, cada um delas consegue obter o comportamento esperado para o sistema, considerando as informações contextuais obtidas do usuário, para o fluxo de vídeo, o comportamento esperado é definido pelos parâmetros de configuração mais apropriados. A precisão dessas técnicas depende da qualidade do conjunto utilizado no treinamento e no caso da rede MLP, também é importante a configuração adotada.

Usando uma dessas técnicas, o Mecanismo de Decisão reduz o impacto do conhecimento do projetista no processo de adaptação, além de facilitar a separação da lógica de adaptação do processo de decisão. O Mecanismo de Decisão define, portanto, um novo módulo dentro da arquitetura do sistema de adaptação (Figura 17) substituindo o algoritmo de adaptação proposto por Manzato, que utilizava uma abordagem estática, por uma ferramenta que atenda as necessidades do usuário, de modo dinâmico e sem sobrecarregar o sistema. Esse módulo pode ser visto na Figura 28.

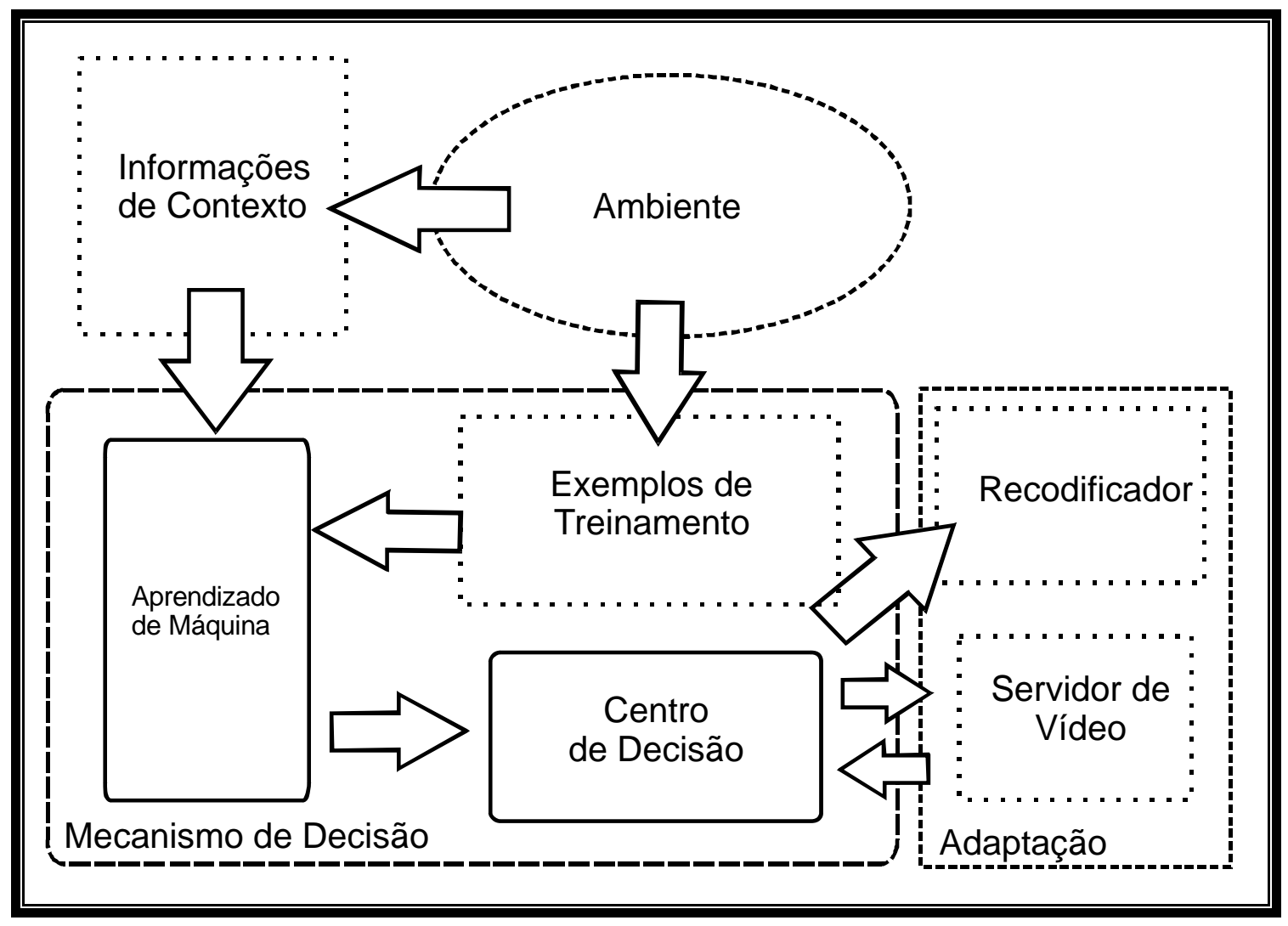

Figura 28 - Arquitetura para o Mecanismo de Decisão

O Mecanismo de Decisão é composto por um bloco com o Aprendizado de Máquina, utilizando uma das técnicas estudadas no presente trabalho, e um Centro de Decisão. O Aprendizado de Máquina é responsável por encontrar a configuração mais adequada para o 
fluxo de vídeo considerando as informações de contexto obtidas do usuário. Ele é executado em duas etapas: Treinamento e Execução.

A etapa de Treinamento é realizada antes de o sistema entrar em funcionamento, preparando-o de modo adequado a partir de um conjunto de exemplos obtidos do usuário, considerando a expectativa que ele tem do sistema e atendendo suas necessidades, e como resultado desse treinamento é gerado um arquivo de configuração. A etapa de Execução utiliza esse arquivo de configuração para processar as informações do usuário e retornar a configuração mais adequada para o fluxo de vídeo. É importante lembrar que um sistema ao usar uma técnica de Aprendizado de Máquina é um sistema especialista, isto é, só consegue resolver um problema de modo satisfatório considerando uma situação para a qual esteja preparado. Assim, se a técnica adotada recebeu treinamento para lidar apenas com a resolução espacial, considerando as restrições na capacidade do dispositivo usado pelo usuário na adaptação da resolução espacial do fluxo de vídeo, o sistema será incapaz ou terá um resultado pouco satisfatório ao atender uma requisição que envolva a largura de banda disponível. Para considerar a capacidade gráfica junto com a largura de banda ou qualquer outro fator é necessário treinar novamente a técnica de Aprendizado de Máquina, adicionando os novos elementos. Essa abordagem exige tempo e preparo antes do sistema entrar em funcionamento, mas garante sua estabilidade e confiabilidade, além de permitir que diferentes arquivos de configuração sejam gerados, armazenados e utilizados conforme a situação.

A configuração obtida pelo Aprendizado de Máquina é repassada ao Centro de Decisão, responsável por verificar a situação do servidor de vídeo, como por exemplo, se já existe um fluxo de vídeo sendo transmitido com a mesma configuração ou se a capacidade de transmissão permite a criação de um novo fluxo. Isso é feito seguindo o algoritmo da Figura 29.

O algoritmo considera uma lista dinâmica contendo os fluxos de vídeo que estão disponíveis no Servidor de Vídeo. Um fluxo de vídeo é mantido ativo enquanto existir pelo um usuário utilizando-o, sendo removido da lista quando se tornar inativo, isto é, quando nenhum usuário o estiver requisitando. Esta lista é composta por uma descrição do fluxo contendo suas configurações e o nome do arquivo SDP associado a este fluxo. Caso a configuração obtida do Aprendizado de Máquina não conste dessa lista, é preciso verificar se o Servidor de Vídeo tem capacidade para enviar um novo fluxo. Caso isso seja possível, o Recodificador receberá a configuração obtida e gerará um novo fluxo de vídeo a ser transmitido pelo Servidor de Vídeo. No caso de não ser possível gerar um novo fluxo, adotou- 
se como convenção tentar obter um fluxo de vídeo com configuração inferior a solicitada, respeitando as restrições do usuário e não existindo configuração inferior, o sistema informa o usuário da impossibilidade de atender essa requisição. Outro caminho é ajustar um dos fluxos em transmissão, para que possa atender essa nova requisição. Também é possível utilizar uma lista de espera, atendendo a requisição do usuário quando um dos fluxos de vídeo fosse liberado.

Obtém a configuração de vídeo do Aprendizado de Máquina;

Verifica a Lista de Fluxos de Vídeo sendo transmitidos:

1. Se já existe fluxo com a mesma configuração, avisa o Servidor de Vídeo e disponibiliza este fluxo ao usuário.

2. Caso contrário, verifica a capacidade de transmissão do Servidor de Vídeo.

a. Se o servidor comporta um novo fluxo de vídeo, solicita sua criação ao Recodificador e depois que o novo fluxo de vídeo for criado, avisa o Servidor de Vídeo e disponibiliza o novo fluxo ao usuário. Adiciona o fluxo a Lista de Fluxos de Vídeo.

b. Caso contrário, verifica se existe um fluxo que tenha uma configuração inferior a solicitada,

i. Se existir, avisa o Servidor de Vídeo e disponibiliza este fluxo ao usuário.

i. Caso contrário, informa o usuário que o sistema não tem condições de atender sua solicitação no momento.

Figura 29 - Algoritmo para o Mecanismo de Decisão

Desta maneira o Mecanismo de Decisão controla o processo de adaptação, usando as informações de contexto obtidas do usuário na definição de uma configuração para o fluxo de vídeo que atenda as necessidades do usuário e as limitações do sistema, evitando que o mesmo fique sobrecarregado.

\subsection{Considerações Finais}

Adaptar vai além de modificar determinado conteúdo para que o mesmo atenda as necessidades e restrições de um usuário, também é importante conhecer a aplicação para a qual esse conteúdo se destina e assim definir também o melhor modo de adaptar esse conteúdo. Por exemplo, na adaptação de um vídeo algumas aplicações precisam que a qualidade da imagem transmitida seja mantida, como é o caso da Telemedicina. Um modo de fazê-lo é reduzindo o número de quadros enviados por segundo, sendo aceitável uma reduzilos a dez ou até mesmo cinco quadros, segundo alguns autores (JONES, 2006). Em outras 
palavras, antes de pensar em como o conteúdo será adaptado é importante considerar a aplicação esperada para esse conteúdo e assim definir o processo de adaptação.

Um processo de adaptação, considerando um fluxo de vídeo, pode ser realizado estaticamente, definindo versões previamente adaptadas, ou dinamicamente, onde a versão adaptada é produzida à medida que são necessárias (LEI; GEORGANAS, 2005). A maioria dos trabalhos encontrados na literatura aborda o problema a partir de uma adaptação estática, como é o caso das técnicas de difusão simultânea ou Simmcast (REAL, 2002), (BIRNEY, 2003), onde diferentes versões da mesma mídia são disponibilizadas, ou de mídias codificadas usando a técnica de vídeo escalável (THANG et al., 2006), (BOURGEOIS et al., 2003), definindo uma mídia com múltiplas camadas codificadas e a adição ou remoção delas definem tanto a qualidade como a taxa de bits necessária a sua transmissão. Uma alternativa a essas técnicas é a transcodificação ou recodificação do vídeo (XIN et al., 2005), (VETRO et al., 2003), (KIM et al., 2003), (CHANG; VETRO, 2005), (MANZATO; GOULARTE, 2006), onde o vídeo é convertido, alterando algumas de suas características como a taxa de bits. Esse processo de adaptação é realizado no servidor (server-side) e dependendo de sua capacidade, é possível adaptar um fluxo de vídeo tanto de modo estático, antes de o cliente receber o fluxo, ou dinamicamente, ao longo da transmissão do fluxo.

Seja de modo estático ou dinâmico, ao considerar a aplicação esperada para um fluxo de vídeo, conhecer o contexto do usuário, suas expectativas e necessidades em relação a este fluxo, torna-se imprescindível. No entanto, a maioria dos trabalhos preocupa-se apenas com o processo de adaptação, não definindo como usar essas expectativas e necessidades na adaptação, ou seja, não definindo um mecanismo de decisão que defina os parâmetros do fluxo de vídeo, considerando essas informações. Os trabalhos que utilizam algo próximo a um mecanismo de decisão definem regras que associam operadores de adaptação, isto é, elementos que definem como adaptar o fluxo de vídeo como a capacidade gráfica do dispositivo ou a largura de banda disponível, com as ferramentas de adaptação e/ou a configuração esperada para esse fluxo (JANNACH et al., 2006), (MANZATO, 2006), (THANG et al., 2006).

No caso da arquitetura de adaptação proposta por Manzato (MANZATO, 2006), esse mecanismo resume-se a uma lista com regras de decisão, definindo como o fluxo de vídeo será adaptado a partir de uma seqüência de if's aninhados e, como explicado na Seção 5.3.4, essa abordagem é limitada pelo conhecimento do projetista tem do problema estudado e o modo como ele define essas regras. O presente trabalho modifica essa arquitetura incluindo 
um módulo que define um Mecanismo de Decisão, separando a lógica de adaptação do processo de decisão e substituindo as regras de decisão por uma técnica de Aprendizado de Máquina, com o propósito de reduzir a dependência do conhecimento do projetista, além de permitir essa separação da lógica de adaptação do processo de decisão, encontrando a configuração para o fluxo de vídeo que melhor atenda as necessidades do usuário e gerenciando o processo de adaptação. Como subsídio ao processo de adaptação, optou-se por utilizar o arcabouço para representação contextual definido por Goularte (GOULARTE, 2003), estendendo-o com a adição de uma biblioteca para representação de dispositivos (EISINGER et al., 2005). As limitações de representação do CC/PP (INDULSKA, J. et al., 2003) e a falta de maturidade do UMA na época dessa decisão, quando a maioria dos trabalhos apenas propunha seu uso, justificam essa escolha.

A Seção 5.3.4 ainda mostrou que o Mecanismo de Decisão é composto por dois blocos: o Aprendizado de Máquina e o Centro de Decisão. O Aprendizado de Máquina utiliza uma das duas técnicas estudadas no presente trabalho, sendo responsável por obter as informações contextuais do usuário, processá-las e repassar o resultado desse processamento para o Centro de Decisão. Antes de ser executado, é preciso preparar o Aprendizado de Máquina, realizando um treinamento com um conjunto de dados que represente a necessidade e expectativa do usuário. Como explicado, o resultado desse treinamento cria um sistema especializado no problema considerado e qualquer mudança, como a adição de novas variáveis ou nos valores esperados como resposta, implica em na necessidade de um novo treinamento. Já o Centro de Decisão é responsável por combinar as informações obtidas do Aprendizado de Máquina e a situação do servidor de vídeo, para definir como o usuário será atendido, dentro das possibilidades do servidor.

Para o Centro de Decisão foi definido um algoritmo que considera a carga no servidor, isto é, sua capacidade máxima de transmissão, controlando a criação de fluxo de vídeo (Figura 29), enquanto que o Aprendizado de Máquina permanece em aberto, definido como uma caixa preta. Para definir o conteúdo dessa caixa preta é necessário avaliar qual das duas técnicas estudadas, a Rede MLP ou a Rede Bayesiana, apresenta o melhor desempenho, considerando o tempo gasto e a precisão de seus resultados, e assim definir a técnica adotada pelo Aprendizado de Máquina. Para realizar essa avaliação é preciso definir um caso de uso, considerando não apenas as restrições de rede como também outras restrições, como as restrições de dispositivo, por exemplo, a capacidade gráfica. Além disso, é necessário definir o que o usuário espera dessa adaptação, uma vez que não é possível manter a qualidade da 
imagem sem sacrificar o número de quadros enviados por segundo. Em outras palavras, é preciso definir as prioridades do usuário em relação ao fluxo de vídeo.

O próximo Capítulo define um caso de uso e avalia as duas técnicas de Aprendizado de Máquina, escolhidas definindo a mais adequada. 
Capítulo6

\section{Resultados e Discussão}

As invenções são, sobretudo, o resultado de um trabalho teimoso.

\section{Santos Dumont}

O Mecanismo de Decisão utiliza o Aprendizado de Máquina no processamento das informações contextuais obtidas do usuário e assim determinar a configuração mais adequada para o fluxo de vídeo. Na literatura diferentes técnicas de Aprendizado de Máquina são encontradas, a maioria foi desenvolvida pensando apenas em resolver um problema específico, seja a classificação, reconhecimento de padrões, processamento de imagem etc. A adaptação de um fluxo de vídeo pode ser considerada um problema de classificação ou reconhecimento de padrões, uma vez que a informação contextual coletada do ambiente define as entradas que podem ser classificadas em um conjunto de padrões, no caso, a configuração do fluxo de vídeo que melhor atenda as necessidades do usuário. Assim, dentre as técnicas de Aprendizado de Máquina, duas delas foram consideradas no presente trabalho, por apresentarem um bom resultado na classificação e reconhecimento de padrões: As Redes Neurais (Capítulo 3), representadas pela Rede MLP (Seção 3.4) e a Inferência Bayesiana (Capítulo 4), usando uma Rede Bayesiana (Seção 4.3).

Apenas uma dessas técnicas, em um primeiro momento, irá ser incorporada ao Mecanismo de Decisão e o presente Capítulo apresenta a avaliação das duas técnicas, partindo da definição de um Caso de Uso, descrito na Seção 6.1, a Metodologia adotada na avaliação de cada técnica usando o Caso de Uso proposto, como mostra a Seção 6.2, e os Resultados desta avaliação podem ser vistos na Seção 6.3. O Capítulo encerra com a Seção 6.4, justificando a técnica que foi escolhida.

\subsection{Caso de Uso}

Como já explicado, o Mecanismo de Decisão coleta as informações contextuais do usuário e, a partir do Aprendizado de Máquina, encontra a configuração mais adequada para o fluxo de vídeo. Para processar essas informações as redes MLP e Bayesiana precisam passar inicialmente por uma etapa de treinamento, como explicado na Seção 5.3.4, usando para isso um conjunto de exemplos que represente o problema estudado. Para definir esse conjunto de 
exemplos é necessário definir o cenário no qual o sistema encontra-se inserido, ou seja, como o usuário espera que o sistema adapte um fluxo de vídeo.

A maioria dos trabalhos envolvendo a adaptação de vídeo considera apenas a largura de banda de rede necessária para sua transmissão, sendo recente o estudo de alternativas que considerem outros elementos que possam influenciar essa adaptação, como é o caso das características do dispositivo. Essa mudança no cenário estudado é uma conseqüência da evolução das tecnologias de comunicação móvel que permitem, por exemplo, que aparelhos celulares possam navegar por um conteúdo multimídia interativo, incluindo fluxos de vídeo. $\mathrm{O}$ ambiente torna-se mais heterogêneo, acrescentando novos desafios à distribuição de um conteúdo multimídia. Assim sendo, para caracterizar o cenário estudado é importante definir um conjunto de exemplos que considere não apenas as restrições de rede, como também outras limitações que possam afetar a adaptação de um fluxo de vídeo. No caso dos dispositivos móveis, um dos fatores que limitam essa adaptação é sua capacidade gráfica, assim, para o presente trabalho considera-se a largura de banda disponível e a capacidade gráfica do dispositivo usado pelo usuário, definindo as informações contextuais obtidas do usuário.

Um conjunto de exemplos é definido associando um grupo de entradas a uma ou mais saídas esperadas para essas entradas. A largura de banda disponível e a capacidade gráfica do dispositivo definem as duas entradas do conjunto de exemplos, restando agora definir as saídas esperadas para essas entradas. Na adaptação de um fluxo de vídeo três dimensões podem ser consideradas na definição desse fluxo: Qualidade, Temporal e Espacial (THANG et al., 2006), (SHEN et al., 2006). A dimensão Temporal refere-se ao tempo, lidando com variáveis como a duração de determinado vídeo ou o número de quadros transmitidos em um segundo. A dimensão Espacial é definida pelas dimensões métricas do fluxo de vídeo, como sua altura, largura ou mesmo sua diagonal, que podem ser medidas em pixels (pontos), centímetros ou mesmo polegadas. Por último, a Qualidade pode ser definida subjetiva ou objetivamente. Subjetivamente, a Qualidade é definida a partir da opinião das pessoas sobre determinado vídeo, sendo portanto uma medida inexata, uma vez que a percepção de diferentes pessoas sobre um mesmo aspecto pode variar. Já de modo objetivo, algumas medidas são definidas para medir a Qualidade, considerando pra isso uma comparação entre o resultado esperado e o resultado obtido. Por exemplo, é possível medir a 
taxa de relação sinal-ruído (SNR, Signal-to-noise ratio $^{8}$ ) ou a taxa de pico da relação sinalruído (PSNR, peak signal-to-noise ratio ${ }^{9}$ ).

Considerando essas dimensões é preciso definir uma ou mais saídas relacionadas com as duas entradas, ou seja, relacionadas à largura de banda disponível e a capacidade gráfica do dispositivo. Sendo assim, para atender a capacidade gráfica do dispositivo, considerou-se como uma das saídas o tamanho de cada quadro (framesize), definido a partir de sua altura e largura em pixels. No caso da largura de banda disponível, o parâmetro de configuração do fluxo de vídeo que melhor se relaciona é a taxa de bits (bitrate). No entanto, variar a taxa de bits mantendo os demais parâmetros de configuração fixos implica em uma variação na Qualidade. Assim sendo, a taxa de quadros por segundo (framerate) foi definida como o segundo parâmetro de configuração usado como saída no conjunto de exemplos. Variando o tamanho de cada quadro e o número de quadros transmitidos por segundo é possível variar indiretamente a taxa de bits, isto é, definindo a largura de banda consumida pelo fluxo de vídeo e portanto estabelecendo uma relação com a largura de banda disponível. Com isso, é possível considerar um cenário onde reduzir a taxa de quadros é aceitável quando o que importa é manter a qualidade da imagem transmitida, como no caso de aplicações de Telemedicina (JONES, 2006).

Com isso define-se um cenário de aplicação, onde o tamanho dos quadros e a taxa de quadros por segundo de um fluxo de vídeo são adaptados considerando a largura de banda disponível e a capacidade gráfica do dispositivo usado pelo usuário. Entretanto, definir apenas os parâmetros de entrada e saída do conjunto de exemplos não é suficiente para caracterizar o problema estudado. É importante definir qual das duas saídas será priorizada, seja para atender as expectativas e necessidades do usuário ou garantir que não exista ambigüidade nos dados, o que possibilitaria a presença de inconsistências nos dados e, portanto, dificultando o processo de treinamento.

Para o presente trabalho adotou-se como caso de uso as aplicações com vídeo que priorizem a captura de movimento, ou seja, a taxa de quadros transmitida por segundo. Como exemplo desse tipo de aplicações pode-se citar uma babá eletrônica, onde é importante

\footnotetext{
${ }^{8}$ Termo oriundo da engenharia elétrica, definido como uma comparação do nível do sinal desejado com o nível do ruído de fundo.

${ }^{9}$ Outro termo da engenharia elétrica que define a taxa entre o maior valor possível de um sinal e o poder de corrupção do ruído que afeta a fidelidade dessa representação.
} 
identifica qualquer movimento estranho que o bebê possa fazer, e a transmissão de eventos esportivos, como é o caso de corridas automobilísticas. Isso define um cenário para a aplicação da adaptação de um fluxo de vídeo, permitindo a definição de um conjunto de exemplos que serão usados no treinamento das duas técnicas de Aprendizado de Máquina. A próxima Seção define uma metodologia para a construção desse conjunto de exemplos, a configuração, treinamento e validação das técnicas de Aprendizado de Máquina estudadas.

\subsection{Metodologia Adotada}

O problema a ser estudado pode ser definido como a adaptação de um fluxo de vídeo considerando como prioridade a taxa de quadros transmitida por segundo. O presente trabalho considera o Aprendizado de Máquina na resolução deste problema e duas técnicas serão avaliadas: a rede MLP (Seção 3.4) e a rede Bayesiana (Seção 4.3). Para avaliar qual técnica é mais adequada, considerando o caso de uso proposto, a seguinte metodologia foi adotada:

(1) Levantamento do conjunto de dados.

(2) Apresentação dos dados.

(3) Configuração.

(4) Treinamento e Validação.

(5) Avaliação dos Resultados.

\subsubsection{Levantamento do Conjunto de Dados}

O propósito desta etapa é definir, a partir do caso de uso, o conjunto de dados que será usado no treinamento e validação de cada técnica de Aprendizado de Máquina. Bailey e Thompson (BAILEY; THOMPSON, 1990) sugerem que a qualidade dos dados coletados é mais importante que a quantidade destes dados, portanto, é importante coletar dados que sejam significativos, cobrindo todo o domínio do problema e evitando ao máximo, erros e ambigüidades na informação coletada.

Inicialmente foi realizada uma pesquisa em páginas especializadas em hardware, como a Tom's Hardware ${ }^{10}$, definindo os valores mais comuns para a capacidade gráfica de diferentes dispositivos. Como resultado obteve-se uma lista com 36 diferentes capacidades gráficas, considerando dispositivos como celulares, handhelds, laptops e computadores pessoais, como mostra a Tabela 4 .

\footnotetext{
${ }^{10}$ http://www.tomshardware.com/
} 
Por sua vez, para determinar os valores para a largura de banda disponível avaliou-se as possíveis aplicações para um fluxo de vídeo. Como explicado na Seção 5.1, um novo cenário surge, aeroportos, bares, hotéis e outros estabelecimentos começam a disponibilizar para seus clientes acesso sem fio a Internet, utilizando "hotspots", estendendo o alcance das redes de informação. Novos dispositivos, como celulares, ganham funções multimídia, incluindo a capacidade de receber vídeo digital, como é o caso do Samsung SPH-a92011, tornando o ambiente computacional cada vez mais heterogêneo. As aplicações, sejam na área educacional, médica ou mesmo de entretenimento, precisam considerar essas mudanças e dentro do possível, manter a compatibilidade com dispositivos antigos, como o acesso discado, usando os antigos modems de 56k. Na Wikipedia encontra-se uma lista com as larguras de banda para diferentes dispositivos ${ }^{12}$, definindo por exemplo que a recepção de um fluxo de dados por um modem de 56k (downstream) pode chegar a $56 \mathrm{kbits} / \mathrm{s}$, enquanto que uma rede sem fio utilizando o padrão $802.11 \mathrm{~b}$ consegue atingir até $11 \mathrm{Mbits} / \mathrm{s}$. Esses valores definem sua capacidade máxima, sendo influenciados por fatores externos, como por exemplo, o estado da rede. Também é preciso considerar o equipamento de captura de vídeo, como por exemplo uma câmera digital com tamanho de quadro de 640x480 e taxa máxima de 30 quadros por segundo, como a Genius G-Shot DV 813.

Assim, considerando esses fatores e a partir de uma estimativa do consumo esperado para um fluxo de vídeo, definiu-se que a largura de banda disponível deve assumir valores dentro da faixa que vai de $5 \mathrm{kbits} / \mathrm{s}$ a $3 \mathrm{Mbits} / \mathrm{s}$. Esses valores foram estimados com a ajuda de uma ferramenta para estimativa da largura de banda ${ }^{13}$, considerando a capacidade gráfica de um celular e uma taxa de cinco quadros por segundo como o limite inferior dessa faixa e uma câmera de vídeo com tamanho de quadro de 640x480 e capaz de transmitir até 30 quadros por segundo como limite superior.

\footnotetext{
${ }^{11}$ http://www.samsung.com/Products/MobilePhones/Sprint/SPH_A920WSSXAR.asp Visitado pela última vez em: $15 / 04 / 2007$.

${ }^{12}$ http://en.wikipedia.org/wiki/List_of_device_bandwidths Visitado pela última vez em 15/04/2007.

${ }^{13} \mathrm{http}$ //sorenson-usa.com/vbe/index.html Visitado pela última vez em 15/04/2007.
} 
Tabela 4 - Capacidade Gráfica para diferentes dispositivos

\begin{tabular}{|r|r|r|r|r|r|}
\hline \multicolumn{6}{|c|}{ Capacidade Gráfica do Dispositivo (em pixels) } \\
\hline Horizontal & Vertical & Horizontal & Vertical & Horizontal & Vertical \\
\hline 80 & 112 & 240 & 100 & 640 & 320 \\
\hline 96 & 80 & 240 & 320 & 800 & 600 \\
\hline 96 & 64 & 240 & 260 & 800 & 225 \\
\hline 96 & 96 & 240 & 160 & 800 & 480 \\
\hline 128 & 160 & 320 & 320 & 832 & 624 \\
\hline 128 & 128 & 320 & 480 & 930 & 234 \\
\hline 160 & 64 & 480 & 160 & 960 & 234 \\
\hline 160 & 240 & 480 & 320 & 1024 & 768 \\
\hline 160 & 160 & 480 & 272 & 1024 & 600 \\
\hline 162 & 176 & 640 & 480 & 1280 & 1024 \\
\hline 176 & 220 & 640 & 200 & 1280 & 960 \\
\hline 176 & 208 & 640 & 240 & 1600 & 1280 \\
\hline
\end{tabular}

Definidos os valores que as entradas do conjunto de exemplo assumirão, é preciso definir quais os valores que as saídas podem assumir, ou seja, quais valores serão definidos para a taxa de quadros por segundo e o tamanho dos quadros. Para o Tamanho do Quadro considerou-se dois padrões: o CIF (Common Intermediate Format), um conjunto de padrões para formatação de vídeo usado em videoconferência e o VGA (Video Graphics Array), um padrão de resolução para vídeos analógicos, possibilitando a definição de 8 diferentes resoluções para o fluxo de vídeo, conforme apresenta a Tabela 5. Uma alternativa seria definir um valor percentual em relação a uma resolução base, como é feito na arquitetura proposta por Manzato (MANZATO, 2006). A taxa de quadros, por sua vez, foi definida com valores inteiros dentro do intervalo que vai de 1 a 30 quadros por segundo.

O cálculo da taxa de bits utiliza a ferramenta para estimativa da banda consumida, combinando a taxa de quadros com o tamanho de cada quadro ${ }^{14}$. Com o tamanho dos quadros e a taxa de bits é possível estabelecer uma relação com as entradas do conjunto de exemplos, respectivamente a capacidade gráfica e largura de banda disponível, priorizando a taxa de quadros, conforme o caso de uso adotado (Seção 6.1). Dois conjuntos de exemplos foram construídos, garantindo que as duas técnicas de Aprendizado de Máquina recebam um treinamento apropriado.

Comparando o conjunto das capacidades gráficas descrito na Tabela 4 com o conjunto dos tamanhos de quadros da Tabela 5 é possível notar que, sem perder a representatividade, é possível definir um novo conjunto das capacidades gráficas com apenas 12 valores distintos, como pode ser visto na Tabela 6 . O primeiro conjunto é definido associando aos valores das

\footnotetext{
${ }^{14}$ http://sorenson-usa.com/vbe/index.html Visitado pela última vez em 15/04/2007.
} 
capacidades gráficas da Tabela 6, valores para a largura de banda disponível, considerando a faixa que vai de $5 \mathrm{kbits} / \mathrm{s}$ a $3 \mathrm{Mbits} / \mathrm{s}$, concentrando os valores na faixa que vai de 5 a 300kbits/s, obtendo um conjunto com 618 amostras. As saídas esperadas, ou seja, a taxa de quadros e o tamanho dos mesmos são calculados priorizando a taxa de quadros, com a ajuda da equação (1.1).

Tabela 5 - Tamanho do Quadro de um Fluxo de Vídeo

\begin{tabular}{|l|r|r|}
\hline \multicolumn{3}{|c|}{ Tamanho do Quadro (em pixels) } \\
\hline \multicolumn{1}{|c|}{ Padrão } & \multicolumn{2}{c|}{ Resolução } \\
\hline 1/32 VGA & 80 & 60 \\
\hline 1/16 VGA & 160 & 120 \\
\hline 1/4 VGA & 320 & 240 \\
\hline VGA & 640 & 480 \\
\hline SQCIF & 88 & 72 \\
\hline QCIF & 176 & 144 \\
\hline CIF & 352 & 288 \\
\hline SCIF & 704 & 574 \\
\hline
\end{tabular}

Tabela 6 - Capacidades Gráficas utilizadas no Primeiro Conjunto de Exemplos.

\begin{tabular}{|r|r|r|r|}
\hline \multicolumn{4}{|c|}{ Capacidade Gráfica do Dispositivo } \\
\hline Horizontal & Vertical & Horizontal & Vertical \\
\hline 160 & 64 & 480 & 320 \\
\hline 96 & 80 & 640 & 480 \\
\hline 240 & 100 & 800 & 600 \\
\hline 480 & 160 & 1024 & 768 \\
\hline 128 & 160 & 1280 & 1024 \\
\hline 176 & 220 & 1600 & 1280 \\
\hline
\end{tabular}

Enquanto o primeiro conjunto procura definir uniformemente todo o espaço amostral, o segundo conjunto foi definido por sorteio, combinando um valor aleatório para a capacidade gráfica, obtido da Tabela 4, com uma largura de banda disponível escolhida aleatoriamente dentro da faixa $5 \mathrm{kbits} / \mathrm{s}$ e $1 \mathrm{Mbits} / \mathrm{s}$. Do mesmo modo que o primeiro conjunto, as saídas esperadas são determinadas com a ajuda da equação (1.1), priorizando sempre a taxa de quadros transmitidos por segundo.

Esses dois conjuntos combinados formam o conjunto que será usado no treinamento e validação das técnicas de Aprendizado de Máquina, utilizando 75\% das amostras no treinamento das redes e $25 \%$ na validação dos resultados. Os exemplos de treinamento são compostos pelas 618 amostras do primeiro conjunto de exemplos e 2095 amostras do segundo conjunto. A validação utiliza 905 amostras do segundo conjunto de exemplos, escolhidas ao acaso. 


\subsubsection{Apresentação dos dados}

Esta etapa define como o conjunto de exemplos será apresentado às técnicas de Aprendizado de Máquina. Considerando o caso de uso proposto para o presente trabalho, foram definidas duas saídas, a taxa de quadros e o tamanho dos quadros. Cada uma dessas saídas pode ser considerada em separado, ou seja, considerando que as duas saídas são independentes uma da outra. Neste caso, as duas entradas são associadas a cada saída e, portanto, cada uma das técnicas será aplicada duas vezes.

Outra possibilidade é considerar que existe uma relação de dependência entre as duas saídas. Utilizando as duas entradas, a largura de banda disponível e a capacidade gráfica do dispositivo, define-se o tamanho do quadro. Para definir a taxa de quadros por segundo, ao invés de usar as mesmas duas entradas, a capacidade gráfica do dispositivo pode ser substituída pelo tamanho do quadro, uma vez que a capacidade gráfica restringe o tamanho do quadro independente do valor assumido pela largura de banda disponível. Assim, a taxa de quadros pode ser determinada usando o tamanho de quadro definido na etapa anterior e a largura de banda disponível.

Ao tratar cada saída em separado, define-se a Apresentação em Separado dos dados ao considerar uma relação de dependência entre essas saídas, define-se a Apresentação em Combo.

\subsubsection{Configuração da Técnica de Aprendizado de Máquina}

Algumas técnicas como a Rede Bayesiana não precisam ser configuradas para serem aplicadas a um conjunto de exemplos, bastando definir as entradas e saídas deste conjunto. O mesmo não pode ser dito das Redes Neurais, como é o caso da Rede MLP. Diversos fatores podem influenciar seu funcionamento, como o número de camadas intermediárias, o número de neurônios em cada camada ou mesmo a taxa de aprendizado adotada. Para a Rede MLP esta etapa define o tempo gasto com o Aprendizado e o Erro Encontrado.

A configuração da Rede MLP é realizada de modo empírico, isto é, ajustando esses parâmetros até encontrar uma configuração que mais se aproxime da resposta esperada para o problema. Uma das dificuldades encontradas ao trabalhar com métodos empíricos na definição da configuração de uma rede neural é que o único modo de avaliar o resultado é esperar o término do treinamento e, dependendo do problema, isso pode levar dias.

Uma típica rede MLP pode ser configurada definindo o número de camadas internas ou camadas escondidas, o número de neurônios nas camadas internas, a taxa de aprendizado, 
o coeficiente Momentum e o número de épocas. Diferentes valores foram considerados, trabalhando com uma ou duas camadas intermediárias, definindo de 5 a 20 neurônios por camada e adotando diferentes valores para os coeficientes Momentum e a Taxa de Aprendizado. Como resultado, a melhor configuração encontrada utiliza duas camadas intermediárias com 10 neurônios em cada, uma taxa de Aprendizado de $0.5 \%$ e um coeficiente Momentum de 0,1. Por último resta definir o método de parada, que pode ser até atingir um coeficiente de erro mínimo ou até completar um certo numero de ciclos de treinamento ou épocas. Para o presente trabalho, considerando que não existia garantia de que o coeficiente de erro mínimo será atingido dentro de um prazo aceitável, optou por limitar o treinamento a 1 milhão de épocas.

Entretanto, como essa configuração é definida empiricamente, é possível que a configuração adotada não represente o melhor resultado possível, mas sim o melhor resultado considerando os testes realizados para o presente trabalho.

\subsubsection{Treinamento e Validação das Técnicas de Aprendizado de Máquina}

Como explicado na Seção 5.3.4, o Aprendizado de Máquina é executado em duas etapas: Treinamento e Execução. O treinamento é realizado antes do sistema ser colocado em uso, utilizando um conjunto de exemplos, no caso do presente trabalho, o conjunto definido na Seção 6.2.1. Esse treinamento torna o sistema apto a resolver problemas que sigam o padrão proposto no conjunto de exemplos. Assim, no caso do presente trabalho, ao apresentar a largura de banda disponível e a capacidade gráfica do dispositivo usado pelo usuário, respeitando o espaço amostral usado no treinamento, durante a etapa de Execução, o sistema retorna os valores esperados para a taxa de quadros e o tamanho do quadro. A validação representa um caso particular da etapa de Execução, utilizando um conjunto de exemplos com as saídas esperadas já definidas, permitindo a comparação com as saídas obtidas.

Duas técnicas de Aprendizado de Máquina foram consideradas: a rede MLP e a rede Bayesiana. Para a rede MLP adotou-se a implementação de Borgelt (BORGELT, 2007), definindo duas aplicações em $\mathrm{C}++$, cada uma delas responsável por uma das etapas de funcionamento da rede neural: Treinamento (mlpt) e Execução (mlpx). A aplicação de Treinamento permite configurar diferentes aspectos da Rede Neural, como mostra a Figura 30, utilizando uma lista de argumentos. Assim, para configurar a aplicação de Treinamento, seguindo a configuração mostrada na Seção 6.2.3, a seguinte linha de comando é definida: 


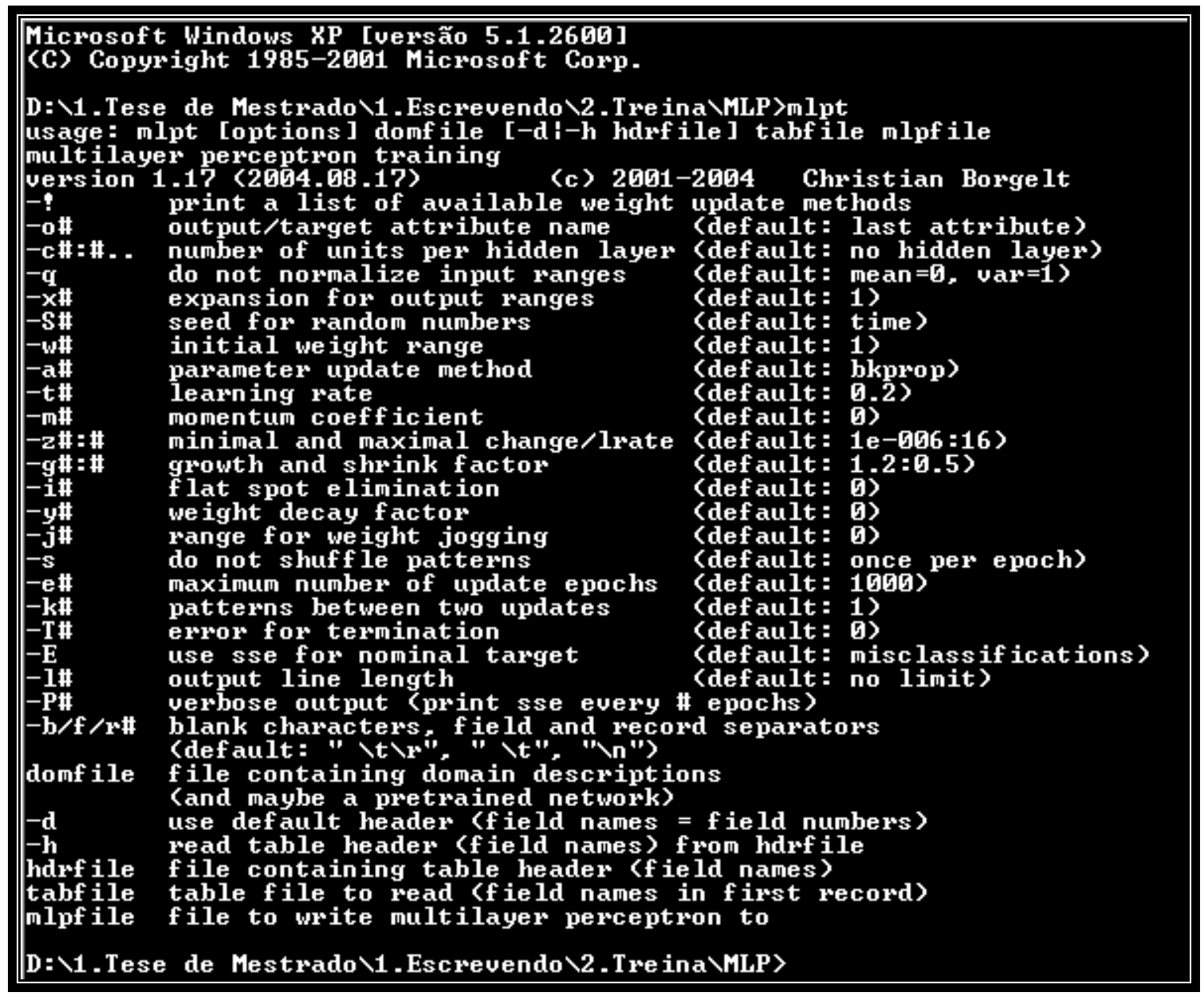

Figura 30 - Configuração da Aplicação de Treinamento de Borgelt (BORGELT, 2006)

Onde o argumento - c define o número de camadas intermediárias e os neurônios em cada camada, -t e -m definem respectivamente a taxa de aprendizado e o coeficiente momentum, por fim, o argumento -e define o número de ciclos de treinamento ou épocas que serão executados para o treinamento da rede. Os arquivos etapa1.dom e etapa1.raw apresentam o conjunto de exemplos que serão usados no treinamento. A configuração da Rede MLP é armazenada, no final do treinamento, no arquivo etapa1vs01.net, sendo usado posteriormente pela aplicação de Execução.

Como explicado, a Validação avalia o desempenho de uma técnica de Aprendizado de Máquina a partir de sua execução, comparando o resultado obtido com o resultado esperado. Assim sendo, a aplicação de Execução mostrada na Figura 31 é utilizada com um conjunto de validação ou teste e o arquivo etapa1vs01.net com as configurações da rede MLP, um conjunto de testes (teste1.raw) para validar os resultados, armazenando-os no arquivo teste1vs01.out. Os argumentos - cconf e - $\mathbf{x}$ são usados para obter a confidência da rede para cada elemento avaliado, como mostra a linha de comando: 


\section{mlpx -cconf -x etapa1vs01.net teste1.raw teste1vs01.out}

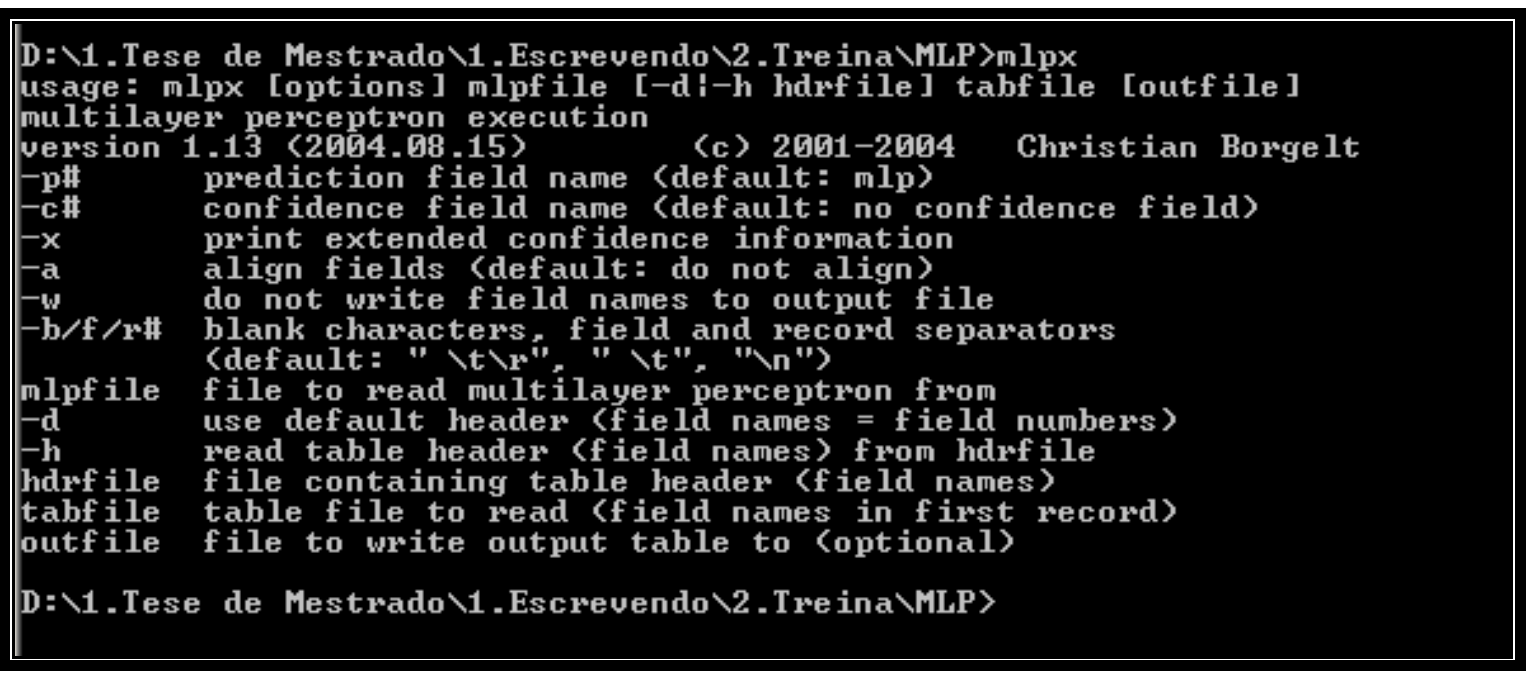

Figura 31 - Configuração da Aplicação para Executar uma Rede Neural (BORGELT, 2006)

A Tabela 7 exemplifica o grau de confidência considerando o tamanho de cada Quadro. Fsize define o valor esperado e mlp o valor sugerido pela rede MLP. O grau de confidência determina para cada tamanho de quadro existente, a chance que a rede neural considera de que seja o valor esperado.

Tabela 7 - Exemplos de Grau de Confidência

\begin{tabular}{|l|l|r|r|r|r|r|r|r|r|}
\hline fsize & mlp & A & \multicolumn{1}{|c}{ B } & C & \multicolumn{1}{c}{ D } & E & F & G & H \\
\hline B & B & $0 \%$ & $100 \%$ & $0 \%$ & $0 \%$ & $0 \%$ & $0 \%$ & $0 \%$ & $0 \%$ \\
\hline A & A & $100 \%$ & $0 \%$ & $0 \%$ & $0 \%$ & $0 \%$ & $0 \%$ & $0 \%$ & $0 \%$ \\
\hline D & D & $0 \%$ & $0 \%$ & $3 \%$ & $97 \%$ & $1 \%$ & $0 \%$ & $0 \%$ & $0 \%$ \\
\hline A & A & $100 \%$ & $0 \%$ & $0 \%$ & $0 \%$ & $0 \%$ & $0 \%$ & $0 \%$ & $0 \%$ \\
\hline E & E & $0 \%$ & $0 \%$ & $0 \%$ & $0 \%$ & $100 \%$ & $0 \%$ & $0 \%$ & $0 \%$ \\
\hline D & D & $0 \%$ & $0 \%$ & $3 \%$ & $97 \%$ & $1 \%$ & $0 \%$ & $0 \%$ & $0 \%$ \\
\hline
\end{tabular}

A rede Bayesiana foi desenvolvida utilizando a biblioteca Yale 3.2 (MIERSWA et al., 2006), utilizada no ensino de técnicas de Aprendizado de Máquina. Também são definidos duas etapas de funcionamento cada uma delas configuradas em um arquivo XML denominado experimento (Experiment), como mostra a Figura 32, definindo a etapa de Treinamento. O Yale tem uma estrutura modular que permite tanto a programação utilizando o arquivo XML com o experimento ou chamando diretamente cada módulo como um objeto dentro de um código Java. O resultado do experimento, no caso a configuração da Rede Bayesiana que resolve o problema apresentado pelo conjunto de exemplos, é armazenado no arquivo etapa1.res e utilizado para configurar a etapa de Execução, cujo arquivo XML de configuração é mostrado na Figura 33, basicamente carregando as informações do arquivo de configuração e executando os testes armazenados em teste1.arff. 


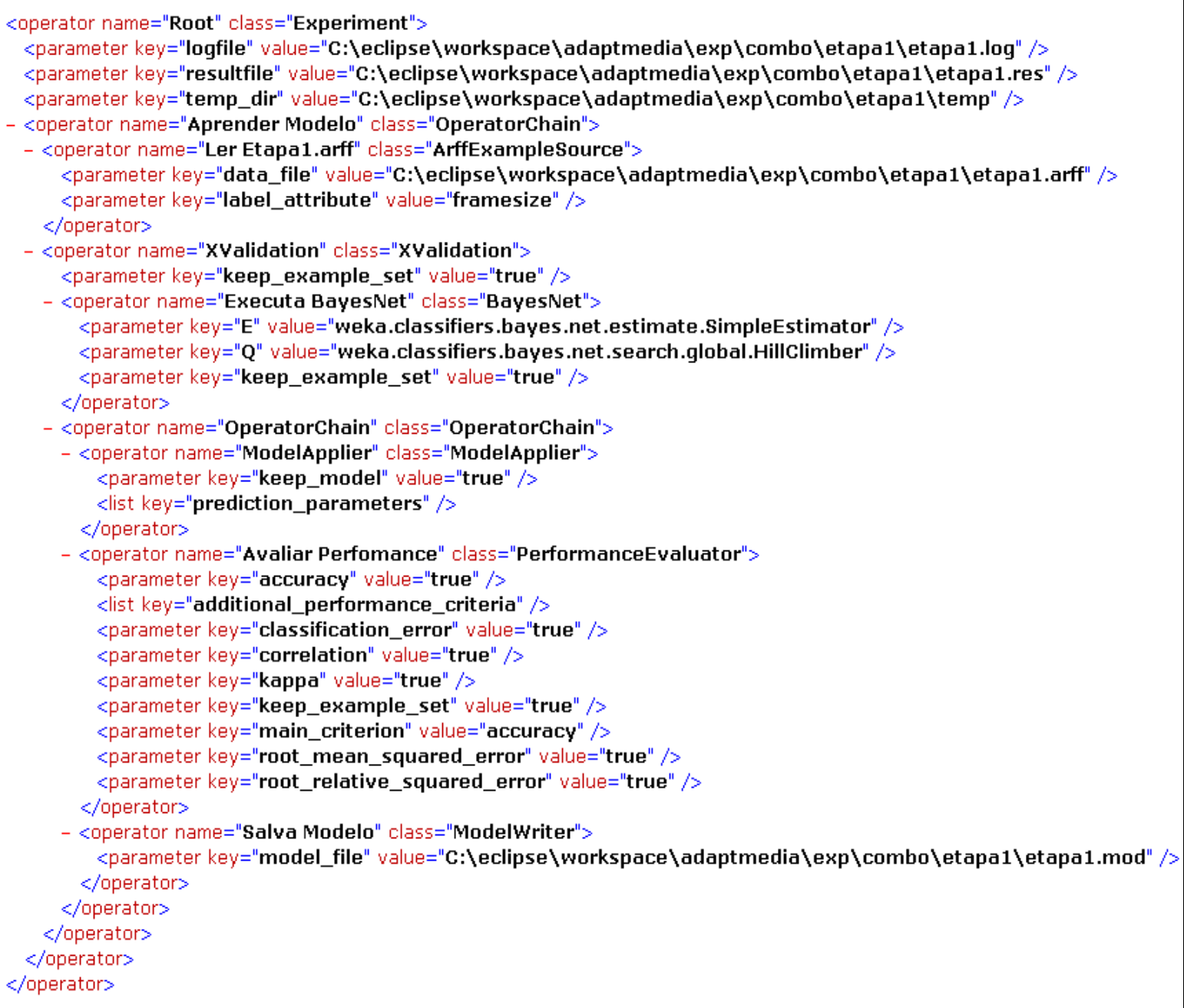

Figura 32 - Configuração do Treinamento da Rede Bayesiana usando Yale 3.2 (MIERSWA et al., 2006)

Cada uma dessas técnicas recebeu o conjunto de exemplos organizado de duas maneiras, apresentando as saídas em Separado ou apresentando-as em Combo, como explicado na Seção 6.2.2, permitindo avaliar se as duas saídas são dependentes ou não, seguindo o caso de uso proposto. Com isso, conseguiu-se avaliar a melhor técnica para o caso de uso proposto, considerando sua configuração e o modo como os dados foram apresentados e o resultado dessa avaliação será mostrado na próxima seção. 


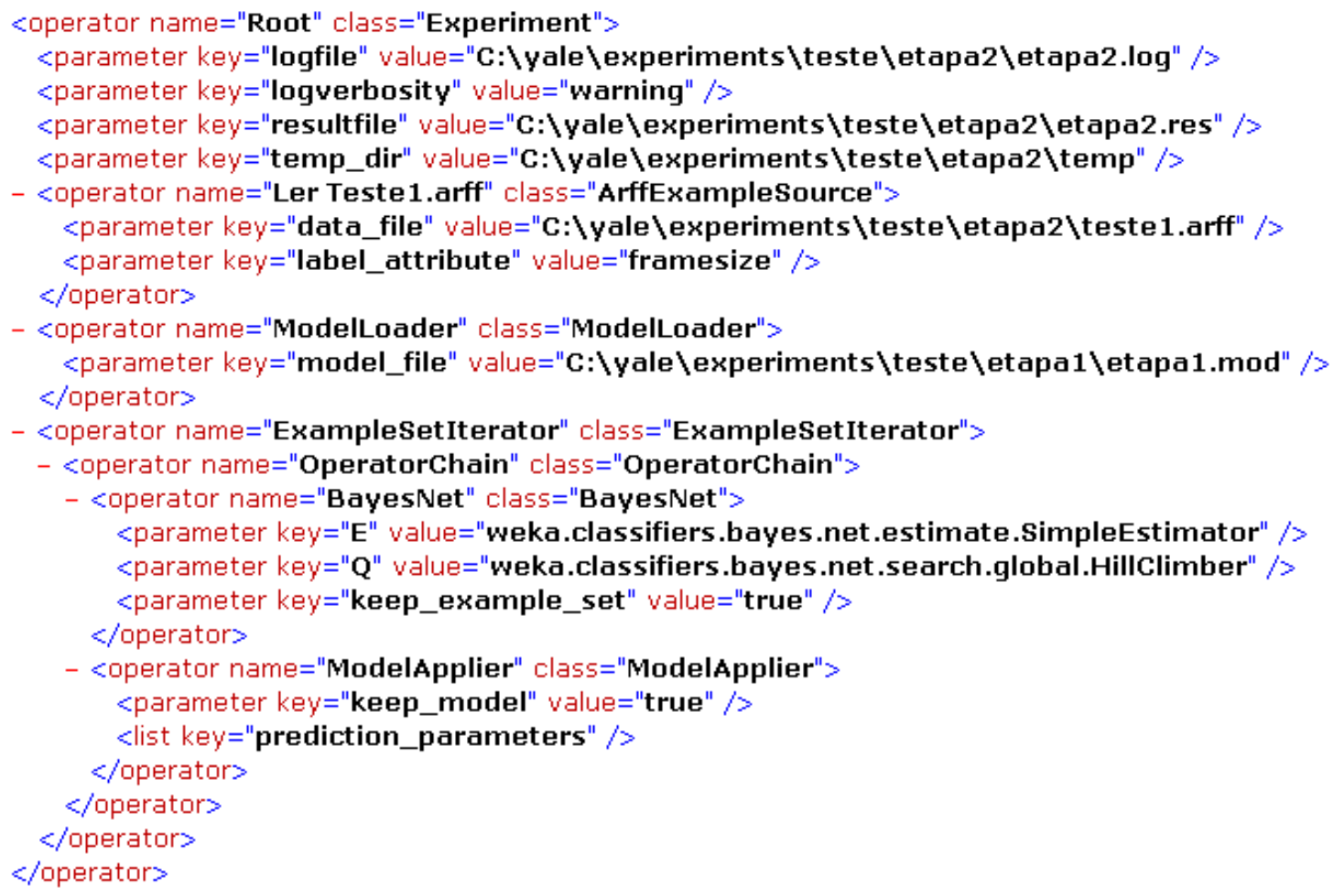

Figura 33 - Configuração da Execução de uma Rede Bayesiana usando Yale 3.2 (MIERSWA et al., 2006)

\subsection{Avaliação dos Resultados}

Dois aspectos podem ser considerados na avaliação dos resultados obtidos com cada uma das técnicas. O primeiro considera os erros encontrados na validação dos resultados, avaliando a taxa de quadros, o tamanho de cada quadro e a taxa de bits, obtida indiretamente. O segundo aspecto envolve a avaliação do desempenho de cada técnica, no caso, avaliando o tempo necessário para encontrar a configuração mais adequada para o fluxo de vídeo, considerando as necessidades do usuário.

\subsubsection{Avaliação dos erros encontrados}

O primeiro passo para a avaliação dos erros é definir uma notação, isto é, definir o que será considerado como um erro. Estatisticamente, um erro pode ser definido como sendo a diferença entre um valor computado, estimado ou medido e o valor teoricamente correto ${ }^{15}$. Para o presente trabalho, todo resultado que ultrapassar um valor esperado será considerado como erro, uma vez que o objetivo é garantir que o fluxo de vídeo execute corretamente no dispositivo do usuário, atendendo suas necessidades.

\footnotetext{
${ }^{15}$ http://www.mspc.eng.br/matm/prob_est4C.shtml Visitado pela última vez em: 15/04/2007
} 
Tabela 8 - Erros encontrados nas redes MLP e Bayesiana

\begin{tabular}{|l|l|l|} 
MLP & \multicolumn{2}{l}{ Combo } \\
\hline Taxa de Quadros & 2 & 38 \\
\hline Tamanho de Quadro & 1 & 10 \\
\hline Taxa de Bits & 3 & 100 \\
\hline Rede Bayesiana & Combo & Separado \\
\hline Taxa de Quadros & 17 & 43 \\
\hline Tamanho de Quadro & 4 & 13 \\
\hline Taxa de Bits & 21 & 108 \\
\hline
\end{tabular}

Assim, na Tabela 8 estão reunidos os erros encontrados ao executar a validação das redes MLP e Bayesiana, considerando um conjunto com 905 exemplos para as saídas organizadas em Separado ou Combo. A Rede MLP apresenta os melhores resultados, com um erro de $0,33 \%$ contra $11 \%$ da Rede Bayesiana, considerando a taxa de bits e organizado em combo. Os resultados mostram ainda que existe uma relação de dependência da taxa de bits com o tamanho dos quadros, uma vez que os erros encontrados ao utilizar as saídas organizadas em Combo foram menores que os erros obtidos com a organização em Separado.

\subsubsection{Desempenho das Redes}

A avaliação do desempenho das Redes MLP e Bayesiana foi realizada considerando 8 conjuntos de exemplos, compostos por diferentes quantidades de elementos, como segue: 1, $10,50,100,500,1000,2000$ e 3000 elementos. Cada uma das redes executou trinta vezes cada um desses 8 conjuntos, com o objetivo de determinar o tempo médio gasto. O resultado dessa avaliação foi reunid o nas Tabela 9 e Tabela 10, respectivamente definindo o tempo gasto com as redes MLP e Bayesiana.

Considerando as saídas organizadas como Combo, observando os dados das duas tabelas é possível notar que conforme aumenta o número de elementos processados em lote (batch mode) por cada rede, aumenta o tempo gasto para processar cada conjunto. Mas enquanto esse aumento é suave para a rede MLP, conforme mostra o gráfico da Figura 34, com a média de tempo estimada para a rede MLP, o tempo médio gasto com a rede Bayesiana sofre um aumento abrupto, quando o número de elementos em cada conjunto ultrapassa a marca dos 100 elementos. Como conseqüência, à medida que o número de unidades processadas em lote aumenta, o tempo gasto por unidade diminui em uma proporção maior quando a rede MLP é usada. 
Tabela 9 - Tempo estimado para execução da rede MLP (em milisegundos)

\begin{tabular}{|l|l|l|l|l|} 
& \multicolumn{2}{|c|}{ Combo } & \multicolumn{2}{c|}{ Separado } \\
\hline & Media & Por unidade & Media & Por unidade \\
\hline $\mathbf{1}$ & 682,84 & 682,84 & 643,44 & 643,44 \\
\hline $\mathbf{1 0}$ & 684,58 & 68,458 & 632,4 & 63,24 \\
\hline $\mathbf{5 0}$ & 684,12 & 13,6824 & 631,94 & 12,6388 \\
\hline $\mathbf{1 0 0}$ & 697 & 6,97 & 641,68 & 6,4168 \\
\hline $\mathbf{5 0 0}$ & 719,38 & 1,43876 & 660,64 & 1,32128 \\
\hline $\mathbf{1 0 0 0}$ & 753,12 & 0,75312 & 683,74 & 0,68374 \\
\hline $\mathbf{2 0 0 0}$ & 823,44 & 0,41172 & 728,44 & 0,36422 \\
\hline $\mathbf{3 0 0 0}$ & 886,26 & 0,29542 & 787,18 & 0,262393 \\
\hline
\end{tabular}

Tabela 10 - Tempo estimado para execução da rede Bayesiana (em milisegundos)

\begin{tabular}{|l|l|l|l|l|} 
& \multicolumn{2}{|c|}{ Combo } & \multicolumn{2}{c|}{ Separado } \\
\hline & Media & Por unidade & Media & por unidade \\
\hline $\mathbf{1}$ & 332,84 & 332,84 & 292,2 & 292,2 \\
\hline $\mathbf{5}$ & 352,28 & 70,456 & 310,72 & 62,144 \\
\hline $\mathbf{1 0}$ & 358,94 & 35,894 & 327,7 & 32,77 \\
\hline $\mathbf{5 0}$ & 503,5 & 10,07 & 470,38 & 9,4076 \\
\hline $\mathbf{1 0 0}$ & 604,5 & 6,045 & 588,24 & 5,8824 \\
\hline $\mathbf{5 0 0}$ & 1150 & 2,3 & 1275,94 & 2,55188 \\
\hline $\mathbf{1 0 0 0}$ & 1758,74 & 1,75874 & 3119,68 & 3,11968 \\
\hline $\mathbf{2 0 0 0}$ & 2964,08 & 1,48204 & 5834,68 & 2,91734 \\
\hline $\mathbf{3 0 0 0}$ & 4125,92 & 1,375306667 & 8263,44 & 2,75448 \\
\hline
\end{tabular}

O desempenho da rede Bayesiana apresenta melhores resultados ao lidar com um conjunto pequeno de unidades em cada lote, sendo a melhor opção para trabalhar com conjuntos com até 50 unidades. No entanto, na média, a rede MLP apresenta o melhor desempenho de tempo.

\subsection{Considerações Finais}

A avaliação da Rede MLP e Bayesiana realizada neste Capítulo, confirmou que a rede MLP é mais adequada na adaptação de um fluxo de vídeo, considerando o caso de uso proposto. Isso é justificado considerando a capacidade da rede MLP em aproximar resultados, conseguindo ir além dos dados utilizados no treinamento, algo que a rede Bayesiana é incapaz de realizar, tendo dificuldades em determinar uma solução quando as entradas utilizadas estão fora do perfil definido pelo conjunto de exemplos usado no treinamento.

Considerando o desempenho de ambas as redes, a rede Bayesiana é a melhor opção para trabalhar na análise de pequenos conjuntos, conseguindo processar um mesmo conjunto com a metade do tempo gasto pela rede MLP. Entretanto, ao considerar todos os conjuntos a rede MLP é mais adequada. 

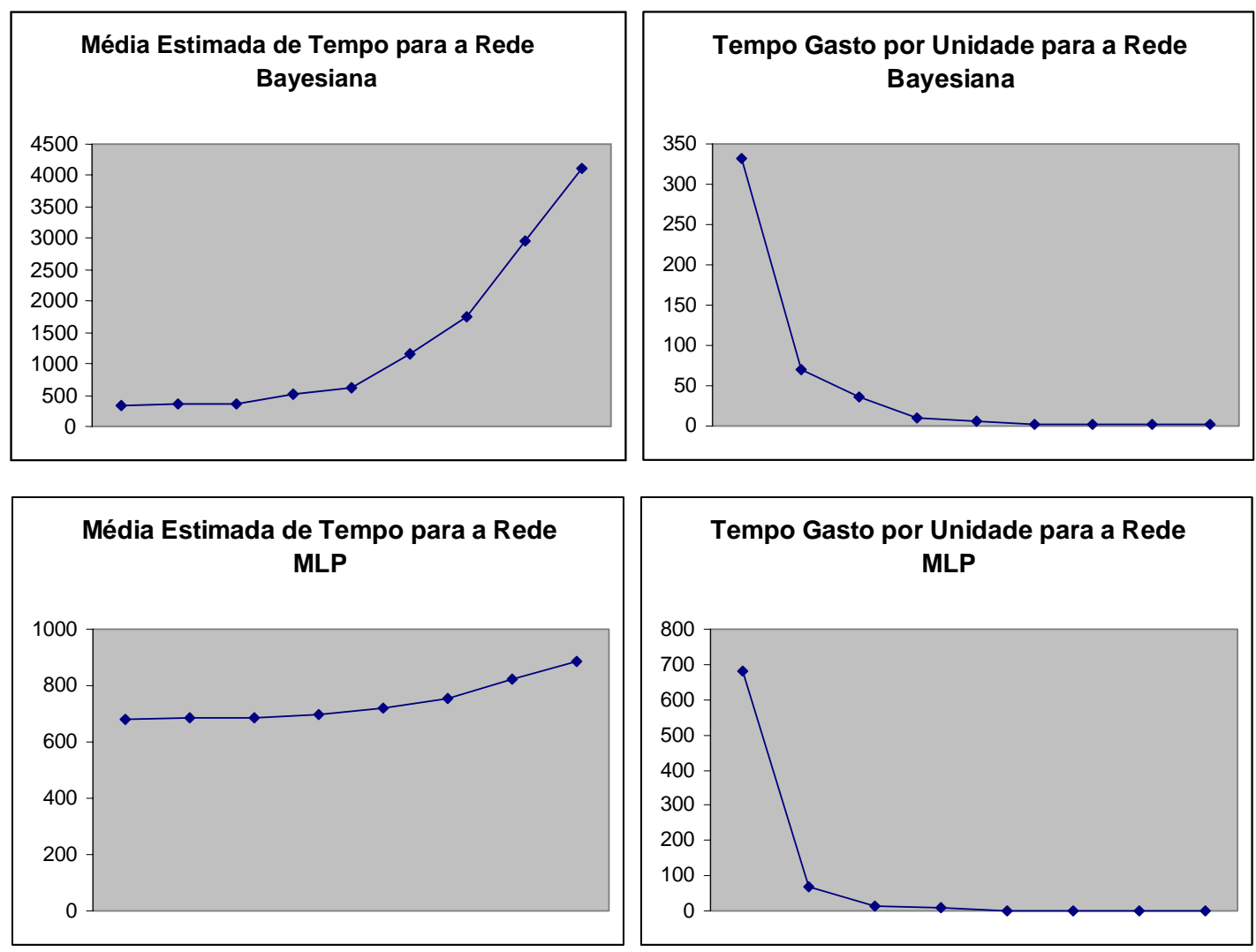

Figura 34 - Estimativa de Tempo Gasto 
Capítulo7

\section{Conclusões}

O presente trabalho apresentou um Mecanismo de Decisão com o propósito de auxiliar o processo de adaptação dinâmica de um fluxo de vídeo. Este mecanismo é capaz de identificar a configuração para o fluxo de vídeo mais adequada, considerando as informações contextuais obtidas do usuário.

Para identificar a configuração mais adequada, o Mecanismo de Decisão utiliza uma técnica de Aprendizado de Máquina. Com essa técnica é possível diminuir a dependência do conhecimento do projetista na construção do sistema de adaptação, ao mesmo tempo em que a lógica de adaptação é separada do processo decisório. Considerando as características do processo de adaptação, duas técnicas de Aprendizado de Máquina foram estudadas, por melhor abordarem o problema proposto: As redes neurais, representadas pela rede MLP e a Inferência Bayesiana, representada pela Rede Bayesiana ou Crença Bayesiana.

O caso de uso estudado considerou tanto a restrição de rede, como a restrição do dispositivo, no caso sua capacidade gráfica e no final de um extenso processo de avaliação, a rede MLP foi escolhida como a mais adequada na adaptação de um fluxo de vídeo, por apresentar uma baixa taxa de erro e, em média, ter um bom desempenho.

A seguir serão discutidas as contribuições deste trabalho para a comunidade (Seção 7.1), as propostas para sua continuidade (Seção 7.2), as dificuldades encontradas (Seção 7.3) e os artigos resultantes dele (Seção 7.4).

\subsection{Contribuições}

O presente trabalho contribui de diferentes maneiras com a comunidade, reunindo diferentes áreas de conhecimento como a Computação Ubíqua e o Aprendizado de Máquina, relacionando trabalhos que representam o estado da arte em adaptação de conteúdo ou mesmo definindo uma nova maneira de representar contextualmente um dispositivo. Entretanto, de todas as contribuições deste trabalho, três se destacam: a extensão do arcabouço proposto por Goularte, acrescentando a representação de dispositivo; o Mecanismo de Decisão, separando a lógica de adaptação do processo decisório e a Avaliação do uso das técnicas de Aprendizado de Máquina na adaptação de um fluxo de vídeo. 


\subsubsection{Modelo para representação contextual de dispositivos}

Como explicado na Seção 2.3, Goularte usou a definição de contexto proposta por Dey et al. (DEY et al., 2001) para desenvolver um arcabouço para representação de contexto (GOULARTE, 2003). Para demonstrar seu arcabouço, Goularte definiu uma biblioteca representando o contexto de Usuário, utilizando XML Schema, deixando em aberto os demais tipos contextuais.

Estendendo o arcabouço proposto por Goularte, na Seção 5.3.3 definiu-se um modelo para representação de dispositivos, descrevendo-os de um modo organizado, hierárquico e extensível (EISINGER et al., 2005). Esse modelo tem como propósito o compartilhamento das informações dos dispositivos entre aplicações cientes de contexto, como é o caso do sistema de Adaptação de Vídeo. Do mesmo modo que Goularte representou o contexto do Usuário, uma biblioteca contextual foi definida utilizando XML Schema. No entanto, foi preciso realizar algumas adaptações nessa representação, para possibilitar por exemplo, a representação de dispositivo como sendo uma extensão de um ou mais dispositivos, permitindo representar dispositivos compostos.

\subsubsection{Mecanismo de Decisão}

A maioria dos trabalhos envolvendo a adaptação de vídeo preocupa-se apenas com o modo como o vídeo será adaptado, não considerando como essa adaptação será definida, isto é, o processo decisório que dá suporte a adaptação. Manzato definiu em seu trabalho uma arquitetura para a adaptação de vídeo utilizando informações de contexto obtidas do usuário para adaptar o fluxo de vídeo (MANZATO, 2006). Usando regras de decisão, Manzato define como essas informações contextuais serão usadas para adaptar esse fluxo. Entretanto, essa abordagem é limitada ao conhecimento que o projetista tem sobre essas informações e seu relacionamento com o sistema e conforme a complexidade do problema aumenta, fica difícil definir regras que considerem todos os aspectos do problema.

O Mecanismo de Decisão substitui essas regras, separando a lógica usada na adaptação do fluxo do processo de decisão, sendo responsável por processar as informações contextuais, encontrando uma configuração que melhor atenda as necessidades do usuário, além de gerenciar o processo de adaptação, evitando por exemplo, que o servidor de vídeo fique sobrecarregado. Além disso, ao utilizar Aprendizado de Máquina no processamento das informações contextuais, é reduzida a dependência do conhecimento do projetista.

Assim, o Mecanismo de Decisão age como um gerente, ou um controlador, definindo as políticas para a transmissão e criação de novos fluxos de vídeo. 


\subsubsection{Comparação entre as Redes MLP e Bayesiana}

Outra contribuição deste trabalho é a comparação das técnicas de aprendizado de máquina considerando as informações de contexto usadas na adaptação dinâmica de vídeo.

Essa comparação envolveu o levantamento dos dados necessários para realizar o treinamento e validação dos resultados obtidos com essas técnicas, como pode ser visto nos Capítulo 6. Como resultado, considerando o caso de uso estudado, das duas técnicas, a rede MLP apresentou os melhores resultados, considerando a taxa de erros e o desempenho médio. Como explicado, isso foi uma conseqüência da capacidade da rede MLP de aproximar resultados.

\subsection{Trabalhos Futuros}

Considerando a contribuição do presente trabalho, algumas sugestões podem ser feitas para sua continuidade e/ou melhoria, como segue:

- Integração com um servidor de vídeo. Até o presente momento, o teste do protótipo para o Mecanismo de Decisão utilizou apenas uma simulação das possíveis entradas, faltando uma avaliação do funcionamento do sistema integrado a um servidor de vídeo, procurando avaliar o impacto no desempenho com a adição do Mecanismo de Decisão, além de validar o trabalho com um resultado prático.

- Coleta das informações contextuais do cliente. Como já foi discutido na Seção 5.3.2, é limitado o processo de coleta das informações contextuais, seja por depender que o navegador tenha suporte ou que o Javascript esteja habilitado ou por adotar uma abordagem semi-automática e inadequada para a adaptação dinâmica. Assim, é preciso encontrar alternativas para a obtenção de informações contextuais.

- Extensão da aplicação para adaptação de conteúdo. Um fluxo de vídeo pode ser tratado como um tipo especializado de conteúdo e, considerando que o Mecanismo de Decisão trabalha com o processamento de informações, não importando seu conteúdo ou contexto, é possível estender essa abordagem, trabalhando com a adaptação dinâmica de conteúdo.

- Considerar outros parâmetros de configuração do fluxo de vídeo. Outros parâmetros podem ser considerados, como o codec, ou padrão de codificação adotado (mp4, divx, mpeg2, quicktime), a profundidade de cores (color deph) ou qualidade desejada, de modo objetivo (THANG et al., 2006), (SHEN et al., 2006).

- Considerar o uso da Rede RBF. A rede RBF é uma rede neural que segue o paradigma de aprendizado supervisionado, sendo uma alternativa a rede MLP. Alguns 
testes foram realizados utilizando uma implementação da rede RBF desenvolvida por Borgelt (BORGELT, 2007). Entretanto, cada ciclo de treinamento levava mais de dez horas e a dificuldade em encontrar parâmetros válidos para a configuração dessa rede, resultou na sua exclusão do presente trabalho. Assim, é interessante avaliar o uso da Rede RBF para resolver o problema da adaptação do fluxo de vídeo.

\subsection{Dificuldades Encontradas}

A maior dificuldade encontrada durante o desenvolvimento do presente trabalho foi à definição da configuração mais adequada para a rede MLP. Por ser um processo empírico, é necessário testar diferentes combinações antes de encontrar a mais adequada. Um dos problemas das redes neurais é a necessidade de rodar todo o treinamento para só então avaliálas, embora seja possível definir um arquivo de lote para executar esses treinamentos para diferentes combinações de parâmetros, a avaliação dos resultados ainda depende de um agente humano.

Outras dificuldades que podem ser citadas são:

- A definição do conjunto de exemplos usado no treinamento das técnicas de Aprendizado de Máquina.

- A construção do Modelo para Representação de Dispositivos de modo a permitir a representação de dispositivos compostos, isto é, dispositivos que possuem outros dispositivos como componentes.

\subsection{Publicações Resultantes}

$\mathrm{O}$ presente trabalho resultou até o presente momento em dois artigos. O primeiro artigo descreve o modelo para descrição de dispositivos que estendeu o arcabouço proposto por Goularte (GOULARTE, 2003), enquanto que o segundo descreve as primeiras experiências com a adaptação dinâmica de vídeo, comparando a tecnologia SureStream da Real Networks com uma implementação utilizando redes neurais, no caso uma rede MLP, na adaptação da largura de banda utilizada.

\subsubsection{Artigo: Device Descriptions for Context-Based Content Adaptation}

Abstract: Nowadays, networks can be accessed by multiple devices with different characteristics. Some of these characteristics such as low processing power and memory capacity restrict the access to multimedia content. Researchers have then focused on making automatic system adaptations in order to present content according to devices' capabilities. 
Most of the works on this area include the description of hardware and software devices' features using the CC/PP specification. However, the indiscriminate and direct use of CC/PP makes it difficult to generate consistent descriptions when using the same device into different contexts. The novel of this paper is an alternative method to describe devices' features. This method aims to facilitate context-based content adaptation decisions to be made before content delivery. This paper also presents an application for content adaptation that uses our method.

Referência: EISINGER, R.; MANZATO, M. G.; GOULARTE, R. Device Descriptions for Context-Based Content Adaptation. In: LATIN AMERICAN WEB CONGRESS (LA-WEB). 2005, Buenos Aires. Proceedings. Los Alamitos: IEEE, 2005, p. 121-129.

Classificação do Simpósio: Internacional Regional (América Latina), Qualis - B

\subsubsection{Artigo: Towards context-based dynamic video adaptation}

Abstract: Nowadays, many devices with different characteristics can be used to access a multimedia content. Some of these characteristics, like memory capacity and screen resolution, turn restricted the access to this content. Researchers have been working in automatically adapting the system, in according with the device capabilities. However, most of this works only consider the network condition, such as bandwidth and packet loss, offering services in a static way. This work presents an alternative for video adaptation. Using a Neural Network we analyze data, suchas devices capabilities, user's preferences or network condition, in order to obtain the most adequate coder's input parameters that will adapt content matching devices' restrictions or users' needs.

Referência: EISINGER, R.. G.; GOULARTE, R. Towards context-based dynamic video adaptation In: BRAZILLIAN SYMPOSIUM ON MULTIMEDIA AND THE WEB (WEBMEDIA). 11., 2005, P. Caldas. Proceedings. N. York: ACM Press, 2005, p. 1-3.

Classificação do Simpósio: Nacional, Qualis A (CAPES) 


\section{Referências Bibliográficas}

(ABOWD; MYNATT, $\quad$ ABOWD, G. D.; MYNATT, E. D. (2000) Charting Past, 2000)

(ABOWD et al., 2002)

Present, and Future Research in Ubiquitous Computing.

ACM Transactions on Conputer-Human Interaction, v. 7, n. 1, p. 29-58, 2000.

ABOWD, G. D.; MYNATT, E. D.; RODDEN, T. (2002).

The Human Experience. IEEE Pervasive Computing 1, 1 (Jan. 2002), p. 48-57.

(ALPAYDIN, 2004) ALPAYDIN, E. (2004) Introduction To Machine Learning Cambridge, MA. MIT Press. 415pg

(BARNARD, 1958) BARNARD, G. A., BAYES, T (1958) Studies in the History of Probability and Statistics: IX. Thomas Bayes's Essay Towards Solving a Problem in the Doctrine of Chances Biometrika, Vol. 45, No. 3/4 (Dec., 1958), pp. 293-315

(BATES; BATES, 2005) BATES T.; BATES A.W. (2005) Technology, E-Learning and Distant Education. Routledge Publishing (UK)

(BAILEY; THOMPSON, BAILEY, D. AND THOMPSON, D. (1990). How to 1990) develop neural-network applications. AI Expert 5, 6 (Apr. 1990), 38-47.

(BEAUDIN et al., 2004) BEAUDIN, J., INTILLE, S., AND TAPIA, E. M. (2004). Lessons learned using ubiquitous sensors for data collection in real homes. In CHI '04 Extended Abstracts on Human Factors in Computing Systems (Vienna, Austria, April 24 - 29, 2004). CHI '04. ACM Press, New York, NY, 1359-1362.

(BIRNEY, 2003) BIRNEY B., "Microsoft's intelligent streaming," 2003. [Online].Available:

http://www.microsoft.com/windows/windowsmedia/howt $\underline{\mathrm{o} / \operatorname{articles} / \text { intstreaming.aspx }}$ 
(BOURGEOIS et al., 2003) BOURGEOIS, J., MORY, E., AND SPIES, F. (2003). Video transmission adaptation on mobile devices. J. Syst. Archit. 49, 10-11 (Nov. 2003), 475-484.

(BORGELT, 2007) BORGELT, C. (2007) Implementação de Redes MLP e RBF [Online] Disponível em: http://fuzzy.cs.unimagdeburg.de/ borgelt/index.html (visitado em 13/02/2007)

(BROTHERTON; BROTHERTON, J. A. AND ABOWD, G. D. (2004). ABOWD, 2004) Lessons learned from eClass: Assessing automated capture and access in the classroom. ACM Trans. Comput.-Hum. Interact. 11, 2 (Jun. 2004), 121-155.

(CHALMERS, 2002) CHALMERS, D. (2002). Contextual Mediation to Support Ubiquitous Computing. Tese de Doutorado, Imperial College of Science, Technology and Medicine, Universidade de Londres.

(CHANG; VETRO, 2005) CHANG, S-F; VETRO, A., (2005) "Video Adaptation: Concepts, Technologies and Open Issues", Proceedings of the IEEE, ISSN: 018-9219, Vol. 93, Issue 1, pp. 148-158, January 2005

(CHEN;ZAKHOR, 2004) CHEN M. AND ZAKHOR A., (2004) Rate control for streaming video over wireless, INFOCOM 2004. Twentythird AnnualJoint Conference of the IEEE Computer and Communications Societies, vol. 2, pp. 1181-1190, 2004.

(CROWLEY et al., 2002) CROWLEY, J. L.; COUTAZ, J.; REY, G.; REIGNIER, P. (2002). Perceptual Components for Context-aware Computing. In Proceedings of the International Conference on Ubiquitous Computing (UbiComp), p. $117-134$. 
(DAVIDSON;HAN, 2006) DAVIDSON, P. L. AND HAN, J. Y. (2006). Synthesis and control on large scale multi-touch sensing displays. In Proceedings of the 2006 Conference on New interfaces For Musical Expression (Paris, France, June 04 - 08, 2006). New Interfaces For Musical Expression. IRCAM - Centre Pompidou, Paris, France, 216-219.

(DEY; ABOWD, 2000) DEY, A.K. ABOWD, G.D. (2000) Towards a Better Understanding of Context and Context-Awareness. CHI 2000 Workshop on the What, Who, Where, When, and How of Context-Awareness (2000)

(DEY et al., 2001) DEY, A., ABOWD, G., AND SALBER, D. (2001). A conceptual framework and a toolkit for supporting the rapid prototyping of context-aware applications. HumanComputer Interaction, 16(2-4).

(DINOFF et al., 2006) DINOFF, R., HULL, R., KUMAR, B., LIEUWEN, D., AND SANTOS, P. (2006). Learning and managing user context in personalized communications services. In Proceedings of the international Workshop in Conjunction with AVI 2006 on Context in Advanced interfaces (Venice, Italy, May 23 - 23, 2006). CAI '06. ACM Press, New York, NY, 33-36.

(DIX et al., 2000) DIX, A.; RODDEN, T.; DAVIES, N.; TREVOR, J.; FRIDAY, A.; PALFREYMAN, K. (2000). Exploiting Space and Location as a Design Framework for Interactive Mobile Systems. ACM Transactions on Computer-Human Interaction (TOCHI) 7(3), 285-321.

(DRISCOLL, 2000) DRISCOLL, G. (2000) The essential guide to digital settop boxes and interactive TV. Ed. Prentice Hall, 2000.

(DRYFUS, 2005) DRYFUS, G. (2005) Neural Networks: Methodology and Applications. Heidelberg, Springer-Verlag Berlin Heidelberg, 2005. 497 pp. 
(DOURISH, 2004) DOURISH, P. (2004). What we talk about when we talk about context. Personal Ubiquitous Computation 8, 1 (Feb. 2004), 19-30.

(EISINGER et al., 2005) EISINGER, R., MANZATO, M. G., AND GOULARTE, R. (2005). Devices Descriptions for Context-Based Content Adaptation. In Proceedings of the Third Latin American Web Congress (October 31 - November 02, 2005). LA-WEB. IEEE Computer Society, Washington, DC, 121.

(EISINGER; GOULARTE, EISINGER, R. AND GOULARTE, R. (2005). Towards 2005) context-based dynamic video adaptation. In Proceedings of the 11th Brazilian Symposium on Multimedia and the Web (Pocos de Caldas - Minas Gerais, Brazil, December 05 - 07, 2005). R. P. Fortes, Ed. WebMedia '05, vol. 125. ACM Press, New York, NY, 1-3.

(FERREIRA; MELlO, FERREIRA, E. A.; MELLO, R. F. (2004) Avaliação de 2004) Desempenho de Protocolos e Bibliotecas de Comunicação entre Processos. In: INTERNATIONAL INFORMATION AND TECHNOLOGIES SYMPOSIUM. 3., 2004, S. Carlos. Proceedings. Upper Saddle River: [s.n.], 2004.

(FERNANDES et al., 2004) FERNANDES, J, LEMOS, G., SILVEIRA, G. (2004) "Introdução à Televisão Digital Interativa: Arquitetura, Protocolos, Padrões e Práticas", In Jornada de Atualização em Informática do Congresso da Sociedade Brasileira de Computação.

(GEYER et al., 2005) GEYER, W., RICHTER, H., AND ABOWD, G. D. (2005). Towards a Smarter Meeting Record--Capture and Access of Meetings Revisited. Multimedia Tools Applications. 27, 3 (Dec. 2005), 393-410 
(GOUlARTE, 2003) GOUlARTE, R. (2003). Personalização e Adaptação de Conteúdo Baseadas em Contexto para TV Interativa. Tese de Doutorado, Instituto de Ciências Matemáticas e de Computação (ICMC-USP).

(GOUlARTE et al., 2006) GOUlARTE, R.; PIMENTEL, M. G. C.; MOREIRA, E. S. (2006) Context-Aware Support in Structured Documents for Interactive-TV. Multimedia Systems, v. 11, n. 4, p. 367-382, 2006.

(HAN, 2006)

HAN, J. Y. (2006). Multi-touch interaction wall. In ACM SIGGRAPH 2006 Emerging Technologies (Boston, Massachusetts, July 30 - August 03, 2006). SIGGRAPH '06. ACM Press, New York, NY, 25.

(HANDLEY; JACOBSON, HANDLEY, M.; JACOBSON, V. (1998) SDP: Session 1998)

Description Protocol. Internet Engineering Task Force, RFC 2327, Abril de 1998.

(HAYKIN, 2001)

(HEATON, 2005) HAYKIN, S. (2001) Redes Neurais: Princípios e Práticas. Segunda Edição. Bookman. 900pgs

HEATON, J. T. (2005) Introduction to Neural Networks with Java. Heaton Research Inc. 380pgs.

(HUIFENG et al., 2006) HUIFENG S., XIAOYAN S., FENG W., SHIPENG L. (2006) Scalable Video Adaptation for IPTV. IPTV Workshop China, 2006.

(INDULSKA, J. et al., INDULSKA, J. et al. (2003) Experiences in Using CC/PP 2003) in Context-Aware Systems. In: International Conference On Mobile Data Management. 4., 2003, Melbourne. Proceedings. Heidelberg: Springer-Verlag, 2003. p. 247261. (Lecture Notes in Computer Science, 2574).

(JANNACH et al., 2006) JANNACH, D.,LEOPOLD, K.,TIMMERER, C., HELLWAGNER, H., (2006) A knowledge-based framework for multimedia adaptation. Journal of Applied Intelligence. Volume 24, number 2. Kluwer Academic Publishers. Pg 109-125. 2006 
(JONES, 2006)

JONES, V. M. (2006). Model Driven Development of mHealth Systems (with a Touch of Formality). In Proceedings of the Fourth Annual IEEE international Conference on Pervasive Computing and Communications Workshops (March 13 - 17, 2006). PERCOMW. IEEE Computer Society, Washington, DC, 580.

(KANDEL et al., 2000) KANDEL E.R., SCHWARTZ, J.H., JESSELL, T.M. (2000). Principles of Neural Science, 4th ed., McGrawHill, New York.

(KIM et al., 2003) KIM J.G, WANG Y, CHANG S.F., (2003) Contentadaptive utility-based video adaptation. In: Multimedia and Expo, 2003. ICME '03. Proceedings. 2003 International Conference Vol 3 pp: III- 281-4, 2003

(LEMLOUMA; LAYAIDA, LEMLOUMA, T.; LAYAIDA, N. SMIL Content 2003) Adaptation for Embebbed Devices. SMIL Europe 2003, 2003.

(LAURENT;

LAURENT S. S.; FITZGERALD M. (2005) XML Pocket FITZGERALD, 2005) Reference. O'Reilly Publisher. pg 47-50

(LEI; GEORGANAS, 2001) LEI, Z.; GEORGANAS,N., (2001) “Context-based media adaptation in pervasive computing," in Proc. of Canadian Conferenceon Electrical and Computer Engineering, 2001.

(LEI; GEORGANAS, 2005) LEI, Z. AND GEORGANAS, N. D. (2005). Adaptive video transcoding and streaming over wireless channels. Journal of Systems and Software. 75, 3 (Mar. 2005), 253270.

(LÉVY, 1993) LÉVY, P. (1993). As tecnologias da inteligência: o futuro do pensamento na era da informática. Tradução Carlos Irineu da Costa. Rio de Janeiro: Ed. 34, 1993. p. 10. 
(LINCK et al., 2006) ～LINCK S., MORY E., BOURGEOIS J., DEDU E., SPIES F., (2006) Video Quality Estimation of DCCP Streaming over Wireless Networks, pdp, pp. 405-412, 14th Euromicro International Conference on Parallel, Distributed, and Network-Based Processing (PDP'06), 2006.

(LUM; LAU, 2005) LUM, W. Y. AND LAU, F. C. (2005). Relationshipaware Content Adaptation of Structured Web Documents for Mobile Computing. In Proceedings of the 11th international Conference on Parallel and Distributed Systems (Icpads'05) - Volume 01 (July 20 - 22, 2005). ICPADS. IEEE Computer Society, Washington, DC, 168174

(MCCULLOCH, 1943) MCCULLOCH, W. W. (1943) A Logical Calculus of the Ideas Imminent in Nervous Activity, Bulletin of Mathematical Biophysics, vol. 5, pp. 115-133, 1943.

(MAGGIORINI; RIBONI, MAGGIORINI, D. AND RIBONI D. (2005), Continuous 2005) media adaptation for mobile computing using coarsegrained asynchronous notifications In 2005 Symposium on Applications and the Internet, 2005. pp. 162-165.

(MANZATO, 2006) Manzato, M. G., (2006) Adaptação de Vídeo ao Vivo apoiada em informações de contexto. Dissertação de Mestrado. ICMC/USP.

(MANZATO; MANZATO, M. G. AND GOULARTE, R. 2006. GOULARTE, 2006) Transcoding Evaluation in Live Video Adaptation. In Proceedings of the Fourth Latin American Web Congress (La-Web'06) - Volume 00 (October 25 - 27, 2006). LAWEB. IEEE Computer Society, Washington, DC, 203-208 
(MIERSWA et al., 2006) MIERSWA， I.; WURST， M.; KLINKENBERG， R.; SCHOLZ, M.; EULER, T. (2006). YALE: Rapid Prototyping for Complex Data Mining Tasks. In Proceedings of the 12th ACM SIGKDD International Conference on Knowledge Discovery and Data Mining (KDD 2006), ACM Press, 2006.

(MITCHEL, 1997) MITCHEL T.M, (1997) Machine Learning (Hardcover). McGraw-Hill Science/Engineering/Math; 1 edition (March 1, 1997) 432pg.

(MOHAN et al., 1999) MOHAN R., SMITH, J. R., LI C. S. (1999) Adapting Content to Client Resources in the Internet, p. 9302, 1999 IEEE International Conference on Multimedia Computing and Systems (ICMCS'99) - Volume 1, 1999.

(NETO et al., 2005) NETO, R. F., MACEDO, A. A., CAMACHOGUERRERO, J., AND DA GRAÇA PIMENTEL, M. 2005. Configurable semantic services leveraging applications context-aware. In Proceedings of the 11th Brazilian Symposium on Multimedia and the Web (Pocos de Caldas - Minas Gerais, Brazil, December 05 - 07, 2005). R. P. Fortes, Ed. WebMedia '05, vol. 125. ACM Press, New York, NY, 1-9.

(ÖNÜR et al., 2004) ÖNÜR, Ö.D. DREGE, P. PERKIS, A. ALATAN, A. A., SOLBERG,R.; (2004) Delivering Adapted Content to Terminals Using MPEG-21 Digital Items Accepted in 7th COST 276 Workshop 4-5 November 2004, Ankara, Turkey.

(PASCOE et al., 2000) PASCOE, J., RYAN, N., AND MORSE, D. (2000). Using while moving: HCI issues in fieldwork environments. ACM Trans. Comput.-Hum. Interact. 7, 3 (Sep. 2000), 417-437. 
(PEREIRA; EBRAHIMI, PEREIRA, F.; EBRAHIMI, T. (2002) The MPEG-4 Book 2002) Upper Saddle River: Prentice Hall PTR, 2002.

(PRANGL et al., 2006) PRANGL,M., HELLWAGNER, H., SZKALICZKI, T., A Semantic-based Multi-modal Utility Approach For Multimedia Adaptation Proceedings of the 7 th International Workshop on Image Analysis for Multimedia Services (WIAMIS), Incheon, Korea, April 2006

(RAKKOLAINEN; RAKKOLAINEN, I. AND PALOVUORI, K. (2005). PALOVUORI, 2005) Laser scanning for the interactive walk-through fogScreen. In Proceedings of the ACM Symposium on Virtual Reality Software and Technology (Monterey, CA, USA, November 07 - 09, 2005). VRST '05. ACM Press, New York, NY, 224-226.

(RAKKOLAINEN et al., RAKKOLAINEN, I., ERDEM, T., ERDEM, Ç., ÖZKAN, 2006) M., AND LAITINEN, M. (2006). Interactive "immaterial" screen for performing arts. In Proceedings of the 14th Annual ACM international Conference on Multimedia (Santa Barbara, CA, USA, October 23 - 27, 2006). MULTIMEDIA '06. ACM Press, New York, NY, 185188.

(REAL, 2002) “Real's surestream technology,” 2002. [Online].Available: http://service.real.com/help/library/guides/realone/Product ionGuide/HTML/htmfiles/realsys.htm\#64854

(SALBER et al., 1999) SALBER, D.; DEY, A. K.; ABOWD, G. D. The Context Toolkit: Aiding the Development of Context-Enabled Applications. In: CONFERENCE ON HUMAN FACTORS AND COMPUTING SYSTEMS. 17., 1999, Pittsburgh. Proceedings. N. York: ACM, 1999. p. 434441. 
(SANTE et al., 2004) SANTE, D. G., CAMACHO-GUERRERO, J. A., MACEDO, A. A., AND FORTES, R. P. (2004). Preparing, Extending and Retrieving Captured Information. In Proceedings of the Webmedia \& La-Web 2004 Joint Conference 10th Brazilian Symposium on Multimedia and the Web 2nd Latin American Web Congress - Volume 00 (October 12 - 15, 2004). LAWEBMEDIA. IEEE Computer Society, Washington, DC, 158-160.

(SCHILIT;THEIMER, SCHILIT, B.; THEIMER, M. (1994). Disseminating 1994)

(SHEN et al., 2006) Active Map Information to Mobile Hosts. IEEE Network $8(5)$, p. 22-32.

SHEN H., SUN X., WU F., LI S., (2006) Scalable Video Adaptation for IPTV, in proc. IPTV services over World Wide Web Workshop WWW2006

(THANG et al., 2006) THANG T. C., KIM Y. S., RO Y. M., KANG J., KIM J., SVC bitstream adaptation in MPEG-21 multimedia framework. Journal of Zhejiang University SCIENCE A 2006. Vol. 7 No. 5 p. 764-772.

(TRUONG et al.., 2001) TRUONG, K. N.; ABOWD, G. D.; BROTHERTON, J. A. (2001). Who, What, When, Where, How: Design Issues of Capture \& Access Applications. In Proceedings of the International Conference on Ubiquitous Computing (UbiComp), p. 209-224.

(TURCHETTI, 2004) TURCHETTI, C. (2004) Stochastic Model of Neural Networks. IOS Press.

(VETRO et al., 2003) VETRO, A.; CHRISTOPOUlOS, C.; SUN, H. (2003) Video Transcoding Architectures and Techniques: An Overview. IEEE Signal Processing Magazine, v. 20, n. 2, p. 18-29, 2003. 
(WANG et al., 2003)

(WANT et al., 1992)

(WANT et al., 1995)

(WEISER, 1991)

(WHO, 2006)

(WU et al., 2001)
WANG, Y., KIM, J.G., CHANG, S.F., (2003). Contentbased utility function prediction for real-time MPEG-4 transcoding. In: ICIP 2003, September 14-17, 2003, Barcelona, Spain

WANT, R.; HOPPER, A.; FALCO, V.; GIBBONS, J. (1992).The Active Badge Location System. ACM Transactions on Information Systems(TOIS)10(1),91-102. WANT, R.; SCHILIT, B. N.; ADAMS, N. I.; GOLD, R.; PETERSEN, K.; GOLDBERG, D.; ELLIS, J. R.; WEISER, M. (1995) An overview of the ParcTab ubiquitous computing experiment. IEEE Personal Communications Magazine, 2(6):28--43, Dec. 1995 WEISER, M. (1991) The Computer for the 21st Century. Scientific American Magazine, Sept., 1991. pp. 94-104; IEEEPervasive Computing, Jan.-Mar. 2002, pp. 19-25. World Health Organization (WHO) Building foundations for eHealth: progress of member states: report of the Global Observatory for eHealth. (2006) WHO Library Cataloguing-in-Publication Data ISBN 9241595043 ISBN 9789241595049 WU, D.; Hou, Y. T.; Zhu, W.; Zhang, Y. Q.; Peha, J.M. (2001) Streaming Video over the Internet: Approaches and Directions. IEEE Transactions on Circuits and Systems for Video Technology, v. 11, n. 3, p. 282-300, 2001. 
(YEH et al., 2006) YEH, R., LIAO, C., KLEMMER, S., GUIMBRETIÈRE, F., LEE, B., KAKARADOV, B., STAMBERGER, J., AND PAEPCKE, A. (2006). ButterflyNet: a mobile capture and access system for field biology research. In Proceedings of the SIGCHI Conference on Human Factors in Computing Systems (Montréal, Québec, Canada, April 22 - 27, 2006). R. Grinter, T. Rodden, P. Aoki, E. Cutrell, R. Jeffries, and G. Olson, Eds. CHI '06. ACM Press, New York, NY, 571-580.

(XIN et al., 2005) XIN, J.; LIN, C. W.; SUN, M. T. (2005) Digital Video Transcoding. IEEE, v. 93, n. 1, p. 84-97, 2005. 